NBER WORKING PAPER SERIES

A RISK-CENTRIC MODEL OF DEMAND RECESSIONS AND SPECULATION

\author{
Ricardo J. Caballero \\ Alp Simsek \\ Working Paper 23614 \\ http://www.nber.org/papers/w23614 \\ NATIONAL BUREAU OF ECONOMIC RESEARCH
1050 Massachusetts Avenue
Cambridge, MA 02138
July 2017, Revised February 2020
}

A previous version of the paper was circulated under the title, "A Risk-centric Model of Demand Recessions and Macroprudential Policy." We thank four anonymous referees and the editor, Andrei Shleifer, for their constructive comments. Chris Ackerman, Masao Fukui, Jeremy Majerovitz, Andrea Manera, Zilu Pan, Olivier Wang, and Nathan Zorzi provided excellent research assistance. We also thank Marios Angeletos, Jaroslav Borovicka, Eduardo Davila, Emmanuel Farhi, Kristin Forbes, Mark Gertler, Zhiguo He, Yueran Ma, Plamen Nenov, Matthew Rognlie, Martin Schneider, Larry Summers, Jaume Ventura, Ivan Werning, and seminar participants at Yale University, Columbia University, Boston College, MIT, Princeton University, the EIEF, Paris School of Economics, the BIS, the Bank of Spain, the Fed Board, the Boston Fed, UNC at Chapel Hill, Northwestern University, Brown University, The University of Chicago, London School of Economics, Bocconi University; as well as conference participants at the CCBS Conference hosted by the Bank of England and MacCalm, the Wharton Conference on Liquidity and Financial Fragility, the Harvard/MIT Financial Economics Workshop, Cowles Conference on General Equilibrium and Applications, NBER meetings (EFG, AP, and SI Impulse and Propagation Mechanisms), AEA annual meetings (2018 and 2019), CEBRA annual meeting, the Barcelona GSE Conference on Asset Pricing and Macroeconomics, the Sciences Po Summer Workshop in International and Macro Finance for their comments. Caballero and Simsek acknowledge support from the National Science Foundation (NSF) under Grant Numbers SES-1848857 and SES-1455319, respectively. First draft: May 11, 2017. The views expressed herein are those of the authors and do not necessarily reflect the views of the National Bureau of Economic Research.

NBER working papers are circulated for discussion and comment purposes. They have not been peer-reviewed or been subject to the review by the NBER Board of Directors that accompanies official NBER publications.

(C) 2017 by Ricardo J. Caballero and Alp Simsek. All rights reserved. Short sections of text, not to exceed two paragraphs, may be quoted without explicit permission provided that full credit, including ( $)$ notice, is given to the source. 
A Risk-centric Model of Demand Recessions and Speculation

Ricardo J. Caballero and Alp Simsek

NBER Working Paper No. 23614

July 2017, Revised February 2020

JEL No. E00,E12,E21,E22,E30,E40,G00,G01,G11

\begin{abstract}
$\underline{\text { ABSTRACT }}$
We provide a continuous-time "risk-centric" representation of the New Keynesian model, which we use to analyze the interactions between asset prices, financial speculation, and macro- economic outcomes when output is determined by aggregate demand. In principle, interest rate policy is highly effective in dealing with shocks to asset valuations. However, in practice monetary policy faces a wide range of constraints. If these constraints are severe, a decline in risky asset valuations generates a demand recession. This reduces earnings and generates a negative feedback loop between asset prices and aggregate demand. In the recession phase, average beliefs matter not only because they affect asset valuations but also because they determine the strength of the amplification mechanism. In the ex-ante boom phase, belief disagreements (or heterogeneous asset valuations) matter because they induce investors to speculate. This speculation exacerbates the crash by reducing high-valuation investors' wealth when the economy transitions to recession, which depresses (wealth-weighted) average beliefs. Macroprudential policy that restricts speculation in the boom can Pareto improve welfare by increasing asset prices and aggregate demand in the recession.
\end{abstract}

Ricardo J. Caballero

Department of Economics, E52-528

MIT

50 Memorial Drive

Cambridge, MA 02142

and NBER

caball@mit.edu

Alp Simsek

Department of Economics, E52-552

MIT

50 Memorial Drive

Cambridge, MA 02142

and NBER

asimsek@mit.edu

A nontechnical summary is available at http://voxeu.org/article/risk-intolerance-and-global-economy 


\section{Introduction}

Prices of risky assets, such as stocks and houses, fluctuate considerably without meaningful changes in the underlying payoffs. These fluctuations, which are due to a host of rational and behavioral mechanisms, are generically described as the result of a "time-varying risk premium" (see Cochrane (2011); Shiller (2014) and Campbell (2014) for recent reviews). While fluctuations in risky asset prices affect the macroeconomy in a multitude of ways, a growing empirical literature suggests that aggregate demand plays a central role and therefore interest rate policy can mitigate the macroeconomic impact of asset price shocks. Pflueger et al. (2018) show that prices of volatile stocks have high predictive power for interest rates and economic activity, and Cieslak and VissingJorgensen (2017) argue that the Fed pays attention to stock prices and cuts interest rates after stock price declines ("the Fed put"). However, the ability of interest policy to quickly respond to asset price shocks is limited by a host of practical concerns such as exchange rate volatility, balance sheet fragilities, decision lags and transmission lags. An important current concern is that, with interest rates close to their effective lower bound in much of the developed world, interest rate policy will be unable to respond to large negative asset price shocks.

This connection between risky asset prices and aggregate demand suggests that speculation - a pervasive feature of financial markets driven by heterogeneous asset valuations - can lead to more severe downturns. There is in fact an old tradition in macroeconomics that emphasizes speculation as a central feature of asset prices in boom-bust cycles (see, e.g., Minsky (1977); Kindleberger (1978)). In recent empirical work, Mian and Sufi (2018) argue that speculation also has played a key role in the U.S. housing cycle. However, speculation and its interaction with aggregate demand are largely missing from the modern macroeconomic theory connecting asset prices with economic activity, which mostly focuses on financial frictions (see Gertler and Kiyotaki (2010) for a review). This omission is especially important in the current low interest rate environment, as monetary policy has even less space than usual to mop up a sharp decline in risky asset prices following a speculative episode.

In this paper, we build a risk-centric macroeconomic model - that is, a model in which risky asset prices are at the core of the analysis - with the two key features highlighted above. First, we explore the role of the aggregate demand channel and interest rate frictions in causing recessions driven by a rise in the "risk premium" - our catchall phrase for shocks to asset valuations. Second, we study the impact of financial speculation on the severity of these recessions and derive the implications for macroprudential policy. In order to isolate our insights, we remove all financial frictions.

Our analysis relies on the standard aggregate demand mechanism present in the New Keynesian model, but formulated in terms of a risk-centric decomposition (as opposed to the usual Eulerequation based approach). Specifically, we decompose the demand block of the equilibrium into two relations: an output-asset price relation that captures the positive association between asset prices and aggregate demand through a wealth effect on consumption (and a marginal-Q effect on 
investment when we add investment); and a risk balance condition that describes asset prices given risks, risk attitudes, beliefs, and the interest rate. This decomposition isolates the characterization of asset prices from the "macroeconomics" side of the model. Therefore, it facilitates the study of a variety of forces that affect asset prices - including financial speculation - in a macroeconomic environment. Our decomposition also highlights that the interest rate policy influences aggregate demand through its impact on financial markets and asset prices (whereas the New Keynesian literature typically emphasizes intertemporal substitution considerations) 1

Our model is set in continuous time with diffusion productivity shocks and Poisson shocks that move the economy between high and low risk premium states. The supply side is a stochastic endowment economy with sticky prices (which we extend to an endogenous growth model when we add investment). The demand side has risk-averse consumer-investors who demand goods and risky assets. We focus on "interest rate frictions" and "financial speculation." By interest rate frictions, we mean factors that might constrain or delay the adjustment of the risk-free interest rate to shocks. For concreteness, we work with a zero lower bound on the policy interest rate, but our mechanism is also applicable with other interest rate constraints such as a currency union, a fixed exchange rate, or delays in the monetary policy reaction. By financial speculation, we mean the trading of risky financial assets among investors that have heterogeneous valuations for these assets. We capture speculation by allowing investors to have belief disagreements (with respect to the transition probabilities between high and low risk premium states), but our results also apply if speculation is driven by other sources of heterogeneous valuations. In particular, optimists in our model can also capture more risk tolerant investors (e.g., banks or institutional investors), whereas pessimists can capture less risk tolerant investors (e.g., households or retail investors).

To fix ideas, consider an increase in perceived volatility (equivalently, a decrease in optimism). This is a "risk premium shock" that exerts downward pressure on risky asset prices without a change in current productivity (the supply-determined output level). Consequently, monetary policy responds by reducing the interest rate, which stabilizes asset prices and aggregate demand. However, if the interest rate is constrained, the rise in the risk premium reduces asset prices and generates a demand recession.

Dynamics play a crucial role in this environment, as the recession is exacerbated by feedback mechanisms. When investors expect the higher risk premium to persist, the decline in future demand lowers expected earnings, which exerts further downward pressure on asset prices. With endogenous investment, there is a second mechanism, as the decline in investment lowers the growth of potential output, which further reduces expected earnings and asset prices. In turn, the decline in asset prices feeds back into current consumption and investment, generating scope for severe spirals in asset prices and output. Figure \illustrates these dynamic mechanisms. The feedbacks are especially powerful when investors are pessimistic and think the higher risk premium will persist. Hence, average beliefs matter in our economy not only because they have a direct impact on asset

\footnotetext{
${ }^{1}$ Our decomposition (and its implications for the transmission of monetary policy) matches the reasoning in actual central banks' statements when dealing with the risk-off events that have plagued the world economy over the last few decades (see, e.g., Cieslak and Vissing-Jorgensen (2017)).
} 


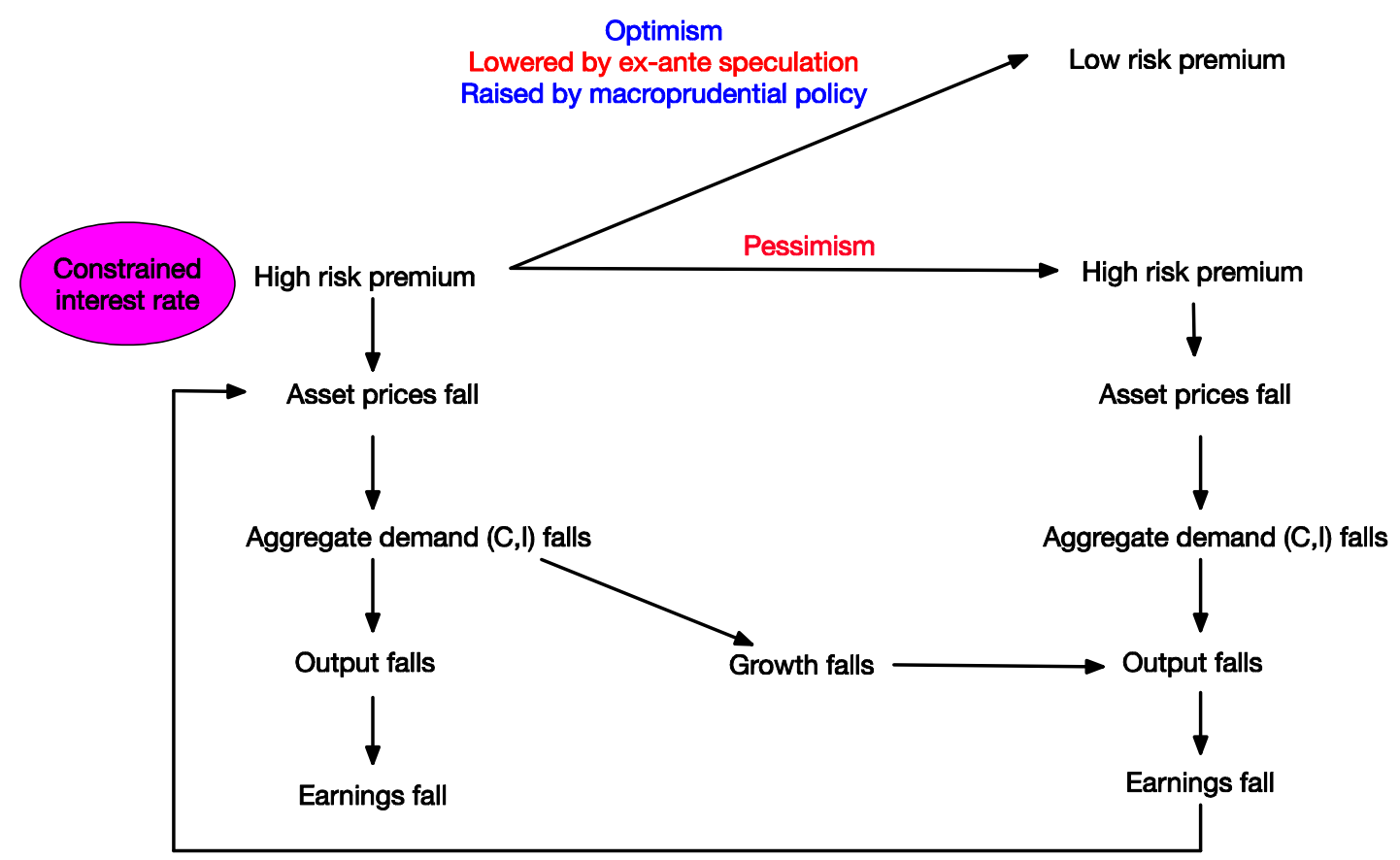

Figure I: Output-asset price feedbacks during a risk-centric demand recession.

prices but also because they determine the strength of the amplification mechanism.

In this environment, belief disagreements (or heterogeneous asset valuations) matter in two important ways. First, asset prices depend on the wealth-weighted average belief among optimists and pessimists. Therefore, in the recession, greater wealth in the hands of optimists increases asset prices as well as aggregate demand and output. This result highlights that wealth distribution matters for aggregate demand not only because of financial frictions (e.g., Bernanke et al. (1999)) or heterogeneous marginal propensities to consume (MPC) (e.g., Auclert (2019)), as emphasized by the previous macroeconomics literature, but also because of heterogeneous asset valuations. In fact, in our model there are no financial frictions, and optimists and pessimists have the same MPCs. Increasing optimists' wealth share in the recession raises aggregate spending, not because optimists spend more than pessimists, but because they raise asset valuations and induce all consumerinvestors to spend more (while also increasing aggregate investment when we add investment).

Second, belief disagreements create speculation, which amplifies the fluctuations in asset valuations and aggregate demand. Investors take speculative positions that reflect their beliefs. This speculation makes the wealth-weighted belief extrapolate recent realizations - even though individual investors have fixed beliefs and do not extrapolate. In particular, good realizations vindicate optimists and increase their wealth share, which makes the wealth-weighted belief more optimistic. Conversely, bad realizations increase pessimists' wealth share and make the wealth-weighted belief more pessimistic. Therefore, speculation amplifies the fluctuations in asset prices. When the interest rate is constrained, speculation also amplifies demand-driven boom-bust cycles and worsens macroeconomic outcomes. 
Specifically, we find that speculation during the low risk premium phase (boom) exacerbates the recession when there is a transition to the high risk premium phase (bust). During the boom, optimists take on risk by selling insurance contracts to pessimists that enrich optimists if the boom persists but reduce their wealth share when there is a transition to recession. This reallocation of wealth in the recession lowers asset prices and leads to a more severe recession.

These effects motivate macroprudential policy that restricts speculation during the boom. We show that macroprudential policy that makes optimistic investors behave as-if they were more pessimistic (implemented via portfolio risk limits) can generate a Pareto improvement in social welfare. This result is not driven by paternalistic concerns - the planner respects investors' own beliefs, and the result does not depend on whether optimists or pessimists are closer to the truth. Rather, the planner improves welfare by internalizing aggregate demand externalities. During the recession, the economy benefits from wealthy optimists (or high valuation investors) since they raise asset prices and aggregate demand. However, optimists that take on speculative positions during the boom (and pessimists that take the opposite side of those positions) do not internalize the effect of their risk taking on asset prices and aggregate demand during the recession. This leads to excessive risk taking by optimists that can be offset by macroprudential policy. Therefore, our model supports a variety of policies used in practice - such as a leverage limit or a risk limit - that preserve optimists' (or high valuation investors') wealth for the recession state. Moreover, our model supports procyclical macroprudential policy. While macroprudential policy can be useful during the recession, these benefits can be outweighed by its immediate negative impact on asset prices. This adverse price impact is not a concern during the boom, as it is offset by the interest rate policy, but it lowers asset prices and output in the recession since the interest rate is constrained.

While there is an extensive empirical literature supporting the components of our model (see Section VII for a brief summary), we present additional empirical evidence consistent with our results. We focus on three implications. First, our model predicts that shocks to asset valuations generate a more severe demand recession when the interest rate is constrained. Second, the recession reduces firms' earnings and leads to a further decline in asset prices. Third, the recession is more severe when the shock takes place in an environment with more speculation.

To investigate these predictions, we assemble a quarterly panel data set of 20 advanced countries between 1990 and 2017, and divide the panel into countries that are part of the Eurozone or the European Exchange Rate Mechanism (the Euro/ERM sample) and those that have their own currencies (the non-Euro/ERM sample). Countries in the first group have a constrained interest rate with respect to local asset price shocks, since they share a common monetary policy. The second group has a less constrained interest rate. We find that a negative house price shock in a non-Euro/ERM country is associated with an initial decline in economic activity, followed by a decline in the policy interest rate and output stabilization. In contrast, a similar shock in a Euro/ERM country is not associated with an interest rate response (compared to other Euro/ERM countries), and is followed by a more persistent and larger decline in economic activity. We also find that the house price shock is followed by a larger decline in earnings and stock prices of publicly 
traded firms in the Euro/ERM sample (although the standard errors are larger for these results). Finally, we find that past bank credit expansion - which we use as a proxy for speculation on house prices - is associated with more severe outcomes following the house price shock in the Euro/ERM sample (but not in the other sample).

Literature review. Our paper is related to three main literatures: two in macroeconomics and one in finance. On the macroeconomics side, several recent papers within the New-Keynesian literature emphasize demand shocks that might drive business cycles while also affecting asset prices, such as "news shocks" (Beaudry and Portier (2006)), "noise shocks" (Lorenzoni (2009); Blanchard et al. (2013)), "confidence shocks" (Ilut and Schneider (2014)), "uncertainty shocks" (Basu and Bundick (2017); Fernández-Villaverde et al. (2015)), and "disaster shocks" (Isoré and Szczerbowicz (2017)). Our first contribution to this literature is to reformulate the standard New Keynesian model in terms of a risk-centric decomposition. With this decomposition at hand, we provide an integrated treatment of these demand shocks. We refer to these demand shocks as "risk premium shocks" to emphasize their close connection with asset prices and the finance literature on time-varying risk premia $:^{2}$ Our second contribution to this literature is to show that heterogeneity in asset valuation matters in these environments. Among other things, heterogeneous valuations lead to speculation that exacerbates demand recessions and provides a distinct rationale for macroprudential regulation.

Another important macroeconomic literature focuses on uncertainty and its role in driving macroeconomic fluctuations (e.g., Bloom (2009); Baker et al. (2016, 2019); Bloom et al. (2018)). We contribute to this literature by showing how uncertainty affects aggregate activity through asset prices and their impact on aggregate demand. We also illustrate that, in our model, uncertainty shocks have stronger effects when monetary policy is constrained, consistent with recent empirical evidence (e.g., Plante et al. (2018)). Finally, we show that ex-ante financial speculation amplifies the damage from uncertainty shocks.

On the finance side, a large literature emphasizes investors' beliefs as a key driver of financial boom-bust cycles (see, e.g., Gennaioli and Shleifer (2018) for the role of beliefs in the recent crisis). A strand of this literature argues that heterogeneity in the degree of optimism combined with short-selling constraints can lead to speculative asset price bubbles that substantially amplify the financial cycle (e.g., Harrison and Kreps (1978); Scheinkman and Xiong (2003); Geanakoplos (2010); Simsek (2013a); Barberis et al. (2018)). Related contributions emphasize that disagreements exacerbate asset price fluctuations more broadly - even without short-selling constraints or bubbles - because they create endogenous fluctuations in agents' wealth distribution (e.g., Basak (2000, 2005); Detemple and Murthy (1994); Zapatero (1998); Cao (2017); Xiong and Yan (2010); Kubler and Schmedders (2012); Korinek and Nowak (2016)). Our paper features similar forces but

\footnotetext{
${ }^{2}$ See Galí (2018) for an OLG variant of the New-Keynesian model with rational bubbles (see also Biswas et al. (2018), which also highlights the role of asset prices on aggregate demand. However, his analysis does not focus on the risk-balance condition, which is a key block in our analysis. Also, there is a large body of work that emphasizes the links between asset prices and macroeconomic outcomes through financial frictions (e.g., Kiyotaki and Moore (1997)). Our model removes all these financial frictions for clarity.
} 
explores them in an environment where output is not necessarily at its supply-determined level ${ }^{3}$

There are five additional connections worth highlighting. In our setting, speculation generates macroeconomic outcomes as if there is a representative agent with extrapolative beliefs. This relates our paper to a growing literature that emphasizes extrapolation as a key driver of asset prices and business cycles (see, e.g., Bordalo et al. (2018, 2019)). While the two mechanisms are likely to reinforce each other, speculation makes distinct predictions for trading volume and heterogeneity in asset positions (see Remark 8).

The interactions between heterogeneous valuations, risk-premia, and interest rate lower bounds are central themes of the literature on structural safe asset shortages and safety traps (see, for instance, Caballero and Farhi (2018); Caballero et al. (2017b)). We contribute to this literature by considering a broader set of factors that can drive the risk premium (in addition to safe asset scarcity) and, more importantly, by focusing on dynamics. We analyze the connections between boom and recession phases of recurrent business cycles driven by risk premium shocks. We show that speculation between "optimists" and "pessimists" during the boom exacerbates a future riskcentric demand recession, and we derive the implications for macroprudential policy. In contrast, Caballero and Farhi (2018) show how "pessimists" can create a demand recession in otherwise normal times and derive the implications for fiscal policy and unconventional monetary policy ${ }^{4}$

At a methodological level, our paper belongs to the new continuous-time macrofinance literature started by the work of Brunnermeier and Sannikov (2014, 2016a) and summarized in Brunnermeier and Sannikov (2016b) (see also Basak and Cuoco (1998); Adrian and Boyarchenko (2012); He and Krishnamurthy (2012, 2013); Di Tella (2017, 2019); Moreira and Savov (2017); Silva (2016); Di Tella and Hall (2019)). This literature highlights the full macroeconomic dynamics induced by financial frictions. While the structure of our economy shares many features with theirs, our model has no financial frictions, and the macroeconomic dynamics stem not from the supply side (relative productivity) but from the aggregate demand side.

Our results on macroprudential policy are related to recent work that analyzes the implications of aggregate demand externalities for the optimal regulation of financial markets. For instance, Korinek and Simsek (2016) show that, in the run-up to deleveraging episodes that coincide with a zero-lower-bound on the interest rate, policies targeted at reducing household leverage can improve welfare (see also Farhi and Werning (2017)). In these papers, macroprudential policy reallocates wealth across agents and states so that agents with a higher MPC hold relatively more wealth when the economy is depressed due to deficient demand. The mechanism in our paper is different and

\footnotetext{
${ }^{3}$ With respect to these papers, we show that speculation during the boom not only worsens the asset price bust but also exacerbates the demand recession. Consequently, and unlike much of this literature, macroprudential policy that restricts speculation can improve welfare even if the planner is not paternalistic and respects investors' (heterogeneous and possibly over-optimistic) beliefs. Adding paternalistic concerns reinforces our normative conclusions (see Section VI. More broadly, our paper is part of a large finance literature that investigates the effect of belief disagreements and speculation on financial markets (e.g., Lintner (1969); Miller (1977); Varian (1989); Harris and Raviv (1993); Chen et al. (2002); Fostel and Geanakoplos (2008); Simsek (2013b); Iachan et al. (2015)).

${ }^{4}$ Our paper is also related to an extensive literature on liquidity traps that has exploded since the Great Recession (see, for instance, Tobin (1975); Krugman (1998); Eggertsson and Woodford (2006); Guerrieri and Lorenzoni (2017); Hall (2011); Christiano et al. (2015); Rognlie et al. (2018); Midrigan et al. (2016); Bacchetta et al. (2016)).
} 
works through heterogeneous asset valuations (instead of heterogenous MPCs) 5

The macroprudential literature beyond aggregate demand externalities is mostly motivated by the presence of pecuniary externalities that make the competitive equilibrium constrained inefficient (e.g., Caballero and Krishnamurthy (2003); Lorenzoni (2008); Bianchi and Mendoza (2018); Jeanne and Korinek (2018)). The friction in this literature is market incompleteness or collateral constraints that depend on asset prices (see Davila and Korinek (2016) for a detailed exposition). We show that a decline in asset prices is damaging not only for the reasons emphasized in this literature, but also because it lowers aggregate demand.

The rest of the paper is organized as follows. In Section [II we present an example that illustrates the main mechanism and motivates the rest of our analysis. Section III presents the general environment and defines the equilibrium. Section [V] characterizes the equilibrium in a benchmark setting with common beliefs. This section shows how risk premium shocks can lower asset prices and induce a demand recession, and how feedback loops between asset prices and aggregate demand exacerbate the recession. Section $\mathrm{V}$ characterizes the equilibrium with belief disagreements and heterogeneous asset valuations. This section illustrates how a greater optimists' wealth share increases asset valuations and mitigates the recession, and how speculation amplifies asset price fluctuations and worsens the recession. Section VI shows the aggregate demand externalities associated with optimists' risk taking and establishes our results on macroprudential policy. Section VII presents our empirical analysis and summarizes supporting evidence from the related literature. Section VIII concludes. The (online) appendices contain the omitted derivations and proofs as well as the details of our empirical analysis.

\section{A stepping-stone risk-centric example}

Here we present a simple, largely static example that serves as a stepping stone to our main dynamic model. We start with a representative agent setup and characterize the standard aggregate demand mechanism in the New Keynesian model, but formulated in terms of our risk-centric decomposition. We use this decomposition to illustrate how "risk premium shocks" generate a demand recession when the interest rate is constrained. We then consider heterogeneous valuations and illustrate how speculation affects demand recessions.

A two-period risk-centric aggregate demand model. Consider an economy with two dates, $t \in\{0,1\}$, a single consumption good, and a single factor of production-capital. For simplicity, capital is fixed and normalized to one. Potential output is equal to capital's productivity, $z_{t}$, but actual output can be below this level due to a shortage of aggregate demand, $y_{t} \leq z_{t}$. For simplicity, we assume output is equal to its potential at the last date, $y_{1}=z_{1}$, and focus on the endogenous determination of output at the previous date, $y_{0} \leq z_{0}$. We assume the productivity at date 1 is

\footnotetext{
${ }^{5}$ See Farhi and Werning $\sqrt{2016}$ ) for a synthesis of some of the key mechanisms that justify macroprudential policies in models that exhibit aggregate demand externalities.
} 
uncertain and log-normally distributed,

$$
\log y_{1}=\log z_{1} \sim N\left(g-\frac{\sigma^{2}}{2}, \sigma^{2}\right)
$$

We also normalize the initial productivity to one, $z_{0}=1$, so that $g$ captures the (log) expected growth rate of productivity, and $\sigma$ captures its volatility.

There are two types of assets. There is a "market portfolio" that represents claims to the output at date 1 (which accrue to production firms as earnings), and a risk-free asset in zero net supply. We denote the price of the market portfolio with $Q$, and its $\log$ return with

$$
r^{m}\left(z_{1}\right)=\log \frac{z_{1}}{Q}
$$

We denote the log risk-free interest rate with $r^{f}$.

For now, the demand side is characterized by a representative investor, who is endowed with the initial output as well as the market portfolio. At date 0 , she chooses how much to consume, $c_{0}$, and what fraction of her wealth to allocate to the market portfolio, $\omega^{m}$, with the residual fraction invested in the risk-free asset. When asset markets are in equilibrium, she will allocate all of her wealth to the market portfolio, $\omega^{m}=1$, and her portfolio demand will determine the risk premium.

We assume the investor has Epstein-Zin preferences with discount factor $e^{-\rho}$ and relative risk aversion coefficient (RRA) $\gamma$. For simplicity, we set the elasticity of intertemporal substitution (EIS) equal to one. Allowing for a more general EIS leaves our results qualitatively unchanged (see Remark 2).

The supply side of the economy is described by New-Keynesian firms that have fixed nominal prices (see Remark 1 below for the role of this assumption and Online Appendix Section B.1.3 for details). These firms meet the available demand at these prices as long as prices are higher than their marginal cost. These features imply that output is determined by the aggregate demand for goods (consumption) up to the capacity constraint,

$$
y_{0}=c_{0} \leq z_{0} .
$$

Since prices are fully sticky, the real interest rate is equal to the nominal interest rate, which is controlled by the central bank. We assume that the interest rate policy attempts to replicate the supply-determined output level. However, there is a lower bound constraint on the interest rate, $r^{f} \geq 0$. Thus, the interest rate policy is described by $r^{f}=\max \left(r^{f *}, 0\right)$, where $r^{f *}$ is the natural interest rate that ensures output is at its potential, $y_{0}=z_{0}$.

To characterize the equilibrium, first note that there is a tight relationship between output and asset prices. Specifically, the assumption on the EIS isolates the consumption wealth effect: the investor consumes a fraction of her lifetime income in the first period,

$$
c_{0}=\frac{1}{1+e^{-\rho}}\left(y_{0}+Q\right) \text {. }
$$


Combining this expression with Eq. (3), we obtain the following equation:

$$
y_{0}=e^{\rho} Q
$$

We refer to this equation as the output-asset price relation - generally, it is obtained by combining the consumption function (and when there is investment, also the investment function) with goods market clearing. The condition says that asset prices increase aggregate wealth and consumption, which in turn leads to greater output.

Next, note that asset prices must also be consistent with equilibrium in risk markets. In Online Appendix Section A.1, we show that, up to a local approximation, the investor's optimal weight on the market portfolio is determined by

$$
\omega^{m} \sigma \simeq \frac{1}{\gamma} \frac{E\left[r^{m}\left(z_{1}\right)\right]+\frac{\sigma^{2}}{2}-r^{f}}{\sigma} .
$$

In words, the optimal portfolio risk (left side) is proportional to "the Sharpe ratio" on the market portfolio (right side). The Sharpe ratio captures the reward per risk, where the reward is determined by the risk premium: the (log) expected return in excess of the $(\log )$ risk free rate. This is the standard risk-taking condition for mean-variance portfolio optimization. It applies approximately in the two-period model, and the approximation becomes exact when there is a representative household and the asset markets are in equilibrium $\left(\omega^{m}=1\right)$.

Substituting the asset market clearing condition, $\omega^{m}=1$, and the expected return on the market portfolio from Eqs. (1) and (2), we obtain the following equation:

$$
\sigma=\frac{1}{\gamma} \frac{g-\log Q-r^{f}}{\sigma} .
$$

We refer to this equation as the risk balance condition-generally, it is obtained by combining investors' optimal portfolio allocations with asset market clearing and the equilibrium return on the market portfolio. The equilibrium level of the Sharpe ratio on the market portfolio (right side) needs to be large enough to convince investors to hold the risk generated by the productive capacity (left side).

Next, consider the supply-determined equilibrium in which output is equal to its potential, $y_{0}=z_{0}=1$. Eq. (5) reveals that this requires the asset price to be at a particular level, $Q^{*}=e^{-\rho}$. Combining this with Eq. (7), the interest rate also needs to be at a particular level,

$$
r^{f *}=g+\rho-\gamma \sigma^{2} .
$$

Intuitively, the monetary policy needs to set the interest rate low enough to induce sufficiently high asset prices and aggregate demand to clear the goods market.

Now suppose the initial parameters are such that $r^{f *}>0$, so the equilibrium features $Q^{*}, r^{f *}$ and supply-determined output, $y_{0}=z_{0}=1$. Consider a "risk premium shock" that raises the 
volatility, $\sigma$, or risk aversion, $\gamma$. The immediate impact of this shock is to create an imbalance in the risk balance condition (7). The economy produces too much risk (left side) relative to what investors are willing to absorb (right side). In response, the monetary policy lowers the risk-free interest rate (captured by the decline in $r^{f *}$ ), which increases the risk premium and equilibrates the risk balance condition (7). Intuitively, the central bank lowers the opportunity cost of risky investment and induces investors to absorb more risk.

Next suppose the shock is large enough that the natural interest rate becomes negative, $r^{f *}<0$, and the actual interest rate becomes constrained, $r^{f}=0$. In this case, the risk balance condition is re-established via a decline in the price of the market portfolio, $Q$. This decline in asset prices increases the expected return on risky investment, which induces investors to absorb risk. However, the decline in $Q$ reduces aggregate wealth and induces a demand-driven recession. Formally, we combine Eqs. (5) and (7) to obtain

$$
\log y_{0}=\rho+\log Q, \quad \text { where } \log Q=g-\gamma \sigma^{2} .
$$

Note that, in the constrained region, asset prices and output are sensitive to beliefs about future prospects. For instance, a decrease in the expected growth rate, $g$ (pessimism) - rational or otherwise - decreases asset prices and worsens the recession. In fact, while we considered shocks that raise $\sigma$ or $\gamma$, Eqs. (8) and (9) reveal that shocks that lower $g$ lead to the same effects. The key point for our risk-centric perspective is that $g$ still operates by reducing the expected return on risky assets and hence creating an imbalance in risk markets.

Heterogeneous valuations and speculation. We next consider heterogeneous asset valuations and investigate how speculation affects demand recessions. We capture heterogeneous valuations with belief disagreements about productivity growth. Specifically, there are two types of investors, optimists and pessimists, that believe $\log z_{1}$ is distributed according to, respectively, $N\left(g^{o}-\frac{\sigma^{2}}{2}, \sigma^{2}\right)$ and $N\left(g^{p}-\frac{\sigma^{2}}{2}, \sigma^{2}\right)$. We assume $g^{o}>g^{p}$ so that optimists perceive greater growth. Beliefs are dogmatic - that is, investors know each others' beliefs and they agree to disagree. Optimists are endowed with a fraction $\alpha$ of the market portfolio and of date 0 output (and pessimists are endowed with the remaining fraction). Hence, $\alpha$ denotes the wealth share of optimists. The rest of the model is unchanged.

Following similar steps to those in the baseline case, we solve for "rstar" as (see Online Appendix Section A.3),

$$
r^{f *} \simeq \alpha g^{o}+(1-\alpha) g^{p}+\rho-\gamma \sigma^{2}
$$

When $r^{f *}<0$, the interest rate is constrained and $r^{f}=0$, so we have a demand recession with

$$
\log y_{0}=\rho+\log Q, \text { where } \log Q \simeq \alpha g^{o}+(1-\alpha) g^{p}-\gamma \sigma^{2} .
$$

Hence equilibrium prices and output depend on optimists' wealth share, $\alpha$. During the recession, 
increasing $\alpha$ improves outcomes because optimists increase asset prices, which increases aggregate wealth and everyone's spending. In our dynamic model, $\alpha$ is endogenous because investors (exante) speculate on their different beliefs. Moreover, speculation reduces $\alpha$ during the recession because optimists think the risk premium shock is unlikely. This exacerbates the recession and motivates macroprudential policy.

Remark 1 (Role of nominal price rigidity). In our model (as well as in other New Keynesian models), nominal price rigidity plays two roles. First, and most importantly, it creates a real interest rate rigidity. To see this, consider an alternative economy in which prices are fully flexible and the nominal interest rate is at a lower bound. How would this economy react to a risk premium shock that requires a decline in the real interest rate? By definition, the real rate is equal to the nominal interest rate minus expected inflation in nominal prices. Since the nominal interest rate is constrained, the economy must generate expected inflation: either the current nominal prices must decline or the future nominal prices must increase (or a combination of the two). Nominal price rigidity hinders such an adjustment and translates into real interest rate rigidity. As our analysis illustrates, this rigidity reduces real asset prices in financial markets, which in turn reduces aggregate demand in goods markets. Nominal price rigidity plays a second role by making firms respond to the decline in aggregate demand by cutting production - instead of cutting their nominal price to increase the demand for their goods (see Online Appendix Section B.1.3 for a formalization and Remark 3 for a discussion of how partial price flexibility affects our results).

Remark 2 (More general EIS). In Online Appendix Section A.2, we extend the baseline two-period model (without disagreements) to cases where the EIS is different from one. In these cases, a risk premium shock affects output through two channels. As before, it exerts a downward influence on asset prices and consumption through a wealth effect. But it also reduces the attractiveness of investment opportunities, which further affects consumption depending on the balance of income and substitution effects. When the EIS is greater than one, the second channel works against the wealth effect because investors substitute toward consumption. When the EIS is less than one, the second channel reinforces the wealth effect. Importantly, we show that the wealth effect dominates regardless of the EIS. When the interest rate is constrained, a risk premium shock reduces equilibrium output as well as the asset price. When the EIS is greater than one, the substitution effect dampens these declines but it does not overturn them.

\section{Dynamic environment and equilibrium}

In this section we introduce our general dynamic environment and define the equilibrium. We then partially characterize the equilibrium. In subsequent sections we further characterize this equilibrium in various special cases of interest. Throughout, we simplify the analysis by abstracting away from investment. In Online Appendix Section D, we extend the environment to introduce investment and endogenous growth. We discuss additional results related to investment at the end of Section IV. 
Potential output and risk premium shocks. The economy is set in infinite continuous time, $t \in[0, \infty)$, with a single consumption good and a single factor of production, capital. Let $k_{t, s}$ denote the capital stock at time $t$ and in the aggregate state $s \in S$. Suppose that, when fully utilized, $k_{t, s}$ units of capital produce $A k_{t, s}$ units of the consumption good. Hence, $A k_{t, s}$ denotes the potential output in this economy. Capital follows the process

$$
\frac{d k_{t, s}}{k_{t, s}}=g d t+\sigma_{s} d Z_{t}
$$

Here, $g$ denotes the expected productivity growth, which is an exogenous parameter in the main text (we endogenize it in Online Appendix Section D). The term $d Z_{t}$ denotes the standard Brownian motion, which captures "aggregate productivity shocks."

The states, $s \in S$, differ only in terms of the volatility of aggregate productivity, $\sigma_{s}$. For simplicity, there are only two states, $s \in\{1,2\}$, with $\sigma_{1}<\sigma_{2}$. State $s=1$ corresponds to a low-volatility state, whereas state $s=2$ corresponds to a high-volatility state. At each instant, the economy in state $s$ transitions into the other state $s^{\prime} \neq s$ according to a Poisson process. We use these volatility shocks to capture the time variation in the risk premium due to various unmodeled factors (see Section II for an illustration of how risk, risk aversion, and beliefs play a similar role in our analysis).

Investor types. There is a finite number of investor types denoted by $i \in I$. Investor types are identical in all respects except for their beliefs about state transitions. Each type consists of a continuum of identical investors with mass normalized to one. We focus on symmetric equilibria in which investors within a type choose identical allocations.

Transition probabilities and belief disagreements. We let $\lambda_{s}^{i}>0$ denote the perceived Poisson transition probability in state $s$ (into the other state) according to type $i$ investors. These probabilities capture the degree of investors' (relative) optimism or pessimism. For instance, greater $\lambda_{2}^{i}$ corresponds to greater optimism because investors expect the high-risk-premium conditions to end relatively soon. Likewise, smaller $\lambda_{1}^{i}$ corresponds to greater optimism because investors expect the low-risk-premium conditions to persist longer. We first analyze the special case with common beliefs (Section IV) and then investigate belief disagreements and speculation (Section $\mathrm{V}$ ). When investors disagree, they know each others' beliefs and they agree to disagree.

Menu of financial assets. There are three types of financial assets. First, there is a market portfolio that represents a claim on all output. We let $Q_{t, s} k_{t, s}$ denote the price of the market portfolio, so $Q_{t, s}$ denotes the price per unit of capital. We let $r_{t, s}^{m}$ denote the instantaneous expected

\footnotetext{
${ }^{6}$ Note that fluctuations in $k_{t, s}$ generate fluctuations in potential output, $A k_{t, s}$. We introduce Brownian shocks to capital, $k_{t, s}$, as opposed to total factor productivity, $A$, since this leads to a slightly more tractable analysis when we extend the model to include investment (see Online Appendix Section D). In the main text, we could equivalently introduce shocks to $A$ and conduct the analysis by normalizing all relevant variables with $A_{t, s}$ as opposed to $k_{t, s}$.
} 
return on the market portfolio conditional on no transition. Second, there is a risk-free asset in zero net supply. We denote its instantaneous return by $r_{t, s}^{f}$. Third, in each state $s$, there is a contingent Arrow-Debreu security that trades at the (endogenous) price $p_{t, s}^{s^{\prime}}$ and pays 1 unit of the consumption good if the economy transitions into the other state $s^{\prime} \neq s$. This security is also in zero net supply and it ensures that financial markets are dynamically complete.

Price and return of the market portfolio. Absent transitions, the price of the market portfolio per unit of capital follows an endogenous diffusion process,

$$
\frac{d Q_{t, s}}{Q_{t, s}}=\mu_{t, s}^{Q} d t+\sigma_{t, s}^{Q} d Z_{t} \quad \text { for } s \in\{1,2\}
$$

Combining Eqs. (12) and (13), the price of the market portfolio (absent transition) follows

$$
\frac{d\left(Q_{t, s} k_{t, s}\right)}{Q_{t, s} k_{t, s}}=\left(g+\mu_{t, s}^{Q}+\sigma_{s} \sigma_{t, s}^{Q}\right) d t+\left(\sigma_{s}+\sigma_{t, s}^{Q}\right) d Z_{t}
$$

The expected return and the volatility of the market portfolio (absent transition) are then given by

$$
r_{t, s}^{m}=\frac{y_{t, s}}{Q_{t, s} k_{t, s}}+g+\mu_{t, s}^{Q}+\sigma_{s} \sigma_{t, s}^{Q} \quad \text { and } \quad \sigma_{t, s}^{m}=\sigma_{s}+\sigma_{t, s}^{Q} .
$$

Here, $y_{t, s}$ denotes the endogenous level of output at time $t$. The first term in $r_{t, s}^{m}$ captures the "dividend yield" component of return. The remaining terms capture the (expected) capital gain conditional on no transition, which reflects the expected growth of capital, of the price per unit of capital, and of their stochastic interaction.

Eqs. 13-15) describe the prices and returns conditional on no state transition. If there is a transition at time $t$ from state $s$ into state $s^{\prime} \neq s$, then the price per unit of capital jumps from $Q_{t, s}$ to a potentially different level, $Q_{t, s^{\prime}}$. Therefore, investors that hold the market portfolio experience instantaneous capital gains or losses.

Consumption and portfolio choice. Investors continuously make consumption and portfolio allocation decisions. Specifically, at any time $t$ and state $s$, each type $i$ investor has some financial wealth denoted by $a_{t, s}^{i}$. She chooses her consumption rate, $c_{t, s}^{i}$; the fraction of her wealth to allocate to the market portfolio, $\omega_{t, s}^{m, i}$; and the fraction of her wealth to allocate to the contingent security, $\omega_{t, s}^{s^{\prime}, i}$. The residual fraction, $1-\omega_{t, s}^{m, i}-\omega_{t, s}^{s^{\prime}, i}$, is invested in the risk-free asset. For analytical tractability, we assume the investor has log utility. In particular, we set the RRA and the EIS equal to one (see Remark 6 in Section IV for a discussion of how a more general RRA affects our results). The investor then solves a standard portfolio problem that we formally state in Online Appendix Section B.1.1. 
Equilibrium in asset markets. Asset markets clear when the total wealth held by investors is equal to the value of the market portfolio before and after the portfolio allocation decisions,

$$
\sum_{i} a_{t, s}^{i}=Q_{t, s} k_{t, s} \quad \text { and } \quad \sum_{i} \omega_{t, s}^{m, i} a_{t, s}^{i}=Q_{t, s} k_{t, s}
$$

Contingent securities are in zero net supply, which implies

$$
\sum_{i} \omega_{t, s}^{s^{\prime}, i} a_{t, s}^{i}=0
$$

The market clearing condition for the risk-free asset (which is also in zero net supply) holds when conditions (16) and (17) are satisfied.

Nominal rigidities and the equilibrium in goods markets. The supply side of our model features nominal rigidities similar to the standard New Keynesian model. We relegate the details to Online Appendix Section B.1.3. There is a continuum of monopolistically competitive production firms that own the capital stock and produce intermediate goods (which are then converted into the final good). For simplicity, these production firms have pre-set nominal prices that never change (see Remark 3 below for a discussion of the case with partial price flexibility). The firms choose their capital utilization rate, $\eta_{t, s} \in[0,1]$, which leads to output $y_{t, s}=\eta_{t, s} A k_{t, s}$. We assume firms can increase factor utilization for free until $\eta_{t, s}=1$ and they cannot increase it beyond this level.

As we show in the online appendix, these features imply that output is determined by aggregate demand for goods up to the capacity constraint. Combining this with market clearing in goods, output is determined by aggregate consumption (up to the capacity constraint),

$$
y_{t, s}=\eta_{t, s} A k_{t, s}=\sum_{i} c_{t, s}^{i}, \quad \text { where } \eta_{t, s} \in[0,1]
$$

Moreover, all output accrues to production firms in the form of earnings.7 Hence, the market portfolio can be thought of as a claim on all production firms.

Interest rate rigidity and monetary policy. Our assumption that production firms do not change their prices implies that the aggregate nominal price level is fixed. The real risk-free interest rate, then, is equal to the nominal risk-free interest rate, which is determined by the interest rate policy of the central bank. We assume there is a lower bound on the nominal interest rate, which we set at zero for convenience,

$$
r_{t, s}^{f} \geq 0
$$

\footnotetext{
${ }^{7}$ In this model, firms own the capital so the division of earnings is indeterminate. Since there is no investment, this division is inconsequential. When we introduce investment in Online Appendix Section D, we make additional assumptions to determine how earnings are divided between returns to capital and monopoly profits.
} 
The zero lower bound is motivated by the presence of cash in circulation (which we leave unmodeled for simplicity).

We assume that the interest rate policy aims to replicate the level of output that would obtain without nominal rigidities subject to the constraint in (19). Without nominal rigidities, capital is fully utilized, $\eta_{t, s}=1$ (see Online Appendix Section B.1.3). Thus, we assume that the interest rate policy follows the rule

$$
r_{t, s}^{f}=\max \left(0, r_{t, s}^{f, *}\right) \quad \text { for each } t \geq 0 \text { and } s \in S
$$

Here, $r_{t, s}^{f, *}$ is recursively defined as the instantaneous natural interest rate that obtains when $\eta_{t, s}=1$ and monetary policy follows the rule in 20 at all future times and states.

Definition 1. The equilibrium is a collection of processes for allocations, prices, and returns such that capital and its price evolve according to $(12)$ and $(13)$, the instantaneous return and the volatility of the market portfolio are given by (15), investors maximize expected utility (cf. Online Appendix Section B.1.1), asset markets clear (cf. Eqs. (16) and (17)), production firms maximize earnings (cf. Online Appendix Section B.1.3), goods markets clear (cf. Eq. (18)), and the interest rate policy follows the rule in 20 .

Remark 3 (Partial price flexibility). Our assumption of fixed nominal prices is extreme. However, allowing some nominal price flexibility does not necessarily circumvent the lower bound in (19). In fact, if monetary policy follows an inflation targeting policy regime, partial price flexibility leads to expected price deflation during a demand recession - the opposite of what the economy needs to circumvent the lower bound on the nominal interest rate (see Remark 1). Intuitively, individual firms respond to the recession by cutting their individual nominal prices, which increases their individual demand given aggregate demand. However, the decline in nominal prices does not necessarily stabilize aggregate demand - whether or not this happens depends on monetary policy. In an inflation targeting regime, nominal prices decline during the recession and get stabilized at a lower level once the economy exits the recession. This creates expected deflation that strengthens the bound in (19) and exacerbates the recession (see Werning (2012); Korinek and Simsek (2016); Caballero and Farhi (2018) for further discussion).

In the rest of this section, we provide a partial characterization of the equilibrium. In subsequent sections, we use this characterization to describe the equilibrium for various specifications of investors' beliefs.

\section{III.A. Equilibrium in the goods market}

First consider the goods market. The following result establishes that there is a tight relationship between output and asset prices as in the two period model. 
Lemma 1 (Output-asset price relation). The equilibrium level of output (per capital) satisfies

$$
\frac{y_{t, s}}{k_{t, s}}=A \eta_{t, s}=\rho Q_{t, s} .
$$

The equilibrium return and the volatility of the market portfolio (absent transition) are given by

$$
r_{t, s}^{m}=\rho+g+\mu_{t, s}^{Q}+\sigma_{s} \sigma_{t, s}^{Q} \quad \text { and } \quad \sigma_{t, s}^{m}=\sigma_{s}+\sigma_{t, s}^{Q} .
$$

As before, the output-asset price relation in 21) follows from the wealth effect. In view of log utility, each investor optimally consumes a constant fraction of her wealth (see Online Appendix Section B.1.1)

$$
c_{t, s}^{i}=\rho a_{t, s}^{i}
$$

This implies that aggregate consumption is a constant fraction of aggregate wealth [cf. (16)],

$$
\sum_{i} c_{t, s}^{i}=\rho Q_{t, s} k_{t, s}
$$

Combining this with Eq. (18), we obtain the relation in (21). Substituting this into Eq. (15), we further obtain Eq. (22). In view of the output-asset price relation, the dividend yield on the market portfolio is equal to the consumption rate $\rho$.

As before, the output-asset price relation implies that full factor utilization, $\eta_{t, s}=1$, obtains only if the price per unit of capital is at a particular level $Q^{*} \equiv \frac{A}{\rho}$. This is the efficient price level that ensures the implied consumption clears the goods market. Likewise, the economy features a demand recession, $\eta_{t, s}<1$, only if the price per unit of capital is strictly below $Q^{*}$. Combining these observations with the interest rate policy in (20), we also summarize the goods market with

$$
Q_{t, s} \leq Q^{*}, r_{t, s}^{f} \geq 0, \quad \text { where at least one condition is an equality. }
$$

The equilibrium at any time and state takes one of two forms. If the natural interest rate is nonnegative, then the interest rate policy ensures that the price per unit of capital is at the efficient level, $Q_{t, s}=Q^{*}$, capital is fully utilized, $\eta_{t, s}=1$, and output is equal to its potential, $y_{t, s}=A k_{t, s}$. Otherwise, the interest rate is constrained, $r_{t, s}^{f}=0$, the price is lower, $Q_{t, s}<Q^{*}$, and output is determined by aggregate demand according to Eq. (21).

\section{III.B. Equilibrium in asset markets}

Next consider asset markets. The equilibrium in these markets depends on investors' relative wealth. We define type $i$ investors' wealth share as

$$
\alpha_{t, s}^{i}=\frac{a_{t, s}^{i}}{k_{t, s} Q_{t, s}}
$$


By definition, the wealth shares sum to one, $\sum_{i} \alpha_{t, s}^{i}=1$ [cf. [16] ]. These wealth shares matter because they determine the wealth-weighted average belief for the transition probability, defined as

$$
\bar{\lambda}_{t, s} \equiv \sum_{i} \alpha_{t, s}^{i} \lambda_{s}^{i}
$$

We will show that asset prices are determined as-if there is a representative investor that has the wealth-weighted average belief. However, the wealth-weighted average belief is not constant over time because investors have speculative portfolios that affect their wealth shares. Therefore, we start by characterizing investors' optimal portfolios and the resulting wealth dynamics. We use the notation $\dot{x}$ to denote the time derivative of variable $x$, i.e., $\dot{\alpha}_{t, s}^{i}=\frac{d \alpha_{t, s}^{i}}{d t}$ denotes the drift in type $i$ investors' wealth share.

Lemma 2 (Wealth-share dynamics). Investors hold identical positions on the market portfolio,

$$
\omega_{t, s}^{m, i}=1 \quad \text { for each } i
$$

They hold possibly heterogeneous positions on the contingent security given by

$$
\omega_{t, s}^{s^{\prime}, i}=\lambda_{s}^{i}-\bar{\lambda}_{t, s}
$$

Type $i$ investors' wealth share evolves according to

$$
\begin{array}{ll}
\frac{\dot{\alpha}_{t, s}^{i}}{\alpha_{t, s}^{i}}=-\omega_{t, s}^{s^{\prime}, i}=\bar{\lambda}_{t, s}-\lambda_{s}^{i}, & \text { if there is no state change, } \\
\frac{\alpha_{t, s^{\prime}}^{i}}{\alpha_{t, s}^{i}}=\frac{\lambda_{s}^{i}}{\bar{\lambda}_{t, s}}, & \text { if there is a state change to } s^{\prime} .
\end{array}
$$

Eq. (28) says that investors' belief disagreements do not affect their positions on the market portfolio. In contrast, Eq. 29) shows that belief disagreements do affect investors' positions on the contingent security, and Eq. 30 describes the resulting wealth dynamics. When type $i$ investors assign a relatively large probability to transition, $\lambda_{s}^{i}>\bar{\lambda}_{t, s}$, they purchase the contingent security that pays if there is a transition, $\omega_{t, s}^{s^{\prime}, i}>0$. As long as the economy remains in the same state, their wealth share drifts downward, $\dot{\alpha}_{t, s}^{i}<0$. However, if there is a transition to the other state, then their wealth share makes an upward jump, $\frac{\alpha_{t, s^{\prime}}^{i}}{\alpha_{t, s}^{i}}>1$. Conversely, when type $i$ investors assign a relatively small probability to transition, they sell the contingent security. This ensures that their wealth share drifts upward if the economy remains in the same state, and it makes a downward jump if there is a transition. These dynamics are important for our main result (see Section $\mathrm{V}$ ).

We provide a sketch proof of Lemma 2, which is useful for developing further intuition and obtaining additional results. We derive investors' portfolio optimality conditions in Online Appendix Section B.1.1. A type $i$ investor's portfolio weight on the market portfolio is determined by

$$
\omega_{t, s}^{m, i} \sigma_{t, s}^{m}=\frac{1}{\sigma_{t, s}^{m}}\left(r_{t, s}^{m}-r_{t, s}^{f}+\lambda_{s}^{i} \frac{1 / a_{t, s^{\prime}}^{i}}{1 / a_{t, s}^{i}} \frac{Q_{t, s^{\prime}}-Q_{t, s}}{Q_{t, s}}\right) .
$$


That is, she invests in the market portfolio until the risk of her portfolio (left side) is equal to the "Sharpe ratio" of the market portfolio (right side). This is similar to the optimality condition in the two period model (cf. Eq. (6)), but the dynamic model also features state transitions. Our notion of the Sharpe ratio accounts for potential revaluation gains or losses from transitions (the term $\left.\frac{Q_{t, s^{\prime}}-Q_{t, s}}{Q_{t, s}}\right)$ and the adjustment of marginal utility in case there is a transition (the term $\left.\frac{1 / a_{t, s^{\prime}}^{i}}{1 / a_{t, s}^{i}}\right) 8^{8}$

Likewise, the investor's optimal portfolio allocation to the contingent securities implies

$$
\frac{p_{t, s}^{s^{\prime}}}{\lambda_{s}^{i}}=\frac{1 / a_{t, s^{\prime}}^{i}}{1 / a_{t, s}^{i}} .
$$

The portfolio weight, $\omega_{t, s}^{s^{\prime}, i}$, is implicitly determined as the level that ensures this equality. The investor buys contingent securities until the perceived price-to-probability ratio of a state (or the state price) is equal to the investor's relative marginal utility in that state.

Substituting (32) into (31) shows that different investor types allocate identical portfolio weights to the market portfolio, $\omega_{t, s}^{m, i}=\omega_{t, s}^{m}$. Together with market clearing [cf. (16)], this implies Eq. (28).

To establish the remaining results in the lemma, we rewrite $(32)$ in terms of wealth shares to obtain [cf. (26)]

$$
\alpha_{t, s^{\prime}}^{i}=\alpha_{t, s}^{i} \lambda_{s}^{i} \frac{1}{\kappa_{t, s}}, \quad \text { where } \kappa_{t, s}=p_{t, s}^{s^{\prime}} \frac{Q_{t, s^{\prime}}}{Q_{t, s}}
$$

Here, $\kappa_{t, s}$ is a variable that depends on asset prices but that is common across investor types. Aggregating this equation across all investor types, and using $\sum_{i} \alpha_{t, s^{\prime}}^{i}=1$, we obtain the second part of Eq. (30). In Online Appendix Section B.1.2, we further derive Eq. (29) and the first part of Eq. (30) by combining Eq. (33) with investors' budget constraints.

Remark 4 (Deterministic wealth dynamics within a state). Lemma 2 shows that investors' wealth shares follow deterministic dynamics absent state transitions. This property is driven by Eq. (28), which ensures that investors' relative wealth shares are not influenced by $d Z_{t}$. As our proof illustrates, Eq. 28) is driven by complete markets and constant RRA preferences. Complete markets ensure disagreements per se do not induce investors to trade the market portfolio. Intuitively, since investors disagree about transition risk, they settle these disagreements by trading the contingent security for the corresponding risk instead of the market portfolio. Constant (and common) RRA preferences ensure risk sharing considerations do not generate trade on the market portfolio either.

Remark 5 (Separability of wealth dynamics and asset prices). Lemma 2 also implies that investors' wealth shares follow the same dynamics regardless of asset prices or monetary policy. This separability property comes from assuming complete markets and log utility. As we discuss in the previous remark, these assumptions imply that investors do not trade the market portfolio - such trade would make asset prices relevant for wealth shares (see Caballero and Simsek (2019)). Log

\footnotetext{
${ }^{8}$ The presence of state transitions makes the Sharpe ratio in our model slightly different from its common definition, which corresponds to the expected return in excess of the risk-free rate normalized by volatility.
} 
utility (which features RRA equal to one) is also necessary because, as captured by Eq. (33), it ensures that investors' marginal utility depends only on their wealth. In particular, investors do not have dynamic hedging motives - these motives would make asset prices relevant for wealth shares (see Remark 6 and Online Appendix Section E for further discussion of the case with more general RRA).

The separability property is convenient because it breaks the analysis with belief disagreements into two steps. We first use Lemma 2 to characterize investors' wealth dynamics and the evolution of the wealth-weighted average belief in $(27)$. We then characterize equilibrium asset prices. The following lemma facilitates the second step by establishing the equilibrium conditions for asset prices given the wealth-weighted average belief. The proof follows from Eqs. $31-33$ and is relegated to Online Appendix Section B.1.2.

Lemma 3 (Risk balance condition). The equilibrium price of the market portfolio satisfies

$$
\begin{aligned}
\sigma_{t, s}^{m} & =\frac{1}{\sigma_{t, s}^{m}}\left(r_{t, s}^{m}-r_{t, s}^{f}+\bar{\lambda}_{t, s}\left(1-\frac{Q_{t, s}}{Q_{t, s^{\prime}}}\right)\right), \\
\text { where } \quad r_{t, s}^{m} & \left.=\rho+g+\mu_{t, s}^{Q}+\sigma_{s} \sigma_{t, s}^{Q} \quad \text { and } \quad \sigma_{t, s}^{m}=\sigma_{s}+\sigma_{t, s}^{Q} \quad \text { [cf. Lemma } 1\right] \text {. }
\end{aligned}
$$

The equilibrium price of the contingent security satisfies

$$
p_{t, s}^{s^{\prime}}=\bar{\lambda}_{t, s} \frac{1 / Q_{t, s^{\prime}}}{1 / Q_{t, s}}
$$

Eqs. (34-35) are identical to their counterparts in an alternative economy in which a representative investor has the wealth-weighted average belief $\bar{\lambda}_{t, s}$.

Lemma 3 shows that asset prices are determined as-if there is a representative investor that has the wealth-weighted average belief. Eq. (34) is the risk balance condition: the dynamic counterpart to Eq. (7) in the two-period model. In each state, the total risk in the economy (the left side) is equal to the Sharpe ratio according to the wealth-weighted average belief (the right side). Note that the Sharpe ratio accounts for the fact that the aggregate wealth and (aggregate) marginal utility will change if there is a state transition $!^{9}$ Likewise, Eq. (35) shows that the equilibrium price of the contingent security reflects the wealth-weighted average belief and the change in (aggregate) marginal utility after transition.

First-best equilibrium. For future reference, we derive the first-best equilibrium without interest rate rigidities. In this case, there is no lower bound constraint on the interest rate, so the price per unit of capital is at its efficient level at all times and states, $Q_{t, s}=Q^{*}$. Combining this with

\footnotetext{
${ }^{9}$ To see this, observe that the term $\frac{Q_{t, s^{\prime}}-Q_{t, s}}{Q_{t, s^{\prime}}}$ is actually equal to $\frac{1 / Q_{t, s^{\prime}}}{1 / Q_{t, s}} \frac{Q_{t, s^{\prime}}-Q_{t, s}}{Q_{t, s}}$. Here, $\frac{Q_{t, s^{\prime}}-Q_{t, s}}{Q_{t, s}}$ denotes the capital gains and $\frac{1 / Q_{t, s^{\prime}}}{1 / Q_{t, s}}$ denotes the aggregate marginal utility adjustment.
} 
Eq. (34), we solve for "rstar" as

$$
r_{s}^{f *}=\rho+g-\sigma_{s}^{2} \quad \text { for each } s \in\{1,2\} .
$$

Hence, in the first-best equilibrium the risk premium shocks are fully absorbed by the interest rate. Note also that, by Lemma 2, investors' wealth shares do fluctuate when there are belief disagreements. In the first-best equilibrium, these wealth-share fluctuations affect the equilibrium price of the contingent security [cf. Eqs. [35] ] but not the equilibrium price of capital, aggregate demand, or the interest rate. Next, we characterize the equilibrium with interest rate rigidities.

\section{Common belief benchmark and amplification}

In this section, we analyze the equilibrium in a benchmark case with a single investor type with belief denoted by $\lambda_{s} \equiv \lambda_{s}^{i}$. We use this benchmark to illustrate how the spirals between asset prices and output exacerbate the recession, and how pessimism amplifies these spirals.

Since the model is linear, we focus on equilibria in which the price per capital and the interest rate remain constant within states, $Q_{t, s}=Q_{s}$ and $r_{t, s}^{f}=r_{s}^{f}$. In particular, there is no price drift or volatility within a state, $\mu_{t, s}^{Q}=\sigma_{t, s}^{Q}=0$. Combining this with Eq. (34), we obtain the risk balance conditions

$$
\sigma_{s}=\frac{\rho+g+\lambda_{s}\left(1-\frac{Q_{s}}{Q_{s^{\prime}}}\right)-r_{s}^{f}}{\sigma_{s}} \quad \text { for each } s \in\{1,2\}
$$

The equilibrium is then characterized by finding four unknowns, $\left(Q_{1}, r_{1}^{f}, Q_{2}, r_{2}^{f}\right)$, that solve the two equations in (37) together with the two goods market equilibrium conditions in (25). We solve these equations under the following parametric restriction.

Assumption 1. $\sigma_{2}^{2}>\rho+g>\sigma_{1}^{2}$.

In view of this restriction, the low-risk-premium state 1 features positive interest rates, efficient asset prices, and full factor utilization, $r_{1}^{f}>0, Q_{1}=Q^{*}$ and $\eta_{1}=1$, whereas the high-riskpremium state 2 features zero interest rates, lower asset prices, and imperfect factor utilization, $r_{2}^{f}=0, Q_{2}<Q^{*}$ and $\eta_{2}<1$. In particular, the analysis with common beliefs reduces to finding two unknowns, $\left(Q_{2}, r_{1}^{f}\right)$, that solve the two risk balance equations in (37) (after substituting $Q_{1}=Q^{*}$ and $\left.r_{2}^{f}=0\right)$.

Equilibrium in the high-risk-premium state. After substituting $r_{2}^{f}=0$, the risk balance equation (37) for the high-risk-premium state $s=2$ can be written as

$$
\sigma_{2}=\frac{\rho+g+\lambda_{2}\left(1-\frac{Q_{2}}{Q^{*}}\right)}{\sigma_{2}}
$$


If the price were at its efficient level, $Q_{2}=Q^{*}$, the risk (the left side) would exceed the Sharpe ratio (the right side). As in the two period model, the economy generates more risk than investors are willing to absorb at the constrained interest rate. As before, the price per unit of capital, $Q_{2}$, must fall to equilibrate the risk markets. Rearranging the expression, we obtain a closed form solution,

$$
Q_{2}=Q^{*}\left(1-\frac{\sigma_{2}^{2}-(\rho+g)}{\lambda_{2}}\right)
$$

As this expression illustrates, we require a minimum degree of optimism to ensure an equilibrium with positive price and output.

Assumption 2. $\lambda_{2}>\sigma_{2}^{2}-(\rho+g)$.

This requirement is a manifestation of an amplification mechanism that we describe next.

Amplification from endogenous output and earnings. In the two period model of Section II] the future payoff from the market portfolio is exogenous $\left(z_{1}\right)$. Therefore, a decline in the price of capital $(Q)$ increases the dividend yield and the market return, $r^{m}\left(z_{1}\right)=\frac{z_{1}}{Q}$ [cf. Eq. (2)]. In contrast, in the current model the instantaneous payoff from the market portfolio is endogenous and given by $y_{t, 2}=\rho Q_{2} k_{t, 2}$. Therefore, a decline in the price of the market portfolio does not affect the dividend yield $\left(\frac{y_{t, 2}}{Q_{2} k_{t, 2}}=\rho\right)$ and leaves the market return absent transitions unchanged, $r_{t, 2}^{m}=\rho+g$ [cf. Eq. [22]]. Unlike in the two period model, a decline in asset prices does not increase the market return (aside from state transitions). The intuition is that a lower price reduces output and economic activity, which reduces firms' earnings and leaves the dividend yield constant. Thus, asset price declines no longer play a stabilizing role through the dividend yield, leaving the economy susceptible to a spiraling decline.

In view of this amplification mechanism, one might wonder how the risk market ever reaches equilibrium once the price, $Q_{2}$, falls below its efficient level, $Q^{*}$. The stabilizing force is captured by the last term in Eq. (38), $\lambda_{2}\left(1-\frac{Q_{2}}{Q^{*}}\right)$. A decline in the price increases the expected capital gain from transition into the recovery state $s=1$, which increases the expected return to capital and the Sharpe ratio. The stabilizing force is stronger when investors are more optimistic and perceive a higher transition probability into the recovery state, $\lambda_{2}$. Assumption 2 ensures that the stabilizing force is sufficiently strong to counter the impact of the risk premium shock. If this assumption were violated, a risk premium shock would trigger a downward price spiral that would lead to an equilibrium with zero asset prices and zero output.

Finally, consider the comparative statics of the equilibrium price with respect to the exogenous shifter of the risk premium, $\sigma_{2}^{2}$ [cf. (36)]. Using Eq. (39), we obtain $\frac{d\left(Q_{2} / Q^{*}\right)}{d \sigma_{2}^{2}}=-\frac{1}{\lambda_{2}}$. Hence, risk premium shocks reduce asset prices and output by a greater magnitude when investors are more pessimistic about recovery (lower $\lambda_{2}$ ). These observations illustrate that average beliefs matter in this environment not only because they have a direct impact on asset prices but also because they determine the strength of the amplification mechanism. 
Equilibrium in the low-risk-premium state. Following similar steps for the low-risk-premium state $s=1$, we also obtain a closed form solution for the interest rate in this state,

$$
r_{1}^{f}=\rho+g-\sigma_{1}^{2}-\lambda_{1}\left(\frac{Q^{*}}{Q_{2}}-1\right)
$$

Intuitively, given the expected return on capital the interest rate adjusts to ensure that the risk balance condition is satisfied at the efficient price level, $Q_{1}=Q^{*}$. For our conjectured equilibrium, we also assume an upper bound on $\lambda_{1}$, which ensures that the implied interest rate is positive.

Assumption 3. $\lambda_{1}<\frac{\rho+g-\sigma_{1}^{2}}{\frac{Q^{*}}{Q_{2}}-1}$, where $\frac{Q^{*}}{Q_{2}}$ is given by Eq. 39.

Note that Eq. 40 implies $r_{1}^{f}$ is decreasing in the transition probability, $\lambda_{1}$, as well as in the asset price drop conditional on transition, $\frac{Q^{*}}{Q_{2}}$. Interest rates are kept relatively low because investors fear a recession triggered by an increase in the risk premium when the interest rate is constrained. The following result summarizes the equilibrium characterization in this section.

Proposition 1. Consider the model with a single belief type and Assumptions 1-3. There is an equilibrium in which the price per capital and the interest rate are constant within each state, $Q_{t, s}=Q_{s}$ and $r_{t, s}^{f}=r_{s}^{f}$. The low-risk-premium state 1 features a positive interest rate, efficient asset prices and full factor utilization, $r_{1}^{f}>0, Q_{1}=Q^{*}$ and $\eta_{1}=1$. The high-risk-premium state 2 features zero interest rate, lower asset prices, and a demand-driven recession, $r_{2}^{f}=0, Q_{2}<Q^{*}$, and $\eta_{2}<1$, as well as lower consumption and output, $\frac{c_{t, 2}}{k_{t, 2}}=\frac{y_{t, 2}}{k_{t, 2}}=\rho Q_{2}$. The price in state 2 and the interest rate in state 1 are given by Eqs. (39) and (40).

Equilibrium with investment and endogenous growth. In Online Appendix Section D, we extend the baseline environment to incorporate investment. This leads to two main changes. First, the growth rate in 12 becomes endogenous, $g_{t, s}=\varphi\left(\iota_{t, s}\right)-\delta$, where $\iota_{t, s}=\frac{i_{t, s}}{k_{t, s}}$ denotes the investment rate per capital, $\varphi(\cdot)$ denotes a neoclassical production technology for capital, and $\delta$ denotes the depreciation rate. Second, under the simplifying assumption that output accrues to agents as returns to capital (i.e., no monopoly profits), optimal investment is an increasing function of the price per unit of capital, $Q_{t, s}{ }^{10}$ Moreover, using a convenient functional form for $\varphi(\cdot)$, we obtain a linear relation between the investment rate and the price, $\iota\left(Q_{t, s}\right)=\psi\left(Q_{t, s}-1\right)$ for some $\psi>0$.

In this setting, aggregate demand is the sum of consumption and investment. Using the expression for optimal investment, we generalize the output-asset price relation (21) to

$$
A \eta_{t, s}=\rho Q_{t, s}+\psi\left(Q_{t, s}-1\right) .
$$

\footnotetext{
${ }^{10}$ Without this assumption, investment would be a function of $\tilde{Q}_{t, s} \leq Q_{t, s}$, which represents a claim on the rental rate of capital in future periods (excluding monopoly profits). The difference, $Q_{t, s}-\tilde{Q}_{t, s}$, captures the price of a claim on monopoly profits. Hence, allowing for profits would have a quantitative impact on investment, though we believe it would leave our qualitative results unchanged. We leave an investigation of this issue for future research.
} 
Hence, output is increasing in asset prices not only because asset prices generate a wealth effect on consumption but also because they increase investment through a marginal-Q channel. Substituting optimal investment into the endogenous growth expression, we further obtain

$$
g_{t, s}=\psi q_{t, s}-\delta, \quad \text { where } \quad q_{t, s}=\log Q_{t, s} .
$$

Hence, this setting also features a growth-asset price relation: lower asset prices reduce investment, which translates into lower endogenous growth and lower potential output in future periods. The rest of the model is unchanged (see Online Appendix Section D for details).

In the online appendix, we characterize the equilibrium in this extended environment and generalize Proposition 1. We find that risk premium shocks - captured by a transition to state 2 generate a decline in investment and endogenous growth as well as consumption and output, as in the baseline model. The decline in investment and endogenous growth generates a second amplification mechanism that reinforces the mechanism we described earlier. Specifically, the recession lowers asset prices further, not only by reducing output and earnings, but also by reducing growth in potential output and earnings. Figure $\mathrm{I}$ in the introduction illustrates the two amplification mechanisms. Henceforth, we return to the baseline model without investment.

Remark 6 (More general RRA). In Online Appendix Section E, we extend the baseline dynamic model to cases where the RRA is different from one while keeping the EIS equal to one (see Remark 2 for the role of the EIS). This introduces dynamic hedging motives: investors' marginal utility for future states reflects not only their wealth but also the attractiveness of investment opportunities in the corresponding state. These motives affect our analysis in two ways. First, investors' wealthshare dynamics are influenced by their relative dynamic hedging motives in addition to belief disagreements. These effects complicate the analysis with belief disagreements (in particular, the separability property from Section III.B no longer applies), but they are largely orthogonal to the effects of speculation that we discuss subsequently. Second, with common beliefs (in which case the analysis is tractable), dynamic hedging motives further amplify the effect of risk premium shocks on asset prices and output in the empirically relevant case of RRA greater than one (see Di Tella (2017)). Specifically, an increase in the (relative) risk premium in the high-risk-premium state makes the investment opportunities in this state (relatively) less attractive, which increases investors' willingness to hedge the high-risk-premium state. In equilibrium, this translates into a lower price and output in the high-risk-premium state (and a lower interest rate in the low-riskpremium state).

\section{Belief disagreements and speculation}

We now turn to the main case with belief disagreements. We show that a greater wealth share for optimists raises asset valuations and mitigates the recession. We also establish that speculation induced by belief disagreements exacerbates asset price fluctuations and worsens the recession. 
We restrict attention to two investor types, optimists and pessimists, with beliefs denoted by $\left\{\left(\lambda_{1}^{i}, \lambda_{2}^{i}\right)\right\}_{i \in\{o, p\}}$. Beliefs satisfy the following assumption:

Assumption 4. $\lambda_{2}^{o}>\lambda_{2}^{p}$ and $\lambda_{1}^{o} \leq \lambda_{1}^{p}$.

When the economy is in the high-risk-premium state, optimists find the transition into the lowrisk-premium state relatively likely $\left(\lambda_{2}^{o}>\lambda_{2}^{p}\right)$; when the economy is in the low-risk-premium state, optimists find the transition into the high-risk-premium state relatively unlikely $\left(\lambda_{1}^{o} \leq \lambda_{1}^{p}\right)$. Hence, optimism and pessimism are relative: an optimist is someone who is optimistic relative to a pessimist. In fact, we do not need to specify the "objective distribution" for our theoretical results (including the welfare results). We do, however, need relative optimism and pessimism to be persistent across the two risk premium states (see Remark 7 at the end of this section).

As our analysis in Section III.B suggests, the equilibrium with belief disagreements depends on investors' wealth shares. In the two-type context, we simplify the notation and denote optimists' wealth share without a superscript [cf. (26)]:

$$
\alpha_{t, s} \equiv \frac{a_{t, s}^{o}}{k_{t, s} Q_{t, s}}
$$

Pessimists' wealth share is the residual, $1-\alpha_{t, s}=\frac{a_{t, s}^{p}}{k_{t, s} Q_{t, s}}$. Optimists' wealth share, $\alpha_{t, s}$, is the relevant state variable for this economy. Specifically, we will establish an equilibrium in which all variables can be written as a function of $\alpha_{t, s}$. To this end, we also write the wealth-weighted average belief as a function of optimists' wealth share [cf. [27]]:

$$
\bar{\lambda}_{t, s}=\bar{\lambda}_{s}\left(\alpha_{t, s}\right) \equiv \alpha_{t, s} \lambda_{s}^{o}+\left(1-\alpha_{t, s}\right) \lambda_{s}^{p}
$$

We next present our main result in this section, which characterizes the equilibrium with belief disagreements. The result requires Assumptions 1-3 from the previous section to hold for both beliefs. These assumptions ensure that there exists an equilibrium in which the low-risk-premium state 1 always features a positive interest rate, efficient price level, and full factor utilization, $r_{t, 1}^{f}>0, Q_{t, 1}=Q^{*}, \eta_{t, 1}=1$, whereas the high-risk-premium state 2 always features a zero interest rate, a lower price level, and insufficient factor utilization, $r_{t, 2}^{f}=0, Q_{t, 2}<Q^{*}, \eta_{t, 2}<1$.

Proposition 2. Consider the model with two belief types. Suppose Assumptions 1-3 hold for each belief, and that beliefs are ranked according to Assumption 4. Then, there is an equilibrium in which the log-price and interest rate can be written as functions of optimists' wealth share, $q_{t, s}=q_{s}\left(\alpha_{t, s}\right), r_{t, s}^{f}=r_{s}^{f}\left(\alpha_{t, s}\right)$, where optimists' wealth share evolves according to

$$
\begin{array}{ll}
\frac{\dot{\alpha}_{t, s}}{\alpha_{t, s}}=-\omega_{t, s}^{s^{\prime}, o} & =\left(\lambda_{s}^{p}-\lambda_{s}^{o}\right)\left(1-\alpha_{t, s}\right) \quad \text { if there is no state change, } \\
\frac{\alpha_{t, s^{\prime}}}{\alpha_{t, s}}=\frac{\lambda_{s}^{o}}{\lambda_{s}\left(\alpha_{t, s}\right)} & \text { if there is a state change to } s^{\prime} .
\end{array}
$$

In the high-risk premium state 2 , the interest rate is zero, $r_{2}^{f}(\alpha)=0$, and the log-price per 
capital is below the efficient level, $q_{2}(\alpha)<q^{*}$. The price function is the solution to the differential equation

$$
q_{2}^{\prime}(\alpha)\left(\lambda_{2}^{o}-\lambda_{2}^{p}\right) \alpha(1-\alpha)=\rho+g+\bar{\lambda}_{2}(\alpha)\left(1-\frac{\exp \left(q_{2}(\alpha)\right)}{Q^{*}}\right)-\sigma_{2}^{2}
$$

with boundary conditions $q_{2}(0)=q_{2}^{p}$ and $q_{2}(1)=q_{2}^{o}$. The solution, $q_{2}(\alpha)$, is strictly increasing in $\alpha$. In particular, greater optimists' wealth share in the high-risk-premium state, $\alpha_{t, 2}$, increases the price per capital, $Q_{t, 2}$, as well as consumption and output, $\frac{c_{t, 2}}{k_{t, 2}}=\frac{y_{t, 2}}{k_{t, 2}}=\rho Q_{t, 2}$.

In the low-risk-premium state 1 , the log-price is at its efficient level, $q_{1}(\alpha)=q^{*}$, and the interest rate is strictly positive, $r_{1}^{f}(\alpha)>0$. The interest rate function is given by

$$
r_{1}^{f}(\alpha)=\rho+g-\bar{\lambda}_{1}(\alpha)\left(\frac{Q^{*}}{\exp \left(q_{2}\left(\alpha^{\prime}\right)\right)}-1\right)-\sigma_{1}^{2} \quad \text { where } \alpha^{\prime}=\alpha \frac{\lambda_{1}^{o}}{\bar{\lambda}_{1}(\alpha)} .
$$

The function $r_{1}^{f}(\alpha)$ is strictly increasing in $\alpha$. In particular, a greater optimists' wealth share in the low-risk-premium state, $\alpha_{t, 1}$, increases the interest rate, $r_{t, 1}^{f}$.

The characterization of optimists' wealth dynamics follows from Lemma 3 . When the economy is in the recession state, optimists purchase the upside contingent security from pessimists (since $\lambda_{2}^{o}>\lambda_{2}^{p}$ ). As long as the economy remains in the recession state, optimists' wealth share drifts downward. However, if there is a transition to the boom state, then optimists' wealth share makes an upward jump. Conversely, when the economy is in the boom state, optimists sell the downside contingent security to pessimists (since $\lambda_{1}^{o} \leq \lambda_{1}^{p}$ ). This ensures that optimists' wealth share drifts upward when the economy remains in the boom state, but it makes a downward jump if there is a transition to the recession state. Figure II illustrates these dynamics for a particular parameterization (described subsequently).

The rest of the proposition characterizes the equilibrium price in the high-risk state and the interest rate in the low-risk state as functions of optimists' wealth share. Eqs. (45) and (46) are similar to their counterparts with common beliefs [cf. Eqs. (38) and 440]]. The main difference is that the asset price and the interest rate depend on the wealth-weighted average belief in the corresponding state, $\bar{\lambda}_{2}(\alpha)$ and $\bar{\lambda}_{1}(\alpha)$. Since increasing optimists' wealth share, $\alpha$, makes the wealth-weighted average belief more optimistic (in either state), these equations suggest that greater $\alpha$ should increase the asset price and the interest rate. The proposition verifies this intuition. Figure III illustrates the equilibrium asset price and interest rate functions for a particular parameterization.

Proposition 2 has two important implications. First, in the recession state, a greater wealth share for optimists increases not only asset prices but also consumption and output (in view of the output-asset price relation). This observation motivates policies that redistribute wealth to optimists in the recession state-including macroprudential policy, which we analyze in the next section. The result is reminiscent of the recent macroeconomics literature that emphasizes the importance of wealth distribution for aggregate spending in environments with heterogeneous MPCs. 

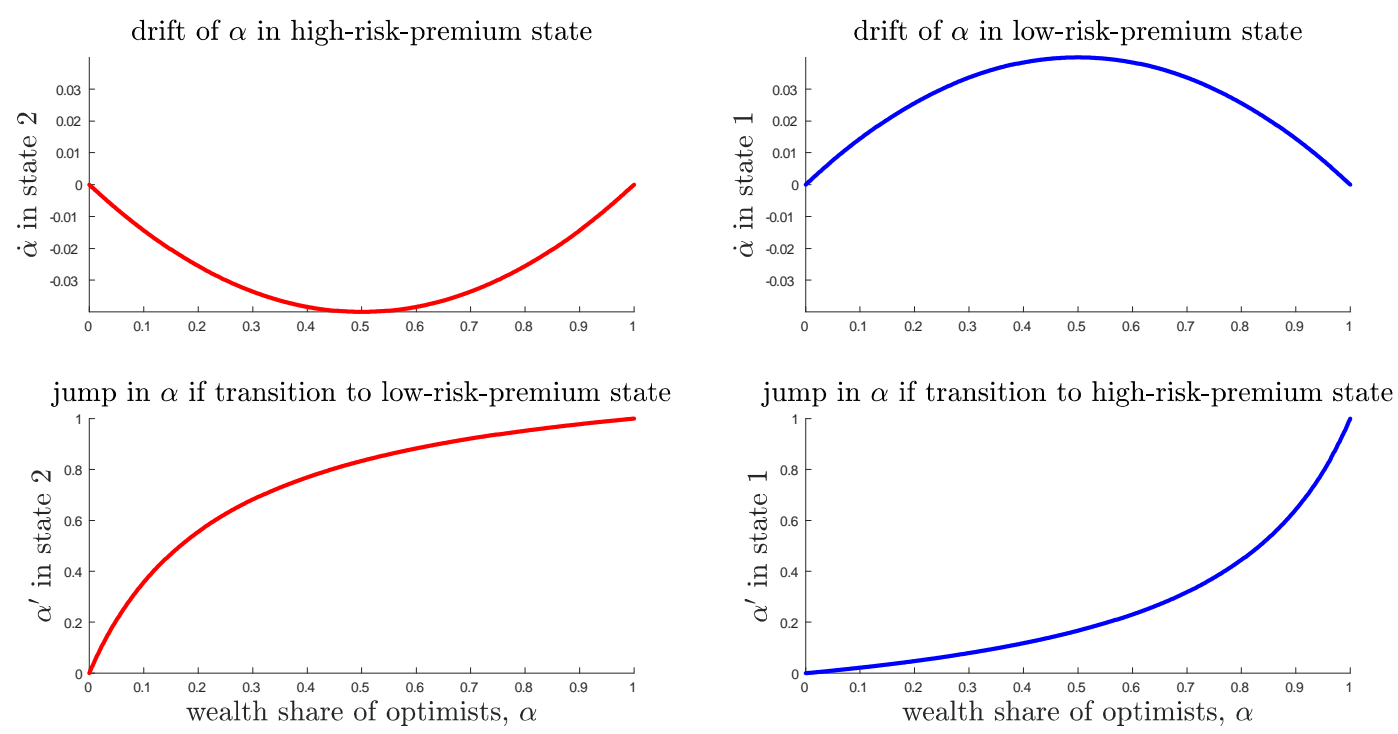

Figure II: Equilibrium dynamics of investors' wealth shares with heterogeneous beliefs.
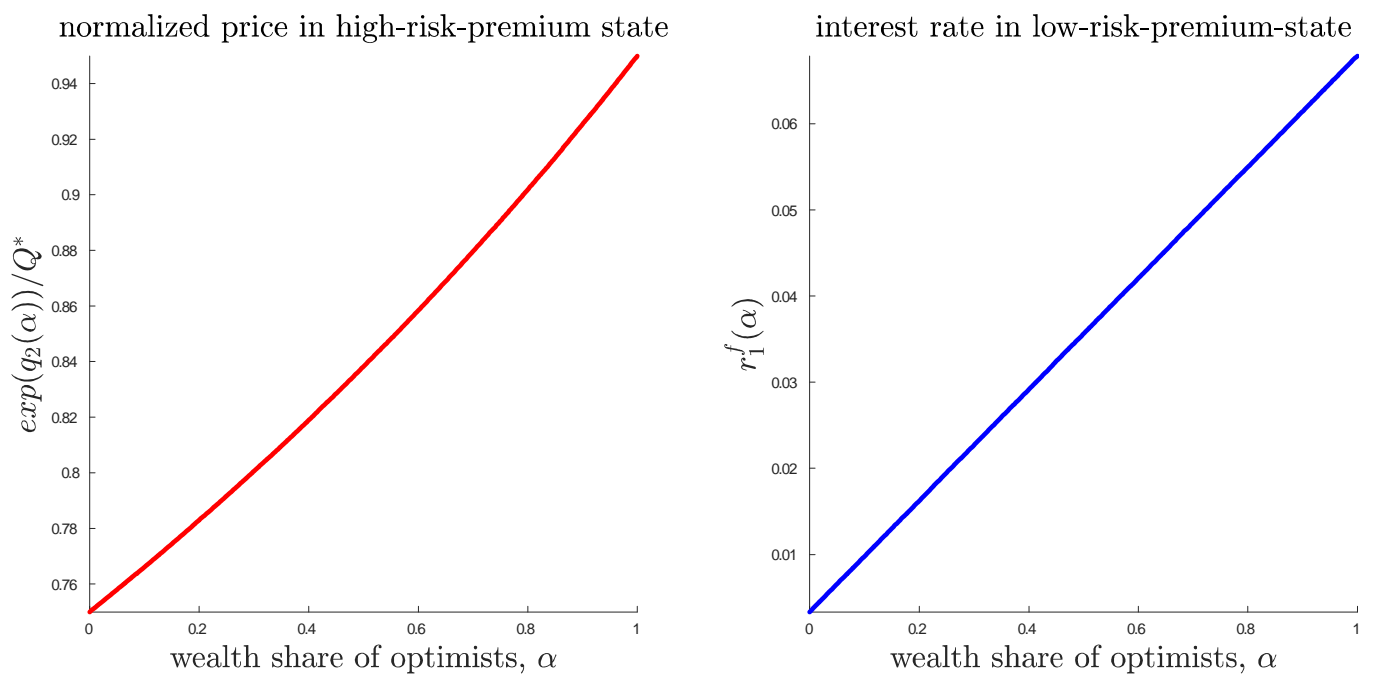

Figure III: Equilibrium price and interest rate functions with heterogeneous beliefs. 
However, the mechanism here is different and works through general equilibrium effects driven by heterogeneous asset valuations. To see this, consider the effect of a wealth transfer from pessimists to optimists in partial equilibrium - keeping asset prices unchanged, and in general equilibriumallowing asset prices to adjust. In partial equilibrium, this transfer would not stimulate aggregate spending because pessimists and optimists have the same MPC (equal to $\rho$ ). As optimists increase their spending, pessimists reduce their spending by the same amount. However, in general equilibrium, the transfer increases asset prices and aggregate spending. In fact, relative to the partial equilibrium benchmark, optimists and pessimists both increase their spending.

Second, the proposition implies that financial markets are effectively extrapolative even though investors' beliefs are fixed. Good realizations increase optimists' wealth share, which raises effective optimism and increases the asset price (in the high-risk-premium state) or the interest rate (in the low-risk-premium state). Conversely, bad realizations reduce optimists' wealth share, which reduces effective optimism and decreases the asset price or the interest rate. These results also imply that speculation exacerbates asset price boom-bust cycles and leads to more severe recessions (see also Remark 8 at the end of this section).

We next provide a sketch proof for Proposition 2, which provides further intuition. We then present a simulation that illustrates how speculation exacerbates boom-bust cycles and demand recessions.

Sketch proof of Proposition 2, The wealth dynamics in Eq. (44) follow from Lemma 2. Since we search for an equilibrium that satisfies $q_{t, s}=q_{s}\left(\alpha_{t, s}\right)$, and since $\alpha_{t, s}$ follows a deterministic path absent transition, $q_{t, s}$ also follows a deterministic path absent transition. Therefore, $\sigma_{t, s}^{Q}=0$ (cf. Remark 4).

To characterize the rest of the equilibrium, consider Lemma 3 that describes the risk balance condition. Applying Eq. (34) for the high-risk-premium state $s=2$ and substituting $r_{t, 2}^{f}=0$ and $\sigma_{t, 2}^{Q}=0, \mu_{t, 2}^{Q}=\frac{d Q_{t, 2} / d t}{Q_{t, 2}}=\dot{q}_{t, 2}$, we obtain

$$
\sigma_{2}=\frac{1}{\sigma_{2}}\left(\rho+g+\dot{q}_{t, 2}+\bar{\lambda}_{t, 2}\left(1-\frac{Q_{2}}{Q^{*}}\right)\right)
$$

This condition is similar to its counterpart with common beliefs, with two differences [cf. (38)]. First, the transition probability effectively depends on the wealth-weighted average belief, $\bar{\lambda}_{t, 2}$. Second, the expected return to the market portfolio features the price drift term $\dot{q}_{t, 2}$ [cf. [22]], which is not necessarily zero because optimists' wealth share changes over time.

Combining Eqs. (44) and (47), we obtain a differential equation system that describes the joint dynamics of the log price and optimists' wealth share, $\left(q_{t, 2}, \alpha_{t, 2}\right)$, conditional on no transition. In Online Appendix Section B.3, we show that this system is saddle path stable: for any initial wealth share, $\alpha_{t, 2} \in(0,1)$, there exists a unique equilibrium price level, $q_{t, 2} \in\left[q_{2}^{p}, q_{2}^{o}\right)$, such that the solution satisfies $\lim _{t \rightarrow \infty} \alpha_{t, 2}=0$ and $\lim _{t \rightarrow \infty} q_{t, 2}=q_{2}^{p}$. We further show that the saddle path is strictly increasing in $\alpha_{t, 2}$. These observations imply that the equilibrium price is an increasing 
function of optimists' wealth share, $q_{2}(\alpha)$ (which corresponds to the saddle path). Substituting this function into Eq. (47) and using Eq. (44), we also obtain the differential equation (45) that characterizes this function in the $\alpha$-domain.

Finally, we obtain Eq. (46) by applying the risk balance condition (34) for the low-risk-premium state $s=1$. The term $\alpha^{\prime}$ denotes optimists' wealth share after an immediate transition into the high-risk-premium state [cf. Eq. (44)]. The interest rate is increasing in $\alpha$ both because the wealth-weighted transition probability to the high-risk-premium state, $\bar{\lambda}_{1}(\alpha)$, is decreasing in $\alpha$; and because the price that would obtain after transition, $q_{2}\left(\alpha^{\prime}\right)$, is increasing in $\alpha$.

Numerical illustration. We next illustrate the equilibrium characterized in Proposition 2 using a simple parameterization (see Online Appendix Section B.4 for details). For the baseline parameters, we set $g=5 \%, \rho=4 \%, \sigma_{1}^{2}=2 \%, \sigma_{2}^{2}=10 \%$. For investors' beliefs about transition probabilities, we set $\lambda_{1}^{o}=\frac{1}{25}, \lambda_{1}^{p}=\frac{1}{5}$ for the boom state and $\lambda_{2}^{o}=\frac{1}{5}, \lambda_{2}^{p}=\frac{1}{25}$ for the recession state.

Figure [II illustrates the corresponding dynamics for optimists' wealth share. Figure III illustrates the corresponding equilibrium prices. The left panel of Figure III illustrates the price of capital in the recession (normalized by the efficient price level) as a function of optimists' wealth share. When pessimists dominate the economy, the price of capital and output decline by $25 \%$. In contrast, when optimists dominate, they decline by only $5 \%$. The right panel of Figure III illustrates the interest rate in the boom as a function of optimists' wealth share. The risk-free rate during the boom is close to $7 \%$ when optimists dominate the economy but it is close to $0 \%$ when pessimists dominate.

Amplification from speculation. We next use our numerical example to illustrate how speculation amplifies the business-cycle driven by risk premium shocks. We fix investors' beliefs and simulate the equilibrium for a particular realization of uncertainty over a 40-year horizon. We choose the objective simulation belief to be in the "middle" of optimists' and pessimists' beliefs in terms of the relative entropy distance ${ }^{11}$ We also focus on the "average path" — the path in which the length of each boom or bust is exactly equal to its mean value implied by the simulation belief. Figure IV illustrates the dynamics of equilibrium variables along this path. For comparison, the dashed red line plots the equilibrium that would obtain in the common-beliefs benchmark if all investors shared the "middle" simulation belief, and the circled blue line plots the first-best equilibrium that would obtain without interest rate rigidities.

The figure illustrates two points. First, as we establish in Section IV, the price per unit of

\footnotetext{
${ }^{11}$ Formally, given two probability distributions $(p(\tilde{s}))_{\tilde{s} \in S}$ and $(q(\tilde{s}))_{\tilde{s} \in S}$, the relative entropy of $p$ with respect to $q$ is defined as $\sum_{\tilde{s}} p(\tilde{s}) \log \left(\frac{p(\tilde{s})}{q(\tilde{s})}\right)$. In a setting similar to ours, Blume and Easley $(2006)$ show that investors whose belief is closer to the objective distribution in terms of the relative entropy distance dominate the economy in the long run. We choose the simulation belief (in both the boom and the recession state) to be in the "middle" of optimists' and pessimists' beliefs to prevent this outcome and to ensure that there is a non-degenerate long-run wealth distribution. This helps to illustrate the destabilizing effects of speculation without taking a stand on whether optimists or pessimists are "correct." Our welfare results in the next section do not require this assumption since we evaluate investors' expected utilities according to their own beliefs.
} 


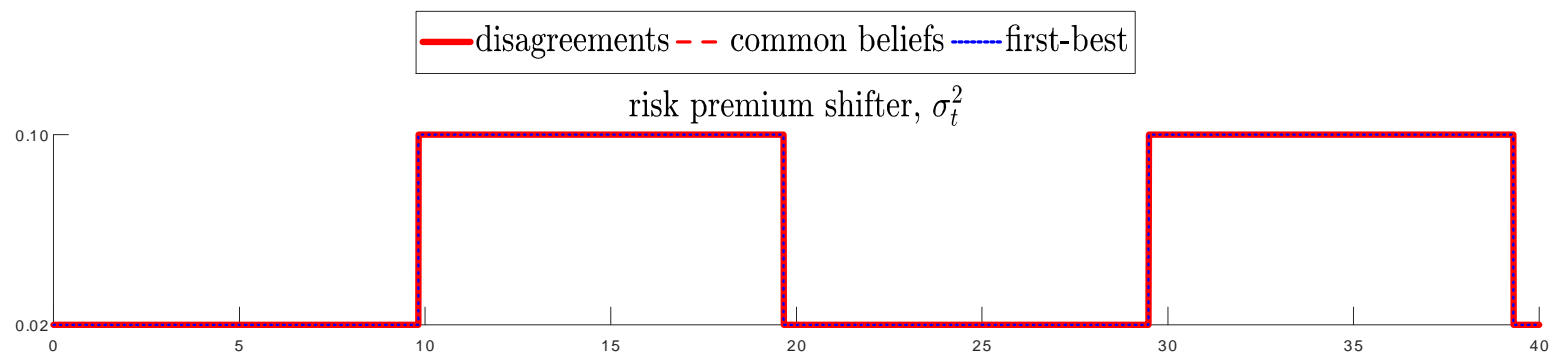

wealth share of optimists, $\alpha_{t}$

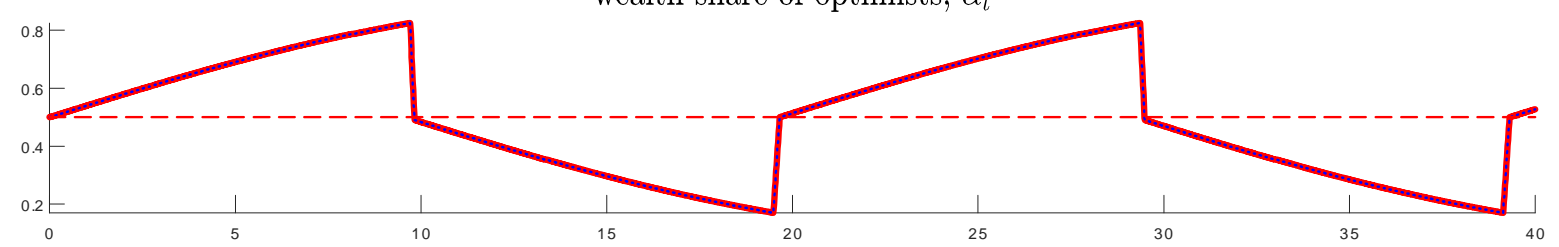

interest rate, $r_{t}^{f}$

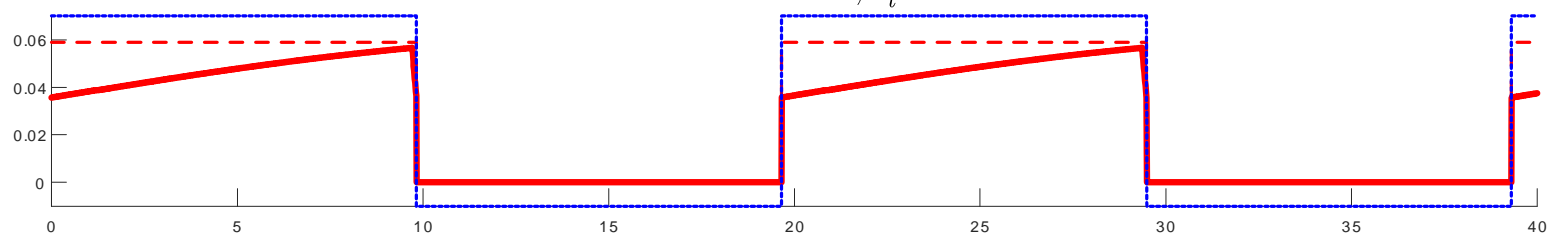

normalized price, $Q_{t} / Q^{*}$

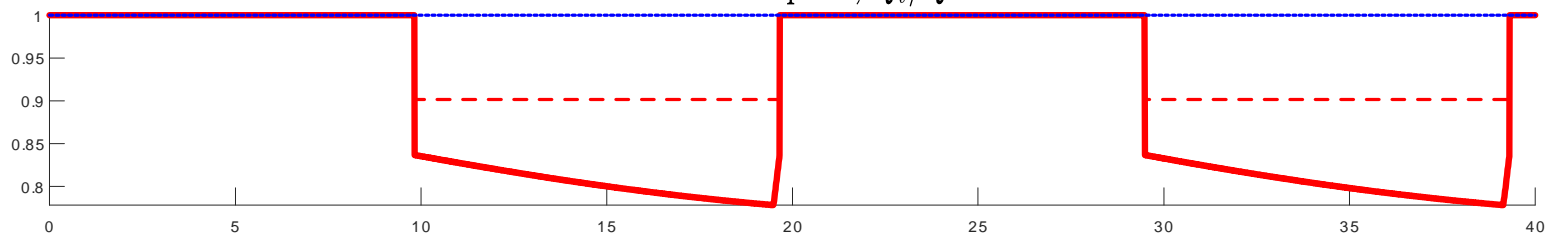

factor utilization (and normalized output), $\eta_{t}$

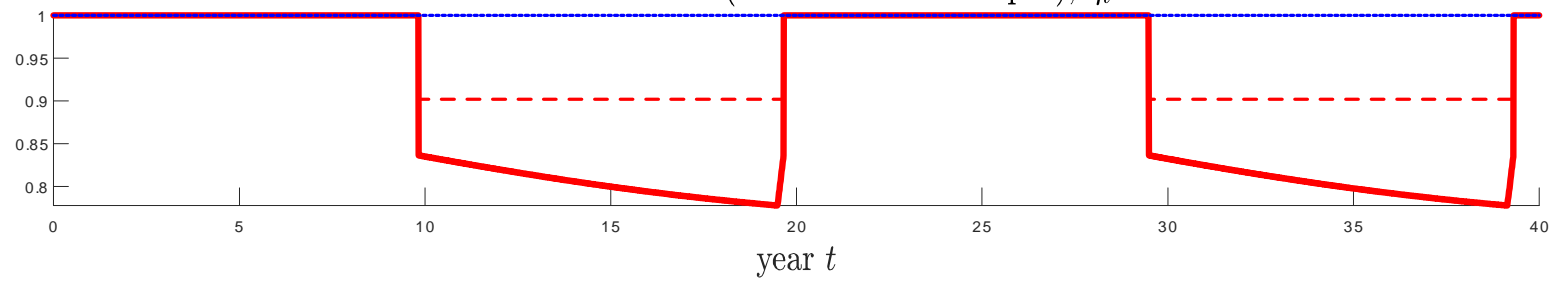

Figure IV: A simulation of the equilibrium variables over time. The solid red lines illustrate the equilibrium with belief disagreements. The dahed red lines (resp. the dotted blue lines) illustrate the common belief benchmark (resp. the first-best benchmark). 
capital is more volatile and the interest rate is more compressed in the common-belief benchmark than in the first-best equilibrium. In the high-risk-premium state, the interest rate cannot decline enough to equilibrate the risk balance condition, which leads to a drop in asset prices and a demand recession. Moreover, asset prices and output decline substantially even though the interest rate is above the first-best level by only one percentage point-illustrating the amplification mechanism. In the low-risk-premium state, the fear of transition into the recessionary high-risk-premium state keeps the interest rate lower than in the first-best benchmark.

Second, risk-centric recessions are more severe when investors have belief disagreements (and this also compresses interest rates). The intuition follows from Proposition 2, Speculation in the low-risk-premium state decreases optimists' wealth share once the economy transitions into the high-risk-premium state, as illustrated by the second-to-top panel of Figure IV]. This translates into lower asset prices and a more severe demand recession, as illustrated by the bottom panels of Figure IV] Speculation also increases optimists' wealth share if the boom continues, but this effect does not translate into higher asset prices or output since it is (optimally) neutralized by the interest rate response. The adverse effects of speculation on demand recessions motivate the analysis of macroprudential policy, which we turn to in the next section.

Remark 7 (Interpretation of belief disagreements). As this discussion suggests, what matters for our results in this section is persistent heterogeneous valuations for risky assets that ensure: (i) during the recession, a greater wealth share for high-valuation investors increases the (relative) price of risky assets, and (ii) during the boom, high-valuation investors absorb relatively more of the recession risks. Belief disagreements generate these features naturally, under the mild assumption that optimists and pessimists do not flip roles between booms and recessions, but other sources of heterogeneous valuations would lead to similar results ${ }^{12}$ For example, with heterogeneous risk aversion, more risk tolerant agents take on more aggregate risk (i.e., they insure less risk tolerant agents), which reduces their wealth share and the (relative) price of risky assets following negative shocks to fundamentals (see, for instance, Garleanu and Pedersen (2011); Longstaff and Wang (2012)). From this perspective, belief disagreements can also capture institutional reasons for heterogeneous valuations such as capacity or mandates for handling risk. Investment banks, for example, have far more capacity to handle and lever risky positions than pensioners and money market funds.

Remark 8 (Other sources of extrapolative dynamics). In our model, asset prices are determined as-if there is a representative investor with the wealth-weighted average belief, $\bar{\lambda}_{t, s}$ [cf. Lemma 3. Our analysis in this section shows that speculation generates extrapolative dynamics for the wealth-weighted average belief. Therefore, an alternative model in which agents are homogeneous but have individually extrapolative beliefs would generate identical price dynamics (as long as the

\footnotetext{
${ }^{12}$ The no-flipping assumption is supported by recent survey evidence that shows belief heterogeneity is largely explained by persistent individual heterogeneity (Giglio et al. $(2019)$ ). The assumption is also consistent with an extensive psychology literature that documents the prevalence of optimism, as well as its heterogeneity and persistence, since it is largely a personal trait (see Carver et al. (2010) for a review).
} 
extrapolation mechanism generates identical paths for $\left.\bar{\lambda}_{t, s}\right)$. However, unlike our model, such an alternative model would feature homogeneous asset positions. Thus, it would not generate trading volume, which is a distinctive feature of speculative episodes in practice (see, e.g., Hong and Stein (2007); DeFusco et al. (2017)). More broadly, extrapolation and speculation are both likely to be at play and reinforce each other during speculative episodes.

\section{Welfare analysis and macroprudential policy}

Since our model features constrained monetary policy, most of the aggregate demand boosting policies that have been discussed in the New Keynesian literature are effective in our environment. We skip a discussion of these policies (our results still apply as long as these policies are imperfect). Instead, we focus on macroprudential policy interventions that impose restrictions on risk market participants with the objective of obtaining macroeconomic benefits. In practice, most macroprudential policies restrict risk taking by banks - especially large ones. Interpreting banks as high-valuation investors (see Remark 7) or as lenders to such investors (see Section VII), we capture these policies in reduced form by imposing portfolio risk limits on optimists.

Our model features heterogeneous beliefs, which makes the welfare analysis challenging. We mainly focus on the standard Pareto criterion in which the planner evaluates investors' expected utility according to the investors' own beliefs. This criterion ensures that our results are not driven by paternalistic concerns. Rather, the planner improves welfare by internalizing aggregate demand externalities. The standard criterion is also appropriate if we interpret belief disagreements as a modeling device that captures heterogeneous valuations due to other factors (see Remark 7 ). However, if we interpret belief disagreements literally, then a paternalistic criterion such as the belief-neutral welfare criterion developed by Brunnermeier et al. (2014) could be more appropriate. In Section VI.C, we illustrate how to use a belief-neutral criterion in our context.

We provide a decomposition of investors' value functions that simplifies the theoretical analysis. Specifically, since our model features complete markets and no frictions other than interest rate rigidities, aggregate demand externalities are the only source of inefficiency. Therefore, the first-best benchmark that corrects for these inefficiencies is Pareto efficient. Motivated by this observation, we decompose investors' value functions into two components: a first-best value function that would obtain if there were no demand recessions and a gap value function that captures the loss of value due to demand recessions. Introducing the gap value function simplifies the analysis considerably because, up to a first order, macroprudential policies affect social welfare only through their impact on investors' gap values.

Using the model with two belief types from the previous section, we first characterize investors' value functions in equilibrium according to their own beliefs. We also define the gap value functions and illustrate the aggregate demand externalities. We then consider macroprudential policy that induces optimists to act more pessimistically (by imposing appropriate portfolio risk limits). We show that this policy can lead to a Pareto improvement of social welfare. We focus on macropru- 
dential policy in the boom (low-risk-premium) state and briefly discuss macroprudential policy in the recession (high-risk-premium) state.

\section{VI.A. Equilibrium value functions}

Because the model is linear, a type $i$ investor's expected utility can be written as (see Online Appendix Section B.1.1)

$$
V_{t, s}^{i}\left(a_{t, s}^{i}\right)=\frac{\log \left(a_{t, s}^{i} / Q_{t, s}\right)}{\rho}+v_{t, s}^{i}
$$

Here, $v_{t, s}^{i}$ denotes the normalized value function per unit of capital stock. Consider the equilibrium characterized in Proposition 2. In Online Appendix Section C.1, we characterize the normalized value corresponding to this equilibrium as the solution to the differential equation system,

$$
\rho v_{t, s}^{i}-\frac{\partial v_{t, s}^{i}}{\partial t}=\log \rho+q_{t, s}+\frac{1}{\rho}\left(\begin{array}{c}
g-\frac{1}{2} \sigma_{s}^{2} \\
-\left(\lambda_{s}^{i}-\bar{\lambda}_{t, s}\right)+\lambda_{s}^{i} \log \left(\frac{\lambda_{s}^{i}}{\bar{\lambda}_{t, s}}\right)
\end{array}\right)+\lambda_{s}^{i}\left(v_{t, s^{\prime}}^{i}-v_{t, s}^{i}\right) .
$$

The equilibrium price, $q_{t, s}$, affects the investor's welfare since it determines output and consumption [cf. Eqs. 24) and (21)]. Consumption growth, $g$, and volatility, $\sigma_{s}^{2}$, also affect welfare. Finally, speculation affects the investor's (perceived) welfare. This is captured by the term $-\left(\lambda_{s}^{i}-\bar{\lambda}_{t, s}\right)+$ $\lambda_{s}^{i} \log \left(\frac{\lambda_{s}^{i}}{\bar{\lambda}_{t, s}}\right)$, which is zero with common beliefs and strictly positive with disagreements.

Gap value function. To facilitate the policy analysis, we break down the normalized value function into two components,

$$
v_{t, s}^{i}=v_{t, s}^{i, *}+w_{t, s}^{i}
$$

Here, $v_{t, s}^{i, *}$ denotes the first-best value function that would obtain if there were no interest rate rigidities. It is characterized by solving Eq. (49) with the efficient price level, $q_{t, s}=q^{*}$, for each $t, s$. The residual, $w_{t, s}^{i}=v_{t, s}^{i}-v_{t, s}^{i, *}$, denotes the gap value function, which captures the loss due to interest rate rigidities and demand recessions. The first-order impact of macroprudential policy on social welfare depends only on the gap value function. Using Eq. (49), we characterize the gap value function as the solution to the following system,

$$
\rho w_{t, s}^{i}=q_{t, s}-q^{*}+\frac{\partial w_{t, s}^{i}}{\partial t}+\lambda_{s}^{i}\left(w_{t, s^{\prime}}^{i}-w_{t, s}^{i}\right) \text {. }
$$

The gap value function corresponds to the investor's present discounted value of utility losses from output gaps relative to the efficient level. In view of the output-asset price relation 21, the function accounts for the output gaps in terms of the asset price gaps. Recall that the equilibrium features $q_{t, 1}=q^{*}$ and $q_{t, 2}<q^{*}$. Thus, the key objective of policy interventions is to increase the 
asset price in the high-risk-premium state, in order to mitigate the demand recession.

\section{VI.B. Aggregate demand externalities}

In Online Appendix Section C.1 we show that the gap value can be written as a function of optimists' wealth share, $w_{s}^{i}(\alpha)$. Combining Eqs. (51) and (44), we characterize this function as the solution to the following system in the $\alpha$-domain,

$$
\rho w_{s}^{i}(\alpha)=q_{s}(\alpha)-q^{*}-\left(\lambda_{s}^{o}-\lambda_{s}^{p}\right) \alpha(1-\alpha) \frac{\partial w_{s}^{i}(\alpha)}{\partial \alpha}+\lambda_{s}^{i}\left(w_{s^{\prime}}^{i}\left(\alpha^{\prime}\right)-w_{s}^{i}(\alpha)\right),
$$

where $\alpha^{\prime}=\alpha \frac{\lambda_{s}^{o}}{\bar{\lambda}_{s}(\alpha)}$. Recall that the price function in the high-risk-premium state, $q_{2}(\alpha)$, is increasing in optimists' wealth share [cf. Figure III]. This leads to the following result.

Lemma 4. The gap value function satisfies $\frac{d w_{s}^{i}(\alpha)}{d \alpha}>0$ for each $s, i$ and $\alpha \in(0,1)$.

Optimists' wealth share is a scarce resource that brings asset prices and output in the recession state closer to its first-best level. Thus, the gap value function in the recession state is increasing in optimists' wealth share. The gap value function in the boom state is also increasing, because the economy can always transition into the recession state, where optimists' wealth share is useful (see Lemma 5 below for a ranking of the marginal value of optimists' wealth across the two states).

This result also illustrates the aggregate demand externality. Optimists' wealth share is an endogenous variable that fluctuates due to investors' portfolio decisions [cf. Figure IV]. Individual optimists who take positions in contingent markets - and pessimists who take the other side of these positions - do not take into account the impact of their decisions on asset prices and social welfare. This leads to inefficiencies that can be corrected by macroprudential policy.

\section{VI.C. Macroprudential policy}

To evaluate the direction of the inefficiency, we consider a constrained policy exercise where the planner can induce optimists to choose allocations as if they have less optimistic beliefs ${ }^{13}$ Specifically, optimists are constrained to choose allocations as-if they have the beliefs $\lambda^{o, p l} \equiv\left(\lambda_{1}^{o, p l}, \lambda_{2}^{o, p l}\right)$, which satisfy $\lambda_{1}^{o, p l} \geq \lambda_{1}^{o}$ and $\lambda_{2}^{o, p l} \leq \lambda_{2}^{o}$. Pessimists continue to choose allocations according to their own beliefs. Throughout, we use $\lambda_{s}^{i, p l}$ to denote investors' as-if beliefs and $\lambda_{s}^{i}$ to denote their actual beliefs. For pessimists, the two beliefs coincide. We also use $\bar{\lambda}_{s}^{p l}(\alpha)=\alpha \lambda_{s}^{o, p l}+(1-\alpha) \lambda_{s}^{p}$ to denote the weighted average as-if belief.

In Online Appendix Section C.2, we show that the planner can implement this policy by imposing inequality restrictions on optimists' portfolio weights, while allowing them to make unconstrained consumption-savings decisions. To understand this implementation, note that optimists'

\footnotetext{
${ }^{13}$ For simplicity, we restrict attention to time-invariant policies. The planner commits to a policy at time zero, $\left(\lambda_{1}^{o, p l}, \lambda_{2}^{o, p l}\right)$, and implements it throughout.
} 
position on the contingent security is given by [cf. Eq. (44)]

$$
\omega_{t, s}^{s^{\prime}, o, p l}=\left(\lambda_{s}^{o, p l}-\lambda_{s}^{p}\right)\left(1-\alpha_{t, s}\right) .
$$

With their own beliefs, optimists sell the contingent security in the boom state, $\omega_{t, 1}^{2, o} \leq 0$ (since $\lambda_{1}^{o} \leq$ $\lambda_{2}^{p}$ ), and purchase it in the recession state, $\omega_{t, 2}^{1, o}>0$ (since $\lambda_{2}^{o}>\lambda_{2}^{p}$ ). Therefore, Eq. (53) implies that, in the boom state, the planner prevents optimists from selling too much of the contingent security, $\omega_{t, 1}^{2, o} \geq \underline{\omega}_{t, 1}^{2, o}$. In the recession state, the policy prevents optimists from purchasing too much of the contingent security, $\omega_{t, 2}^{1, o} \leq \bar{\omega}_{t, 2}^{1, o}$. In either state, the policy also constrains optimists' weight on the market portfolio not to exceed the market average, $\omega_{t, s}^{m, o} \leq 1$. In the absence of this constraint, optimists would speculate by increasing their exposure to the market portfolio.

The characterization of the equilibrium with macroprudential policy is the same as in Section V] In particular, Eqs. (44) and (47) still hold with the only difference that investors' beliefs are replaced by as-if beliefs, $\lambda_{s}^{i, p l}$. We denote the resulting price functions with $q_{s}^{p l}(\alpha)$ to emphasize that they are determined by as-if beliefs. The equation system that characterizes the gap value function is given by the following analogue of Eq. (52),

$$
\rho w_{s}^{i}(\alpha)=q_{s}^{p l}(\alpha)-q^{*}-\left(\lambda_{s}^{o, p l}-\lambda_{s}^{p}\right) \alpha(1-\alpha) \frac{\partial w_{s}^{i}(\alpha)}{\partial \alpha}+\lambda_{s}^{i}\left(w_{s^{\prime}}^{i}\left(\alpha^{\prime}, p l\right)-w_{s}^{i}(\alpha)\right),
$$

where $\alpha^{\prime, p l}=\alpha \frac{\lambda_{s}^{o, p l}}{\bar{\lambda}_{s}^{o, p l}(\alpha)}$. This system illustrates that the macroprudential policy can affect the gap value through two channels. First, it might affect equilibrium asset prices (captured by the term $\left.q_{s}^{p l}(\alpha)\right)$. Second, the policy affects the dynamics of optimists' wealth share, which influence the gap value. For example, in the boom state $s=1$, the policy increases $\lambda_{1}^{o, p l}$, which increases optimists' wealth share after a transition to the recession (captured by the term, $\alpha^{\prime}, p l$ ) at the expense of reducing optimists' wealth share if there is no transition (captured by the term $-\left(\lambda_{s}^{o, p l}-\lambda_{s}^{p}\right)$ ).

Planner's Pareto problem. To trace the Pareto frontier, we allow the planner to make a onetime wealth transfer among the investors at time zero. In Online Appendix Section C.2, we show that the planner's Pareto problem can be reduced to

$$
\max _{\lambda^{o, p l}} v_{0, s}^{p l}=\alpha_{0, s} v_{0, s}^{o}+\left(1-\alpha_{0, s}\right) v_{0, s}^{p}
$$

Hence, the planner maximizes a wealth-weighted average of investors' normalized values. The wealth shares (chosen by the planner via the one-time transfer) correspond to the planner's Pareto weight on optimists and pessimists. We decompose the planner's value function into first-best and gap value components, $v_{0, s}^{p l}=v_{0, s}^{p l, *}+w_{0, s}^{p l}$.

Since the first-best benchmark does not feature any frictions, it is Pareto efficient (due to the First Welfare Theorem). This in turn implies that the marginal impact of the policy on the planner's first-best value function is zero, $\left.\frac{\partial v_{0, s}^{p l, *}}{\partial \lambda^{o, p l}}\right|_{\lambda^{o, p l}=\lambda^{o}}=0$. Consequently, the first order impact 
of the policy is characterized by its impact on the planner's gap value function,

$$
w_{0, s}^{p l}=\alpha_{0, s} w_{0, s}^{o}+\left(1-\alpha_{0, s}\right) w_{0, s}^{p} .
$$

Macroprudential policy in the boom state. Now suppose the economy is in the boom state $s=1$. The planner can use macroprudential policy in the current state, $\lambda_{1}^{o, p l} \geq \lambda_{1}^{o}$ (she can induce optimists to act as if transition into the recession is more likely), but not in the other state $\lambda_{2}^{o, p l}=\lambda_{2}^{o}$ (she cannot influence optimists' actions in the recession state). Effectively, this policy induces optimists to sell less of the contingent security that pays in case there is a transition to the recession, while also preventing optimists from increasing their position in the market portfolio. We next present our main result in this section that shows this policy improves welfare. The result requires a technical assumption (no disagreement in state $s=1$ ) that we discuss subsequently.

Proposition 3. Consider the equilibrium with two belief types characterized in Proposition 2 . Suppose agents' beliefs satisfy $\lambda_{1}^{o}=\lambda_{1}^{p}$ and consider the macroprudential policy in the boom state, $\lambda_{1}^{o, p l} \geq \lambda_{1}^{o}$ (and suppose $\lambda_{2}^{o, p l}=\lambda_{2}^{o}$ ). The policy increases the gap value according to each belief,

$$
\left.\frac{\partial w_{1}^{i}(\alpha)}{\partial \lambda_{1}^{o, p l}}\right|_{\lambda_{1}^{o, p l}=\lambda_{1}^{o}}>0 \text { for each } i \in\{o, p\} \text { and } \alpha \in(0,1) \text {. }
$$

The policy also increases the planner's value, $\left.\frac{\partial v_{1}^{p l}(\alpha)}{\partial \lambda_{1}^{o, p l}}\right|_{\lambda_{1}^{o}}=\left.\frac{\partial w_{1}^{p l}(\alpha)}{\partial \lambda_{1}^{o, p l}}\right|_{\lambda_{1}^{o}}>0$. In particular, regardless of the planner's Pareto weight, there exists a Pareto improving macroprudential policy.

We next present a heuristic derivation of this result, which facilitates the intuition. For small changes, macroprudential policy in the boom state does not affect current asset prices, which remain equal to the efficient level, $q_{1}^{p l}(\alpha)=q^{*}$ (since the interest rate in the boom state is not constrained). Hence, the policy affects the gap value only through its impact on optimists' wealth dynamics and the associated aggregate demand externalities. Differentiating Eq. (54), for $s=1$, with respect to optimists' as-if beliefs and evaluating at the no-policy benchmark, $\lambda_{1}^{o, p l}=\lambda_{1}^{o}$, we obtain

$$
\left(\rho+\lambda_{1}^{i}\right) \frac{\partial w_{1}^{i}(\alpha)}{\partial \lambda_{1}^{o, p l}}=\alpha(1-\alpha)\left[\frac{\partial w_{2}^{i}\left(\alpha^{\prime}\right)}{\partial \alpha}-\frac{\partial w_{1}^{i}(\alpha)}{\partial \alpha}\right]+\lambda_{1}^{i} \frac{\partial w_{2}^{i}\left(\alpha^{\prime}\right)}{\partial \lambda_{1}^{o, p l}} .
$$

Here, $\alpha^{\prime}=\alpha \frac{\lambda_{1}^{o}}{\bar{\lambda}_{1}(\alpha)}=\alpha$ given the assumption $\lambda_{1}^{o}=\lambda_{1}^{p}$.

The two terms inside the brackets capture the direct impact of the policy on welfare through aggregate demand externalities. The first term illustrates that the policy generates positive aggregate demand externalities - because it increases optimists' wealth share if there is a transition into the recession state. On the other hand, the second term illustrates that the policy also generates negative aggregate demand externalities - because it reduces optimists' wealth share if there is no transition. In a dynamic setting, macroprudential policy in the boom state is associated with some costs as well as benefits. The costs emerge because the policy prevents optimists from accumulating 
wealth that could be useful in a future recession. However, intuition suggests the benefits should outweigh the costs as long as future recessions are not too different from an imminent recession. The following lemma verifies this under the assumption $\lambda_{1}^{o}=\lambda_{1}^{p}$.

Lemma 5. When $\lambda_{1}^{o}=\lambda_{1}^{p}$, the gap value function satisfies $\frac{d w_{2}^{i}\left(\alpha^{\prime}\right)}{d \alpha}>\frac{d w_{1}^{i}(\alpha)}{d \alpha}$ for each $i$ and $\alpha \in(0,1)$.

As expected, optimists are more useful if there is an immediate transition to the recession state, in which case their benefits materialize immediately. Any delay in this transition reduces the benefits by postponing them. Combining this lemma with Eq. (57) provides a heuristic derivation of Proposition 3 (see Online Appendix Section C.2 for the proof).

What happens when we relax the assumption $\lambda_{1}^{o}=\lambda_{1}^{p}$ ? This is largely a technical assumption. Our numerical simulations (e.g., Figure V) suggest that a version of Proposition 3 also holds when $\lambda_{1}^{o}<\lambda_{1}^{p}$ under appropriate technical assumptions, but we are unable to provide a proof

Figure $\mathrm{V}$ illustrates the result for our earlier parameterization, which features $\lambda_{1}^{o}<\lambda_{1}^{p}$. We fix the optimists' wealth share $\left(\alpha=\frac{1}{2}\right)$ and calculate the effect of macroprudential policy on the planner's value function and on its components. The policy reduces the planner's first-best value function, since it distorts investors' allocations according to their own beliefs. However, for small policy changes, this decline is small (due to the First Welfare Theorem). The policy also increases the planner's gap value function. This increase is large enough that the policy increases the actual value function and generates a Pareto improvement. As the policy becomes larger, the gap value continues to increase whereas the first-best value decreases. Moreover, the decline in the first-best value is negligible for small policy changes but it becomes sizeable for large policy changes. Thus, the constrained-optimal macroprudential policy obtains at an intermediate level.

Macroprudential policy according to a belief-neutral gap-value criterion. When we interpret belief disagreements literally (see Remark 7), it is questionable whether the utility from speculation should count toward social welfare. A recent literature argues that the Pareto criterion is not the appropriate notion of welfare for environments with belief disagreements. If investors' beliefs are different due to mistakes (e.g., in Bayesian updating), then it is arguably more appropriate to evaluate their utility according to a belief that is common across investors. This approach removes the speculative utility from welfare calculations, and it motivates larger policy interventions. In this case, macroprudential policy not only improves macroeconomic outcomes but it also

\footnotetext{
${ }^{14}$ There are two distinct challenges. First, we cannot generalize Lemma 5 although the ranking is intuitive and should hold unless there are strong nonlinearities in the gap value function. Specifically, the proof of Lemma 5 establishes

$$
\frac{\partial w_{1}^{i}\left(b_{0,1}\right)}{\partial b}=\frac{\lambda_{1}^{i}}{\lambda_{1}^{i}+\rho} \int_{0}^{\infty} e^{-\left(\rho+\lambda_{1}^{i}\right) t}\left(\rho+\lambda_{1}^{i}\right) \frac{\partial w_{2}^{i}\left(b_{t, 2}\right)}{\partial b} d t
$$

where $b_{0,1}$ denotes a transformed version of $\alpha$ at the initial state, and $b_{t, 2}$ denotes the same variable after a transition into the recession state after a period of length $t$. When $\lambda_{1}^{o}=\lambda_{1}^{p}$, we also have $b_{t, 2}=b_{0,1}$ (since there is no speculation in the boom state), which yields $\frac{\partial w_{1}^{i}\left(b_{0,1}\right)}{\partial b}=\frac{\lambda_{1}^{i}}{\lambda_{1}^{i}+\rho} \frac{\partial w_{2}^{i}\left(b_{0,1}\right)}{\partial b}<\frac{\partial w_{2}^{i}\left(b_{0,1}\right)}{\partial b}$. When $\lambda_{1}^{o}<\lambda_{1}^{p}$, the same result holds and the ranking is unchanged if the value function is linear in the transformed variable $b$. Hence, the ranking can fail only if there are sufficiently large nonlinearities in the gap value function.

Second, in the more general case pessimists and optimists disagree about the benefits of macroprudential policy. The planner takes a weighted average of these perceptions, which complicates the analysis.
} 


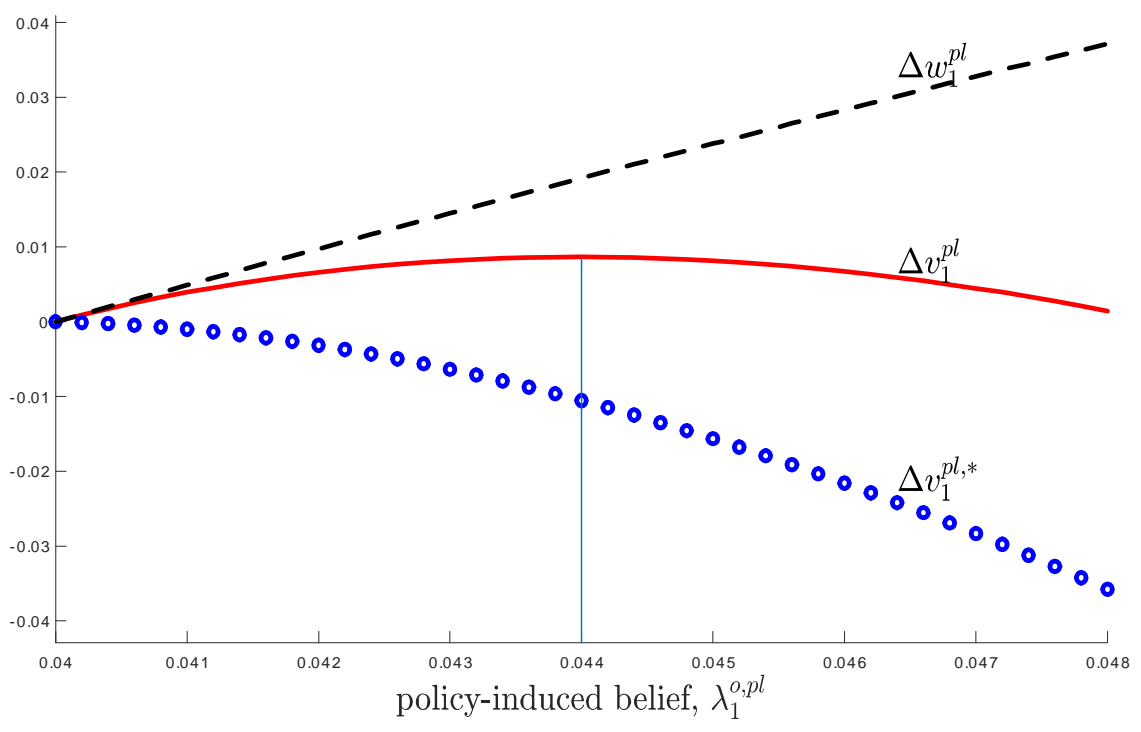

Figure V: Welfare effect of macroprudential policy in the boom state according to the Pareto criterion. The solid red line illustrates the change in the planner's total value. The dashed black line (resp. the dotted blue line) illustrates the change in the planner's gap value (resp. the first-best value).

mitigates the microeconomic costs associated with speculation (see, e.g., Simsek (2013b); Dávila (2017); Heimer and Simsek (2019)).

In our context, when investors have belief disagreements it might be natural for a planner to focus exclusively on increasing investors' gap value, $w_{s}^{i}(\alpha)$, as opposed to their total value, $v_{s}^{i}(\alpha)$. This sidesteps difficult questions about whether speculation increases or reduces welfare. It also accords well with the goals of macroprudential policy in practice: the planner exclusively focuses on minimizing output gaps relative to a frictionless benchmark. While reasonable, this approach still faces a major challenge: given that the planner thinks investors' beliefs might be wrong, what belief should she use to evaluate the gap value?

In recent work, Brunnermeier et al. (2014) offer a belief-neutral welfare criterion that circumvents this problem. The basic idea is to require the planner to evaluate welfare according to a single belief, but also to make the welfare comparisons robust to the choice of the single belief. Specifically, their baseline criterion says that an allocation is belief-neutral superior to another allocation if it increases welfare under every belief in the convex hull of investors' beliefs. Proposition 3 suggests their criterion can be useful in this context since macroprudential policy increases the gap value according to each belief.

For a numerical illustration, fix some $h \in[0,1]$ and let $w_{s}^{h}\left(\alpha ; \lambda_{1}^{o, p l}\right)$ denote the value function for an investor when the planner implements policy $\lambda_{1}^{o, p l}$ and evaluates utility under the beliefs $\lambda_{s}^{h}=$ $\lambda_{s}^{p}+h\left(\lambda_{s}^{o}-\lambda_{s}^{p}\right)$ for each $s \sqrt{15}$ Figure VI illustrates the effect of macroprudential policy on the gap value according to the optimists' belief (solid line) and the pessimists' belief (dotted line). As the figure suggests, tightening the policy toward $\lambda_{1}^{o, p l}=0.104$ generates a belief-neutral improvement in

\footnotetext{
${ }^{15}$ This value function solves the differential equation system (54) after replacing the actual belief, $\lambda_{s}^{i}$, with the belief $\lambda_{s}^{h}$.
} 


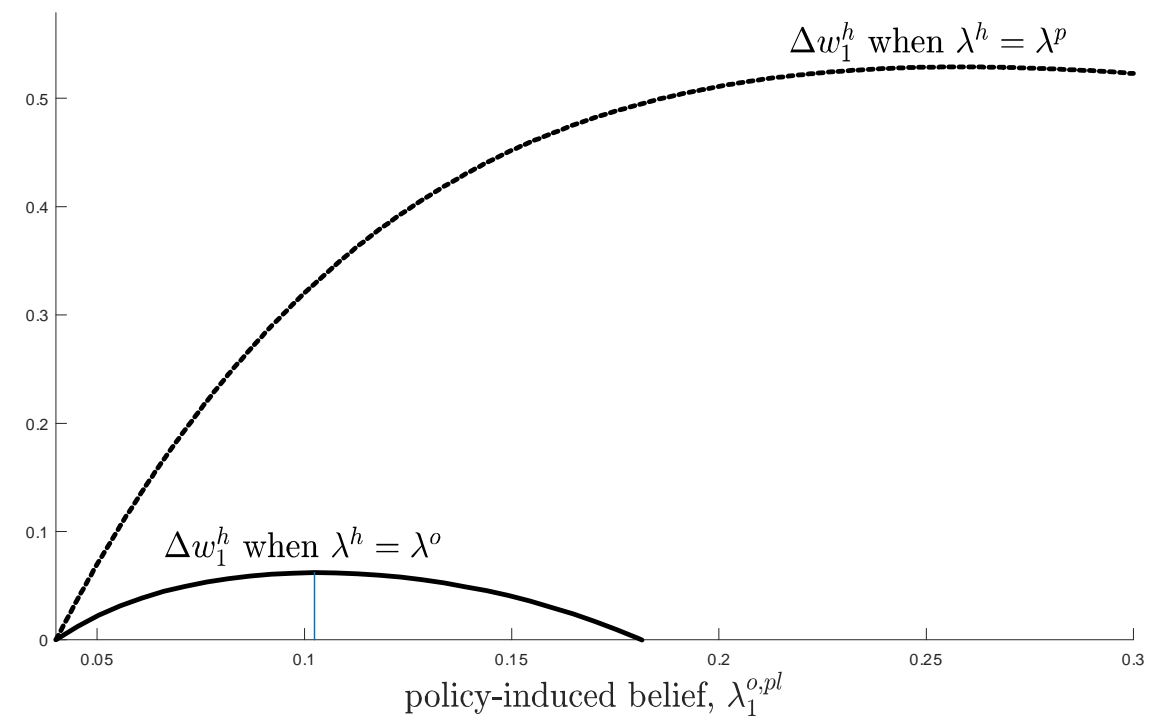

Figure VI: Welfare effect of macroprudential policy in the boom state according the beliefneutral gap value criterion. The solid line (resp. the dotted line) illustrates the change in the gap value evaluated under the optimists' belief (resp. the pessimists' belief).

gap value. Beyond this level, tightening the policy improves the gap value according to pessimists but not according to optimists - who perceive smaller benefits from macroprudential policy since they find the transition into the recession state unlikely. In this example, the belief-neutral optimal policy represents a substantial intervention: it induces optimists to act as if $\lambda_{1}^{o, p l}=0.104$ (roughly a $10 \%$ chance of transition to recession in a year) whereas optimists' own belief is $\lambda_{1}^{o}=0.04$ (roughly a $4 \%$ chance of transition) and pessimists' belief is $\lambda_{1}^{p}=0.2$ (roughly a $20 \%$ chance of transition). Note that the belief-neutral gap-value criterion supports a much larger policy intervention than the Pareto criterion (cf. Figure V).

Dynamics of equilibrium with macroprudential policy. We next consider how macroprudential policy in the boom state affects the dynamics of equilibrium variables. Figure VII illustrates the evolution of equilibrium over a 40-year horizon when the planner implements the belief-neutral optimal policy, $\lambda_{1}^{o, p l}=0.104$. For comparison, the figure also replicates the evolution of the equilibrium variables without macroprudential policy from Figure IV. Macroprudential policy in the boom state ensures optimists' wealth share drops less when there is a transition into the recession state. This leads to higher asset prices and output when the economy transitions to the recession. However, the policy is not without its drawbacks. As the periods before year 10 illustrate, macroprudential policy in the boom state slows down the growth of optimists' wealth share when the economy remains in the boom state.

Macroprudential policy in the recession state. Our analysis so far concerns macroprudential policy in the boom state and maintains the assumption that $\lambda_{2}^{o, p l}=\lambda_{2}^{o}$. In Online Appendix Section C.2, we analyze the opposite case when the economy is currently in the recession state $s=2$ and 

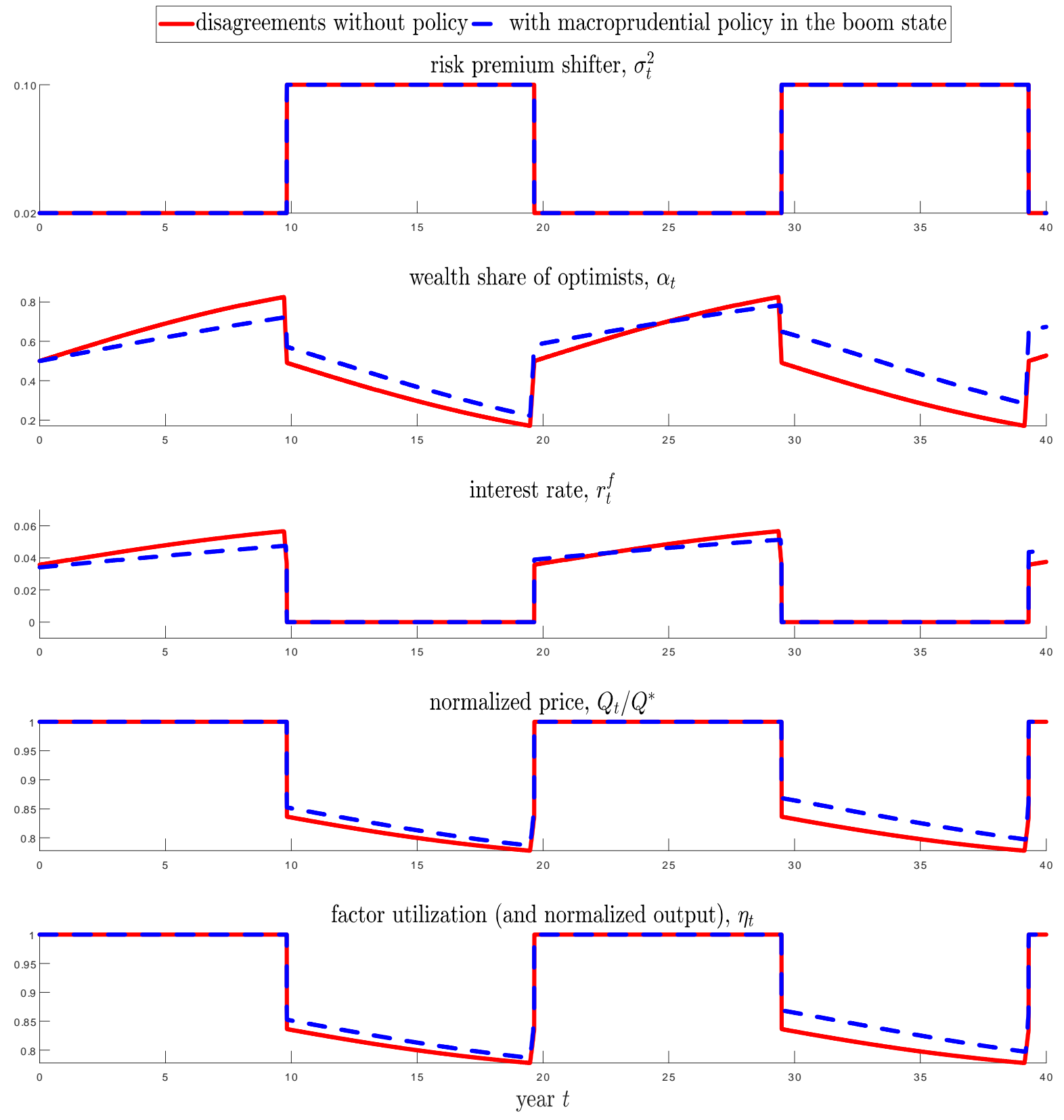

Figure VII: A simulation of the equilibrium variables over time with macroprudential policy. The dashed blue line (resp. the solid red line) illustrates the equilibrium with disagreements and with macroprudential policy (resp. without macroprudential policy). 
the planner can apply macroprudential policy in this state, $\lambda_{2}^{o, p l} \leq \lambda_{2}^{o}$ (she can induce optimists to act as if the recovery is less likely), but not in the other state, $\lambda_{1}^{o, p l}=\lambda_{1}^{o}$. Proposition 4 in the appendix shows that, in contrast to Proposition 3, this policy can reduce social welfare. Consider the two counteracting forces. As before, macroprudential policy increases the gap value by increasing optimists' wealth share if the economy stays in the recession state. However, unlike before, macroprudential policy also reduces current asset prices because the price is below the efficient level, $q_{2}^{p l}(\alpha)<q^{*}$, and it is increasing in optimists' as-if optimism, $\lambda_{2}^{o, p l}$ (see Eq. (39)). This channel reduces the gap value (see Eq. (54)). When optimists' wealth share is large $(\alpha \rightarrow 1)$, the latter channel dominates and macroprudential policy reduces the gap value and social welfare. Even when the current asset price channel does not dominate, macroprudential policy in the recession state is less useful than in the boom state. We verify this intuition in numerical simulations.

It is important to emphasize that macroprudential policy in the boom state does not lower asset prices due to the monetary policy response. Specifically, recall that the policy increases optimists' as-if pessimism in the boom state, $\lambda_{1}^{o, p l}$. While this does not affect the asset price in the boom state, $q_{1}^{p l}(\alpha)=q^{*}$, it reduces the interest rate for a given level of optimists' wealth share, $r_{1}^{f}(\alpha)$ (see Eq. 40 ). As macroprudential policy reduces the demand for risky assets, monetary policy lowers the interest rate to dampen its effect on asset prices and aggregate demand.

Our analysis in this section provides support for procyclical macroprudential policy. In states where output is not demand constrained (in our model, the boom state $s=1$ ), macroprudential policy that restricts high-valuation investors' risk taking is desirable. This policy improves welfare by ensuring that high-valuation investors bring more wealth to the demand-constrained states, which increases asset prices and output. In states where output is demand constrained (in our model, the recession state $s=2$ ), macroprudential policy is less useful because it has an immediate negative impact on asset prices and aggregate demand.

\section{Empirical evidence}

Our empirical analysis focuses on three predictions. First, our model predicts that risk premium shocks generate an interest rate reduction when the interest rate is not constrained, and a more severe demand recession when the interest rate is constrained. Second, the recession reduces firms' earnings and leads to a further reduction in asset prices. Third, the recession is more severe when the shock takes place in an environment with more speculation. To investigate these predictions, we compare the response to house price shocks in Eurozone countries (which have constrained interest rates with respect to national shocks) to the response in non-Eurozone developed countries (which have less constrained interest rates). At the end of the section, we discuss empirical evidence from the recent literature which suggests that similar results apply for price shocks to other asset classes, such as stocks, and for other interest rate constraints, such as the zero lower bound.

While our model relies on the zero lower bound constraint, the mechanisms are more general, and we find it more convenient to work with the currency-union constraint in our empirical analysis. 
The zero lower bound has only recently become a practical constraint, limiting data availability, and it calls for an asymmetric specification that requires separate responses to positive and negative price shocks (since the monetary policy can raise the interest rate in response to positive shocks). In contrast, individual Eurozone countries have had constrained interest rates (with respect to national shocks) for much longer, and the constraint has been symmetric.

A major challenge in this exercise is identifying the risk premium shock that drives asset prices. As we clarify in Section II the exact source of the shock is not important for our mechanisms (e.g., risk, risk aversion, and beliefs have similar effects). Therefore, our strategy is to control for factors that do not act as a risk premium shock according to our model. In particular, we control for supply shocks and demand shocks that are not specific to house prices-including monetary policy shocks - and we interpret the residual change in house prices as a plausibly exogenous risk premium shock. Specifically, our risk premium shock is a surprise change in house prices in a country after controlling for contemporaneous and recent changes in output and the policy interest rate 16

Our model has a single type of capital, which can be interpreted as a value-weighted average of housing, stocks, and other assets in positive net supply. We focus on house prices for two reasons. First, housing wealth is large and its size (relative to output) is comparable between Eurozone and non-Eurozone developed countries (see Table F.3 in Online Appendix Section F). In contrast, stock markets in Eurozone countries are typically much smaller than in non-Eurozone developed countries, which makes stocks less suitable for our empirical strategy (see Table F.4 in the online appendix). Second, house prices are less volatile and seem to react to monetary policy shocks with some delay (see Figure F.6 in the online appendix). This feature enables us to control for monetary policy shocks by including contemporaneous and past realization of policy interest rates. We also interpret the future changes in interest rates as the monetary policy response to the risk premium shock, which enables us to test a key prediction of our model. This strategy works less well for stocks, because stock prices react to monetary policy shocks quickly, which might create a correlation between stock prices and interest rates with the opposite sign (since stock price declines driven by monetary policy shocks are typically followed by interest rate hikes - the opposite of risk premium shocks) 17

Data sources. We assemble a quarterly cross-country panel data set of financial and economic variables for advanced economies. We obtain data on house price indices from the quarterly dataset

\footnotetext{
${ }^{16}$ While our controls are imperfect, we also report the differential effects of these shocks in Eurozone countries compared to their effects outside the Eurozone, which provides additional robustness. For example, our model illustrates that permanent supply shocks (e.g., an increase in $A$ ) shift asset prices and output regardless of whether the interest rate is constrained (see Sections III and IV]. This suggests that common omitted supply shocks would lead to a similar bias inside and outside the Eurozone, and this bias is mitigated by focusing on the differential responses.

${ }^{17}$ Formally, we assume house prices react to monetary policy shocks with a delay of at least one quarter. Figure F.6 in the appendix plots impulse responses to shocks to the policy interest rate and provides support for this assumption. Specifically, a surprise increase in the policy interest rate is followed by a decline in house prices, but the response starts after the first quarter and takes several quarters to complete. The same figure shows that the assumption is clearly violated for stock prices. A surprise increase in the policy interest rate also reduces stock prices, but all of the response takes place in the same quarter as the shock.
} 
described in Mack et al. (2011). We obtain data on macroeconomic activity such as GDP, investment, and consumption from the OECD. We also obtain financial market data such as the policy interest rate, stock price indices, and earnings (of publicly traded firms) from Global Financial Data (GFD) and the Bank for International Settlements (BIS). Online Appendix Section F describes the data sources and variable construction.

Sample selection. Our sample covers 20 advanced economies from the first quarter of 1990 until the last quarter of 2017. Our selection of countries is driven by the availability of consistent house price data. We start the sample in 1990 because monetary policy in most advanced economies had shifted from focusing on stabilizing inflation to stabilizing output by this time, as in our model. Our results are robust to alternative sample selections ${ }^{18}$

To capture interest rate constraints, we divide the data into two categories. The first category, which we refer to as the Euro/ERM sample, consists of country-quarters in which the country was a member of the Euro area or the European Exchange Rate Mechanism (ERM) for most of the calendar year. The ERM system, which preceded the Euro, required member countries to keep their exchange rates within a narrow band of a central currency. This system constrained countries' relative policy interest rates (albeit imperfectly) and most member countries eventually adopted the Euro. The countries in the Euro area share the same policy interest rate (determined by the European Central Bank). The second category, which we refer to as the non-Euro/ERM sample, consists of the remaining country-quarters. Table F.1 in the online appendix describes the Euro/ERM status by country and year.

Empirical specification. To describe how the economy behaves after house price shocks, we follow the local projection method developed by Jordà (2005). In particular, we regress several outcome variables at various horizons after time $t$ on (residual) house price changes at time $t$. Specifically, we estimate equations of the type

$$
Y_{j, t+h}^{h}-Y_{j, t-1}^{h}=\alpha_{j}^{h}+\gamma_{t}^{h}+\beta^{p, h}\left(-\Delta \log P_{j, t}\right)+\beta^{c, h} \operatorname{controls}_{j, t}+\varepsilon_{j, t}^{h},
$$

where $j$ denotes the country, $t$ denotes the quarter, $h$ denotes the horizon, $Y$ denotes an outcome variable, $P$ denotes the (real) house price index, and $\Delta \log P_{j, t}=\log P_{j, t}-\log P_{j, t-1}$ denotes its quarterly log change. We include time and country fixed effects, so our "house price shock" is a decline in house prices in a quarter, after accounting for the average price decline in the sample countries and various other controls within the country. Our control variables include the contemporaneous value and 12 lags of the first difference of log GDP - to control for supply shocks and demand shocks that are not specific to house prices. Likewise, we include the contemporaneous value and 12 lags of the policy interest rate - to control for monetary policy shocks. We also include 12 lags of the first difference of log house prices - to capture the momentum in house prices - and

\footnotetext{
${ }^{18}$ Figures F.4 and F.5 in the online appendix show that starting the sample in 1980 leaves our results (except for the effect on inflation) qualitatively unchanged.
} 
12 lags of the first difference of the outcome variable - to control for other dynamics that might influence the outcomes. We weight each regression by countries' relative GDP, and estimate (58) for horizons 0 to 12 .

To evaluate the responses within and outside the Eurozone, we include indicator variables for Euro/ERM and non-Euro/ERM status, and we interact all right-hand-side variables (including the fixed effects) with these indicators. We let $\beta_{\text {euro }}^{p, h}$ and $\beta_{\text {non }}^{p, h}$ denote the coefficient on the interaction of the price shock with the corresponding indicator. Our specification is equivalent to running the regressions separately within the Euro/ERM and non-Euro/ERM samples 19 We report the sequence of coefficients, $\left\{\beta_{\text {euro }}^{p, h}\right\}_{h=0}^{12}$ and $\left\{\beta_{\text {non }}^{p, h}\right\}_{h=0}^{12}$, which provide an estimate of the impulse response functions for the respective samples. We also report $95 \%$ confidence intervals calculated according to Newey and West (1987) standard errors with a bandwidth of 20 quarters.

We look at outcome variables for which our model makes a clear prediction, such as the policy interest rate, the unemployment rate (a proxy for factor underutilization), and the logs of GDP, investment, and consumption. We also include the log (core) CPI. Even though it is constant in our model (by assumption), variants of our model predict that it should decline in a demand recession. We analyze public firms' earnings and log stock prices to investigate spillover and amplification effects, as well as log house prices to investigate the price dynamics following the initial shock. All relevant variables except for the policy interest rate are adjusted for inflation to focus on real effects, as in our model. For earnings, we use the ratio of earnings to the initial stock price level as our dependent variable (which generates meaningful units) 20

Table F.2 in the online appendix describes the summary statistics by Euro/ERM status for the variables that enter our regression analysis. The Euro/ERM sample has 760 country-quarters and the non-Euro/ERM sample has 1130 country-quarters ${ }^{21}$ Both samples are unbalanced because a few countries have imperfect data coverage in earlier years (and because a few countries transition between samples). The two samples are comparable except that the non-Euro/ERM sample experienced slightly faster growth over the sample period.

House price shocks and demand recessions. Figure VIII plots the estimated sequences of coefficients by Euro/ERM status (see Figure F.1 in the online appendix for the differenced coefficients). The panels in the top two rows illustrate our main empirical findings. The top left panel shows that, in the non-Euro/ERM sample (dashed blue line), a decline in house prices is followed

\footnotetext{
${ }^{19}$ The point estimates from our regression are identical to those obtained from running separate regressions within each sample. However, because our standard errors account for autocorrelation of the residuals, the joint regression will have slightly different standard errors (for example, the joint regression will account for the fact that residuals are correlated from before and after a country joined the ERM). The joint regression is preferable because it uses more data and thus gives more precise standard errors.

${ }^{20}$ Earnings sometimes take a negative value, which makes a log transformation problematic. Instead, we change the specification in (58) slightly so that the dependent variable is $\frac{\text { earnings }_{t+h}-\text { earnings }_{t-1}}{\text { stock } \text {. Lice } t-1}$. Likewise, we adjust the control variables that feature earnings by dividing them by the stock price at quarter $t-1$.

${ }^{21}$ These are the sample sizes for our baseline regression in which the outcome variable is the policy interest rate and the horizon is 0 (see $(58)$ ). For some regressions, the sample size is slightly smaller, because we estimate outcomes at future horizons (which removes some data from the end of the sample period) and because some variables do not have complete coverage.
} 
by a sizeable and persistent decline in the policy interest rate. By contrast, in the Euro/ERM sample (solid red line), a decline in house prices does not lead to an additional decline in the country's interest rate relative to other Euro/ERM countries, illustrating the interest rate constraint. ${ }^{22}$ The remaining panels in the top two rows illustrate that the shock is followed by a more severe demand recession in a Euro/ERM country than in a non-Euro/ERM country. In fact, the panels on GDP, investment, and consumption suggest that the shock initially leads to similar effects in both samples but is followed by milder outcomes in the non-Euro/ERM sample.

These results are consistent with our prediction that risk premium shocks lead to a more severe demand recession when the interest rate is constrained. From the lens of our model, the interest rate policy mitigates a demand recession driven by a local risk premium shock outside the Eurozone but not within the Eurozone 23

Spillover effects and amplification. The panels at the bottom row of Figure VIII illustrate the effect of the house price shock on asset markets. The panels on earnings and stock prices establish that there are spillover effects on the stock market: specifically, earnings and stock prices decline more in the Euro/ERM sample than in the other sample (although the estimates are imprecise due to the high volatility of earnings and prices). The remaining panel illustrates that, after the initial shock, house prices decline more persistently and by a larger amount in the Euro/ERM sample.

These results are consistent with our prediction that the demand recession reduces firms' earnings and leads to a further decline in asset prices. From the lens of the model, stock prices (resp. house prices) decline less in the non-Euro/ERM sample due to the interest rate response, which not only increases the price to earnings ratio (resp. price to rent ratio) but also mitigates the recession and supports earnings (resp. rents).24

Speculation and further amplification. We need a proxy for speculation to test the final prediction of our model. We choose a measure of bank credit, which is a major catalyst of specula-

\footnotetext{
${ }^{22}$ For the Euro era, the Euro/ERM-wide policy interest rate response is common to all countries and is captured by our time-fixed effects. During the ERM era, there were severe cross-country monetary policy constraints. Figure F.3 in the online appendix illustrates the results from the same regression without time-fixed effects. The figure shows that a negative house price shock in the Euro/ERM sample leads to a decline in the Euro/ERM-wide policy interest rate, but the magnitude of this decline is smaller than in the other sample. This is because house price shocks have a national (or idiosyncratic) component, and the Euro/ERM-wide policy interest rate arguably responds only to the Euro/ERM-wide (or systematic) component of these shocks.

${ }^{23}$ In our model, risk premium shocks generate a less severe recession in unconstrained countries because the interest rate policy response leads to a smaller decline in asset prices. This suggests that asset price changes might provide an inaccurate measure of the underlying shock. We believe our analysis is robust to this concern for three reasons. First, to the extent that this concern is relevant, it biases the empirical analysis against finding support for our mechanisms because it implies that an equivalent magnitude of asset price decline corresponds to a larger underlying shock if the country has an unconstrained interest rate. Second, the concern is less relevant in practice than in our model because the interest rate policy affects all assets, which implies that risk-driven price declines in one asset class (such as housing) are partially absorbed by price increases in other asset classes. Third, the concern is less relevant for house prices because they seem to react to interest rate changes with some delay (see Figure F.6 in the online appendix). In fact, the panel of Figure VIII on house prices suggests that the interest rate response only partially stabilizes risk-driven house price changes, and only with some delay.

${ }^{24}$ We cannot test the predictions on rents because we do not have reliable data.
} 

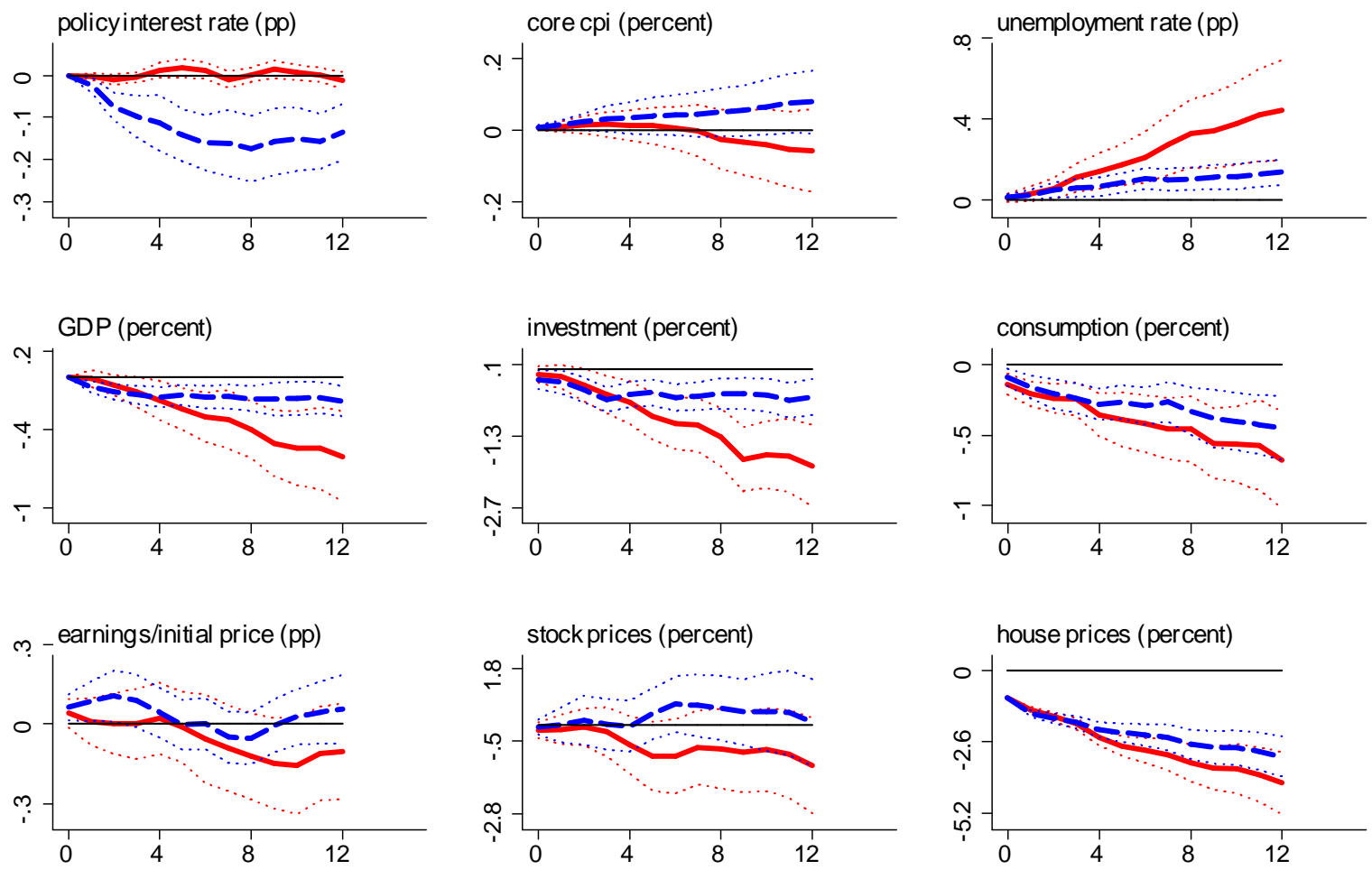

Euro/ERM

Non-Euro/ERM

Figure VIII: Impulse responses to one percent decrease in real house prices. The panels illustrate the results from the regression specification in (58) with the addition of the indicator variables for Euro/ERM and non-Euro/ERM status as well as the interaction of all right-hand-side variables with these indicators. The solid red (resp. dashed blue) lines plot the coefficients corresponding to the the negative log house price variable when the Euro/ERM status is equal to 1 (resp. 0). For the units, "percent" corresponds to $0.01 \log$ units (i.e., it is approximate) and "pp" corresponds to percentage points. All regressions include time and country fixed effects; contemporaneous value and 12 lags of the first difference of log GDP; contemporaneous value and 12 lags of the policy interest rate; 12 lags of the first difference of log house prices; 12 lags of the first difference of the outcome variable. The dotted lines show $95 \%$ confidence intervals calculated according to Newey-West standard errors with a bandwidth of 20 quarters. All regressions are weighted by countries' PPP-adjusted GDP in 1990. Data is an unbalanced quarterly panel that spans 1990Q1-2017Q4. All variables except for those in the top panel are adjusted for inflation. Earnings are normalized by the stock price in the quarter before the shock (see Footnote 20). We describe our sources and variable definitions in Online Appendix Section F. 
tion in housing markets. First, banks can be thought of as high-valuation investors ("optimists") because they have a greater capacity to handle risk than non-institutional investors, and they have real estate exposures through mortgage loans. Under this interpretation, bank credit provides a measure of banks' exposure to the housing market. Second, banks lend to other high-valuation investors in the housing markets, such as optimistic homebuyers that use bank credit to purchase larger homes or second homes. When bank credit is easily available, perhaps because of banks' optimism about house prices, these high-valuation investors wield a greater influence in the housing market (see Simsek (2013a) for a formalization). Thus, bank credit provides a broad proxy for speculation in the housing market.

Our specific measure of bank credit comes from Baron and Xiong (2017), who construct a variable, "credit expansion", defined as the change in the bank credit-to-GDP ratio in the last three years. They standardize this variable by its mean and standard deviation within each country so that the measure is high when bank credit expansion in a country has been high in recent years relative to its historical trends. They show that their standardized measure predicts the likelihood of a large decline in bank equity prices, and despite the elevated risk it also predicts lower average returns on bank equity. Their preferred interpretation is that bank equity investors are excessively optimistic or neglect crash risk, which in our framework would translate into greater speculation (by banks or their borrowers).

We use BIS data on bank credit to households and nonfinancial firms to construct a close analogue of Baron and Xiong's standardized credit expansion variable (see Online Appendix Section $\mathrm{F}$ for details). We then run the same regressions as in (58), but we include the interaction of the price shock with standardized credit expansion. That is, we estimate

$Y_{j, t+h}^{h}-Y_{j, t-1}^{h}=\alpha_{j}^{h}+\gamma_{t}^{h}+\left[\begin{array}{c}\beta^{p, h}\left(-\Delta \log P_{j, t}\right) \\ +\beta^{p c, h}\left(-\Delta \log P_{j, t}\right) \times \text { credit expansion-std }\end{array}\right]+\beta^{c, h} \operatorname{controls}_{j, t}+\varepsilon_{j, t}$.

In addition to the earlier controls, we include 12 lags of standardized credit expansion to capture its direct impact. As before, we interact all right-hand-side variables with the Euro/ERM and the nonEuro/ERM status indicators. We let $\beta_{\text {euro }}^{p c, h}$ and $\beta_{\text {non }}^{p c, h}$ denote the coefficient on the interaction of the shock and credit with these indicators. The sequence of coefficients, $\left\{\beta_{\text {euro }}^{p c, h}\right\}_{h=0}^{12}$ and $\left\{\beta_{n o n}^{p c, h}\right\}_{h=0}^{12}$, provide an estimate of the additional effect of the shock when credit expansion has been one standard deviation above average (relative to its baseline effect with average credit).

Figure IX plots these sequences and illustrates our findings (see Figure F.2 in the online appendix for the differenced coefficients). The panels in the first two rows show that, in the Euro/ERM sample, house price shocks lead to a greater decline in economic activity when credit expansion has been high in recent years. In contrast, credit expansion does not change the effect of the house price shock in the non-Euro/ERM sample. These results support our prediction that risk premium shocks lead to a more severe demand recession (in constrained economies) when they take place in an environment with elevated speculation. 
On the other hand, the bottom row of Figure IX presents inconclusive results that neither support nor refute our predictions. We do not find meaningful differences for the additional effect of house price shocks on earnings or house prices when credit expansion has been high (in either sample). We do find a negative effect on stock prices for the Euro/ERM sample, but the effect is not statistically significantly different from the other sample. That said, since standard errors are large, we cannot rule out sizeable effects either. While we tentatively conclude that speculation proxied by credit expansion is associated with deeper risk-centric demand recessions, further empirical research should verify the robustness of this conclusion and the precise channels through which speculation affects the recession.

Other supporting evidence. Our empirical analysis is related to Mian and Sufi (2014, 2018), who use regional data within the U.S. to provide evidence for the central role played by the house price cycle and housing speculation in the Great Recession.

Mian and Sufi (2014) argue that house price declines explain much of the job losses between 2007 and 2009. Our results for the Euro/ERM sample suggest that similar results hold in crosscountry data, while the non-Euro/ERM sample suggests that monetary policy can mitigate the adverse effects of house price shocks. Moreover, while Mian and Sufi (2014) emphasize household deleveraging as the key channel by which house price declines cause damage, some of our empirical results (e.g., the investment response) suggest there are other mechanisms as well. As our model demonstrates, house price declines could lower aggregate demand even without household deleveraging or other financial frictions - although these additional ingredients would amplify the effects.

Mian and Sufi (2018) argue that housing speculation amplified the house price cycle and led to a more severe downturn. As in our empirical exercise, they emphasize bank credit expansion as a major catalyst of speculation. They find that the U.S. areas more exposed to credit expansion in the early 2000s featured greater speculative trading activity (measured from detailed transaction data) and greater belief disagreements (measured from survey data). They argue that the same areas experienced a larger housing boom but also a much greater bust, so they ended the housing cycle with lower house prices and economic activity. Our empirical results on speculation (although less detailed) suggest similar results hold in cross-country data. Our model illustrates how greater speculation during the boom naturally leads to lower prices and economic activity once the economy transitions to recession.

In recent work, Pflueger et al. (2018) present evidence that suggests risk premium shocks in the stock market also affect aggregate demand and interest rates. Specifically, they construct a measure of risk appetite for the U.S. as the price of high (idiosyncratic) volatility stocks relative to low volatility stocks. They show that a decrease in their measure of risk appetite is followed by a slowdown in economic activity and a decline in the risk-free rate - similar to our results for the non-Euro/ERM sample. Pflueger et al. (2018) argue that their risk appetite measure explains almost half of the variation of the one year risk-free rate in the U.S. since 1970. This suggests that 

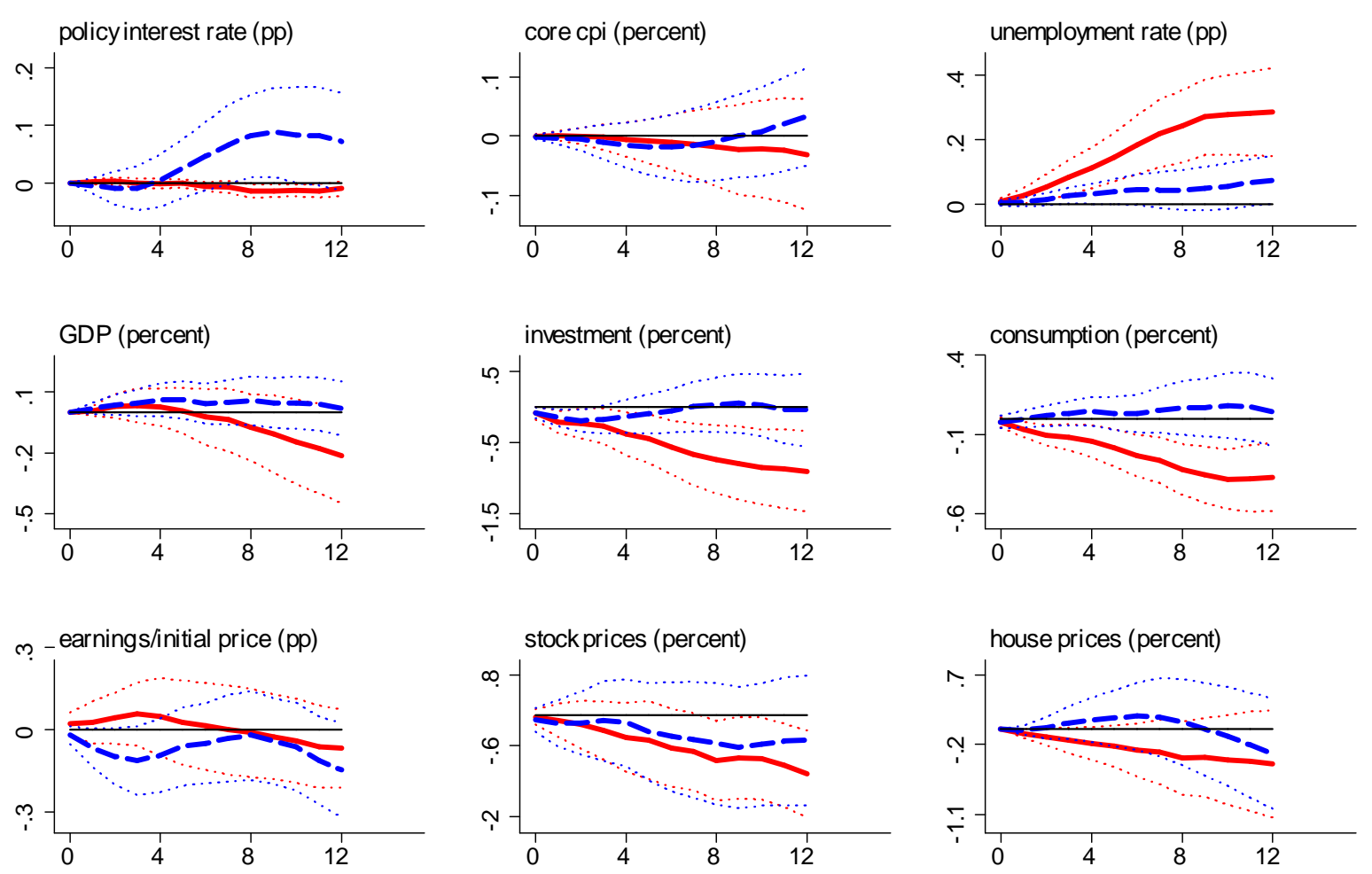

\section{Euro/ERM -}

Figure IX: Additional impulse responses to one percent decrease in real house prices when credit expansion has been one standard deviation above average. The panels illustrate the results from the regression specification in (59) with the addition of the indicator variables for Euro/ERM and non-Euro/ERM status as well as the interaction of all right-hand-side variables with these indicators. The solid red (resp. dashed blue) lines plot the coefficients corresponding to the interaction of the negative log house price and the standardized credit expansion variables when the Euro/ERM status is equal to 1 (resp. 0 ). For the units, "percent" corresponds to $0.01 \log$ units (i.e., it is approximate) and "pp" corresponds to percentage points. All regressions include time and country fixed effects; contemporaneous value and 12 lags of the first difference of log GDP; contemporaneous value and 12 lags of the policy interest rate; 12 lags of the first difference of log house prices; 12 lags of the first difference of the outcome variable; and 12 lags of standardized credit expansion. The dotted lines show $95 \%$ confidence intervals calculated according to Newey-West standard errors with a bandwidth of 20 quarters. All regressions are weighted by countries' PPP-adjusted GDP in 1990. Data is an unbalanced quarterly panel that spans 1990Q1-2017Q4. All variables except for those in the top panel are adjusted for inflation. Earnings are normalized by the stock price in the quarter before the shock (see Footnote 20p. We describe our sources and variable definitions in Online Appendix Section F. 
the time varying risk premium is an important driver of the risk-free rate in practice. ChodorowReich et al. (2019) provide further support for the link between the stock market and aggregate demand. Using regional data within the U.S., they find that a decline in local stock wealth (driven by aggregate stock prices) decreases local payroll and employment. They also find stronger effects in nontradable industries but no effects for tradable industries, consistent with a consumption wealth effect as in our model.

Focusing on a value-weighted average of house and stock prices, Jordà et al. (2019) argue that low frequency fluctuations in the risk premium in developed economies have been associated with a collapse of safe asset returns (as opposed to a spike in risky asset returns). In particular, when the risk premium rises, the risk-free rate tends to fall and the value-weighted average risky asset returns remain relatively stable, as in our model. Looking at more recent years, Del Negro et al. (2017) provide a comprehensive empirical evaluation of the different mechanisms that have put downward pressure on interest rates and show that risk and liquidity considerations played a central role (see also Caballero et al. (2017a)).

Finally, our mechanisms are supported by a literature that investigates the macroeconomic impact of "uncertainty shocks." Using vector autoregressions (VARs), Bloom (2009) shows that an increase in the volatility index in the U.S. is followed by a slowdown in economic activity. Moreover, although his model does not emphasize monetary policy, his empirical analysis shows that the shock is followed by a decline in the federal funds rate. This response suggests the effects could be more severe if the interest rate were constrained. Recent empirical work verifies this intuition and shows that uncertainty shocks in the U.S. are associated with a greater decline in economic activity when the federal funds rate is close to zero, arguably because of the zero lower bound constraint on the interest rate (see, for instance, Caggiano et al. (2017); Plante et al. (2018)).

\section{Final remarks}

We develop a risk-centric macroeconomic model to focus on the role of the aggregate demand channel in causing recessions driven by risky asset price fluctuations, and to study the effect of financial speculation on the severity of these recessions. Our analysis reformulates the standard New Keynesian model in terms of a risk-centric decomposition that puts asset prices at the center of the analysis. When the interest rate is constrained, a rise in the risk premium lowers asset prices and triggers a demand recession, which further drives down asset prices. The feedbacks are especially powerful when investors are pessimistic and think the higher risk premium will persist. Hence, average beliefs play a central role in the recession phase not only because they affect asset valuations but also because they determine the strength of the amplification mechanism. In the exante boom phase, belief disagreements (and more broadly, heterogeneous valuations) matter because they induce investors to speculate. This speculation exacerbates the recession because it depletes high-valuation investors' wealth when the risk premium rises, which leads to a greater decline in asset prices and economic activity. Macroprudential policy in the boom improves outcomes by 
restricting speculation and preserving high-valuation investors' wealth during the recession. This policy intervention leads to a Pareto improvement because it internalizes the aggregate demand externalities that result from speculation.

Our analysis supports "the Fed put": the tendency of central banks to cut interest rates in response to asset price declines driven by risk premium shocks. In our model, as long as the central bank can cut interest rates without constraints, the economy remains in the first best. The lower bound constraint on the interest rate can be thought of as the inability to provide a put beyond a certain point. Moreover, our amplification mechanism implies that even small constraints on the interest rate can generate large recessions (see Figure IV for an illustration). This highlights that "the Fed put" is important not only because of its direct effect on aggregate demand but also because it stabilizes expected future outcomes and prevents a large decline in current asset prices.

In addition, our approach highlights that the interest rate policy affects aggregate demand through its impact on financial markets and asset prices. From this perspective, our analysis supports unconventional monetary policies - such as central bank asset purchases - that attempt to stimulate aggregate demand through their impact on asset prices. More broadly, any policy that reduces perceived market volatility and prevents sudden asset price drops should have a similar effect, providing support for various policies implemented after the subprime and European crises.

In our model, we use a lower bound constraint as the interest rate friction, but our mechanisms apply if the interest rate is constrained for other reasons. When the interest rate has both an upper bound and a lower bound (such as in a currency union or fixed exchange rate regime), our results often become stronger. In this setting, speculation causes damage not only by lowering asset prices during the recession but also by raising asset prices during the boom, when aggregate demand is stretched above its natural level, which exacerbates the inefficiency. Moreover, in this case macroprudential policy during the boom is beneficial not only because it preserves high-valuation investors' wealth for a future recession but also because it immediately contains the excessive rise in asset prices.

Our results with belief disagreements do not depend on whether optimists or pessimists are right about the transition probabilities. In fact, since the equilibrium is a function of investors' subjective beliefs, the objective belief does not enter the equilibrium characterization ${ }^{25}$ Moreover, the objective belief is largely irrelevant for our policy analysis because we mainly focus on the Pareto criterion and evaluate investors' welfare under their subjective beliefs. For example, we could think of optimists as rational agents and pessimists as Knightian agents (see, e.g., Caballero and Krishnamurthy (2008); Caballero and Simsek (2013)). Absent any direct mechanism for alleviating Knightian behavior during severe recessions, the key point that reducing optimists' risk taking

\footnotetext{
${ }^{25}$ The objective belief matters if one is interested in understanding the evolution of investors' wealth shares along the objective path (that would be realized in practice). The market selection hypothesis, formulated by Friedman (1953), posits that investors with incorrect beliefs should be driven out of the market as they consistently lose money. Our model features a version of this hypothesis in the long run (see Footnote 11). However, recent research has identified many reasons why this hypothesis is unlikely to apply in practice (see, e.g., Cao (2017); Borovička (2020)). We view our model as capturing the short run given belief disagreements (or more broadly, heterogeneous valuations) that result from various unmodeled factors.
} 
during the boom leads to Pareto improvements survives this alternative motivation. More generally, our results are driven by persistent heterogeneous valuations, so similar results would also apply if investors share the same beliefs but value risky assets heterogeneously for other reasons such as differences in risk tolerance (see Remark 7).

Our model illustrates that wealth distribution matters for aggregate demand, not only because of financial frictions or heterogeneous MPCs as emphasized in the previous macroeconomics literature but also because of heterogeneous asset valuations. In the recession, a greater wealth share for highvaluation investors improves asset prices and raises everyone's spending. From this perspective, our analysis supports not only ex-ante macroprudential policy but also a variety of ex-post policies that transfer wealth to high-valuation investors in recessions. In recent work, Kekre and Lenel (2019) show that heterogeneous asset valuations (which they refer to as a heterogeneous marginal propensity to take risk) also strengthen the transmission of monetary policy.

As we noted in the introduction, we removed all financial frictions in order to isolate the aggregate demand mechanism and its interactions with speculation. However, if we were to introduce these realistic frictions in our setting, many of the themes in that literature would reemerge and be exacerbated by aggregate demand feedbacks. For example, asset price declines would not only depress aggregate demand directly, but also indirectly by tightening collateral constraints. This mechanism would amplify the feedback loops between asset prices and aggregate demand. While our analysis shares many similarities with the financial frictions literature, we have a different focus. Financial frictions highlight the importance of constrained firms or commercial banks that lend to such firms, whereas our heterogeneous valuations approach highlights the importance of institutional investors or financial intermediaries that lend to such investors, e.g., hedge funds, active mutual funds, investment banks, broker-dealers, and so on. Consistent with our main mechanism, a growing empirical literature suggests that financial intermediaries' balance sheets have a large impact on asset prices (see, e.g., Adrian et al. (2014); He et al. (2017)).

Related, we assumed complete markets so investors speculate only via contingent Arrow-Debreu securities. When these securities are not available, investors engage in proxy-speculation with leverage. In Caballero and Simsek (2019), we analyze this modified environment and show that our main results still hold: that is, contingent securities do not play an important role beyond providing analytical tractability. However, speculation via leverage breaks the separability property that we derive in Section III.B; asset prices and the interest rate become relevant for the dynamics of investors' wealth shares. Once the separability property breaks down, monetary policy can be an effective prudential tool. In particular, raising interest rates during the low risk-premium state can reduce speculation. We explore the role of prudential monetary policy in Caballero and Simsek (2019).

While this is mostly an applied theory paper, we surveyed some of the extensive empirical evidence supporting our analysis, and provided our own evidence by contrasting the local response to risk premium shocks - captured by surprise house price changes - in constrained Euro/ERM countries with the local response in less constrained non-Euro/ERM countries. Our evidence suggests 
that risk premium shocks lead to more severe recessions when the interest rate is constrained, as in our model. The evidence also supports our model's prediction that recessions reduce firms' earnings and lead to a further reduction in asset prices. When we proxy speculation with the size of the bank credit expansion before the shock, we also find some evidence that high speculation increases the severity of recessions driven by risk premium shocks.

\section{References}

Adrian, T., Boyarchenko, N., 2012. Intermediary leverage cycles and financial stability.

Adrian, T., Etula, E., Muir, T., 2014. Financial intermediaries and the cross-section of asset returns. The Journal of Finance 69 (6), 2557-2596.

Auclert, A., 2019. Monetary policy and the redistribution channel. American Economic Review 109 (6), 2333-67.

Bacchetta, P., Benhima, K., Kalantzis, Y., 2016. Money and capital in a persistent liquidity trap.

Baker, S. R., Bloom, N., Davis, S. J., 2016. Measuring economic policy uncertainty. The quarterly journal of economics 131 (4), 1593-1636.

Baker, S. R., Bloom, N., Terry, S., 2019. Does uncertainty reduce growth? using disasters as natural experiments. working paper.

Barberis, N., Greenwood, R., Jin, L., Shleifer, A., 2018. Extrapolation and bubbles. Journal of Financial Economics 129 (2), 203-227.

Baron, M., Xiong, W., 2017. Credit expansion and neglected crash risk. The Quarterly Journal of Economics 132 (2), 713-764.

Basak, S., 2000. A model of dynamic equilibrium asset pricing with heterogeneous beliefs and extraneous risk. Journal of Economic Dynamics and Control 24 (1), 63-95.

Basak, S., 2005. Asset pricing with heterogeneous beliefs. Journal of Banking \& Finance 29 (11), 2849-2881.

Basak, S., Cuoco, D., 1998. An equilibrium model with restricted stock market participation. Review of Financial Studies 11 (2), 309-341.

Basu, S., Bundick, B., 2017. Uncertainty shocks in a model of effective demand. Econometrica $85(3), 937-958$.

Beaudry, P., Portier, F., 2006. Stock prices, news, and economic fluctuations. American Economic Review 96 (4), 1293-1307.

Bernanke, B. S., Gertler, M., Gilchrist, S., 1999. The financial accelerator in a quantitative business cycle framework. Handbook of macroeconomics 1, 1341-1393.

Bianchi, J., Mendoza, E. G., 2018. Optimal time-consistent macroprudential policy. Journal of Political Economy 126 (2), 588-634. 
Biswas, S., Hanson, A., Phan, T., 2018. Bubbly recessions.

Blanchard, O. J., L'Huillier, J.-P., Lorenzoni, G., 2013. News, noise, and fluctuations: An empirical exploration. The American Economic Review 103 (7), 3045-3070.

Bloom, N., 2009. The impact of uncertainty shocks. econometrica 77 (3), 623-685.

Bloom, N., Floetotto, M., Jaimovich, N., Saporta-Eksten, I., Terry, S. J., 2018. Really uncertain business cycles. Econometrica 86 (3), 1031-1065.

Blume, L., Easley, D., 2006. If you're so smart, why aren't you rich? belief selection in complete and incomplete markets. Econometrica 74 (4), 929-966.

Bordalo, P., Gennaioli, N., Shleifer, A., 2018. Diagnostic expectations and credit cycles. The Journal of Finance 73 (1), 199-227.

Bordalo, P., Gennaioli, N., Shleifer, A., Terry, S. J., 2019. Real credit cycles.

Borovička, J., 2020. Survival and long-run dynamics with heterogeneous beliefs under recursive preferences. Journal of Political Economy 128 (1).

Brunnermeier, M. K., Sannikov, Y., 2014. A macroeconomic model with a financial sector. The American Economic Review 104 (2), 379-421.

Brunnermeier, M. K., Sannikov, Y., 2016a. The i theory of money. NBER working paper no. 22533.

Brunnermeier, M. K., Sannikov, Y., 2016b. Macro, money, and finance: A continuous-time approach. Handbook of Macroeconomics 2, 1497-1545.

Brunnermeier, M. K., Simsek, A., Xiong, W., 2014. A welfare criterion for models with distorted beliefs. The Quarterly Journal of Economics 129 (4), 1753-1797.

Caballero, R. J., Farhi, E., 2018. The safety trap. The Review of Economic Studies 85 (1), 223-274.

Caballero, R. J., Farhi, E., Gourinchas, P.-O., 2017a. Rents, technical change, and risk premia accounting for secular trends in interest rates, returns on capital, earning yields, and factor shares. American Economic Review 107 (5), 614-620.

Caballero, R. J., Farhi, E., Gourinchas, P.-O., 2017b. The safe asset shortage conundrum. The Journal of Economic Perspectives 31 (3).

Caballero, R. J., Krishnamurthy, A., 2003. Excessive dollar debt: Financial development and underinsurance. The Journal of Finance 58 (2), 867-894.

Caballero, R. J., Krishnamurthy, A., 2008. Collective risk management in a flight to quality episode. The Journal of Finance 63 (5), 2195-2230.

Caballero, R. J., Simsek, A., 2013. Fire sales in a model of complexity. The Journal of Finance 68 (6), 2549-2587.

Caballero, R. J., Simsek, A., 2019. Prudential monetary policy. NBER working paper no. 25977.

Caggiano, G., Castelnuovo, E., Pellegrino, G., 2017. Estimating the real effects of uncertainty shocks at the zero lower bound. European Economic Review 100, 257-272. 
Campbell, J. Y., 2014. Empirical asset pricing: Eugene Fama, Lars Peter Hansen, and Robert Shiller. The Scandinavian Journal of Economics 116 (3), 593-634.

Campbell, J. Y., Viceira, L. M., 2002. Strategic asset allocation: portfolio choice for long-term investors. Clarendon Lectures in Economic.

Cao, D., 2017. Speculation and financial wealth distribution under belief heterogeneity. The Economic Journal.

Carver, C. S., Scheier, M. F., Segerstrom, S. C., 2010. Optimism. Clinical psychology review 30 (7), 879-889.

Chen, J., Hong, H., Stein, J. C., 2002. Breadth of ownership and stock returns. Journal of Financial Economics 66 (2), 171-205.

Chodorow-Reich, G., Nenov, P. T., Simsek, A., 2019. Stock market wealth and the real economy: A local labor market approach. NBER working paper no. 25959.

Christiano, L. J., Eichenbaum, M. S., Trabandt, M., 2015. Understanding the great recession. American Economic Journal: Macroeconomics 7 (1), 110-167.

Cieslak, A., Vissing-Jorgensen, A., 2017. The economics of the fed put.

Cochrane, J. H., 2011. Presidential address: Discount rates. The Journal of finance 66 (4), $1047-$ 1108.

Dávila, E., 2017. Optimal financial transaction taxes. working paper.

Davila, E., Korinek, A., 2016. Pecuniary externalities in economies with financial frictions. The Review of Economic Studies.

DeFusco, A. A., Nathanson, C. G., Zwick, E., 2017. Speculative dynamics of prices and volume. NBER working paper no. 23449.

Del Negro, M., Giannone, D., Giannoni, M. P., Tambalotti, A., Wu, J. C., 2017. Safety, liquidity, and the natural rate of interest.

Detemple, J., Murthy, S., 1994. Intertemporal asset pricing with heterogeneous beliefs. Journal of Economic Theory 62 (2), 294-320.

Di Tella, S., 2017. Uncertainty shocks and balance sheet recessions. Journal of Political Economy 125 (6), 2038-2081.

Di Tella, S., 2019. Risk premia and the real effects of money. Stanford University working paper.

Di Tella, S., Hall, R. E., 2019. Risk premium shocks can create inefficient recessions. Stanford University working paper.

Duffie, D., Epstein, L. G., 1992. Stochastic differential utility. Econometrica: Journal of the Econometric Society, 353-394.

Eggertsson, G. B., Woodford, M., September 2006. Optimal Monetary and Fiscal Policy in a Liquidity Trap. The MIT Press, pp. 75-144. 
Farhi, E., Werning, I., 2016. A theory of macroprudential policies in the presence of nominal rigidities. Econometrica 84 (5), 1645-1704.

Farhi, E., Werning, I., 2017. Fiscal unions. American Economic Review forthcoming.

Fernández-Villaverde, J., Guerrón-Quintana, P., Kuester, K., Rubio-Ramírez, J., 2015. Fiscal volatility shocks and economic activity. American Economic Review 105 (11), 3352-84.

Fostel, A., Geanakoplos, J., 2008. Leverage cycles and the anxious economy. The American Economic Review 98 (4), 1211-1244.

Friedman, M., 1953. Essays in positive economics. University of Chicago Press.

Galí, J., 2018. Monetary policy and bubbles in a new keynesian model with overlapping generations.

Garleanu, N., Pedersen, L. H., 2011. Margin-based asset pricing and deviations from the law of one price. The Review of Financial Studies 24 (6), 1980-2022.

Geanakoplos, J., 2010. The leverage cycle. NBER macroeconomics annual 24 (1), 1-66.

Gennaioli, N., Shleifer, A., 2018. A crisis of beliefs: Investor psychology and financial fragility. Princeton University Press.

Gertler, M., Kiyotaki, N., 2010. Financial intermediation and credit policy in business cycle analysis. Handbook of monetary economics 3 (3), 547-599.

Giglio, S., Maggiori, M., Stroebel, J., Utkus, S., 2019. Five facts about beliefs and portfolios. NBER working paper no. 25744 .

Guerrieri, V., Lorenzoni, G., 2017. Credit crises, precautionary savings, and the liquidity trap. Quarterly Journal of Economics forthcoming.

Hall, R. E., 2011. The long slump. The American Economic Review 101 (2), 431-469.

Harris, M., Raviv, A., 1993. Differences of opinion make a horse race. Review of Financial studies $6(3), 473-506$.

Harrison, J. M., Kreps, D. M., 1978. Speculative investor behavior in a stock market with heterogeneous expectations. The Quarterly Journal of Economics 92 (2), 323-336.

He, Z., Kelly, B., Manela, A., 2017. Intermediary asset pricing: New evidence from many asset classes. Journal of Financial Economics 126 (1), 1-35.

He, Z., Krishnamurthy, A., 2012. A model of capital and crises. The Review of Economic Studies 79 (2), 735-777.

He, Z., Krishnamurthy, A., 2013. Intermediary asset pricing. The American Economic Review $103(2), 732-770$.

Heimer, R., Simsek, A., 2019. Should retail investorsâĂŹ leverage be limited? Journal of Financial Economics 132 (3), 1-21.

Hong, H., Stein, J. C., 2007. Disagreement and the stock market. Journal of Economic perspectives $21(2), 109-128$. 
Iachan, F. S., Nenov, P. T., Simsek, A., 2015. The choice channel of financial innovation. NBER working paper no. 21686.

Ilut, C. L., Schneider, M., 2014. Ambiguous business cycles. The American Economic Review 104 (8), 2368-2399.

Isoré, M., Szczerbowicz, U., 2017. Disaster risk and preference shifts in a new keynesian model. Journal of Economic Dynamics and Control 79, 97-125.

Jeanne, O., Korinek, A., 2018. Managing credit booms and busts: A pigouvian taxation approach. Journal of Monetary Economics.

Jordà, Ò., 2005. Estimation and inference of impulse responses by local projections. American economic review 95 (1), 161-182.

Jordà, Ò., Knoll, K., Kuvshinov, D., Schularick, M., Taylor, A. M., 2019. The rate of return on everything, 1870-2015. The Quarterly Journal of Economics 134 (3), 1225-1298.

Kekre, R., Lenel, M., 2019. Monetary policy, redistribution, and risk premia. Tech. rep., Princeton University working paper.

Kindleberger, C. P., 1978. Manias, panics and crashes: a history of financial crises. Basic Books.

Kiyotaki, N., Moore, J., 1997. Credit cycles. Journal of political economy 105 (2), 211-248.

Korinek, A., Nowak, M., 2016. Risk-taking dynamics and financial stability.

Korinek, A., Simsek, A., 2016. Liquidity trap and excessive leverage. American Economic Review $106(3), 699-738$.

Krugman, P., 1998. It's baaack: Japan's slump and the return of the liquidity trap. Brookings Papers on Economic Activity 1998 (2), 137-205.

Kubler, F., Schmedders, K., 2012. Financial innovation and asset price volatility. The American Economic Review 102 (3), 147-151.

Lintner, J., 1969. The aggregation of investor's diverse judgments and preferences in purely competitive security markets. Journal of financial and quantitative analysis 4 (04), 347-400.

Longstaff, F. A., Wang, J., 2012. Asset pricing and the credit market. The Review of Financial Studies 25 (11), 3169-3215.

Lorenzoni, G., 2008. Inefficient credit booms. The Review of Economic Studies 75 (3), 809-833.

Lorenzoni, G., 2009. A theory of demand shocks. The American economic review 99 (5), 2050-2084.

Mack, A., Martínez-García, E., et al., 2011. A cross-country quarterly database of real house prices: a methodological note. Globalization and Monetary Policy Institute Working Paper 99.

Mian, A., Sufi, A., 2014. What explains the 2007-2009 drop in employment? Econometrica 82 (6), 2197-2223.

Mian, A., Sufi, A., 2018. Credit supply and housing speculation. NBER working paper no. 24823. 
Midrigan, V., Philippon, T., Jones, C., et al., 2016. Beyond the liquidity trap: the secular stagnation of investment. In: 2016 Meeting Papers. No. 1429. Society for Economic Dynamics.

Miller, E. M., 1977. Risk, uncertainty, and divergence of opinion. The Journal of finance 32 (4), $1151-1168$.

Minsky, H. P., 1977. The financial instability hypothesis: An interpretation of keynes and an alternative to standard theory. Challenge 20 (1), 20-27.

Moreira, A., Savov, A., 2017. The macroeconomics of shadow banking. The Journal of Finance forthcoming.

Newey, W. K., West, K. D., 1987. A simple, positive semi-definite, heteroskedasticity and autocorrelation consistent covariance matrix. Econometrica 55 (3), 703-708.

Pflueger, C., Siriwardane, E., Sunderam, A., 2018. A measure of risk appetite for the macroeconomy. NBER working paper no. 24529.

Plante, M., Richter, A. W., Throckmorton, N. A., 2018. The zero lower bound and endogenous uncertainty. The Economic Journal 128 (611), 1730-1757.

Rognlie, M., Shleifer, A., Simsek, A., 2018. Investment hangover and the great recession. American Economic Journal: Macroeconomics 10 (2), 113-53.

Romer, C. D., Romer, D. H., 2018. Phillips lecture--why some times are different: Macroeconomic policy and the aftermath of financial crises. Economica 85 (337), 1-40.

Scheinkman, J. A., Xiong, W., 2003. Overconfidence and speculative bubbles. Journal of political Economy 111 (6), 1183-1220.

Schularick, M., Taylor, A. M., 2012. Credit booms gone bust: Monetary policy, leverage cycles, and financial crises, 1870-2008. American Economic Review 102 (2), 1029-61.

Shiller, R. J., 2014. Speculative asset prices. American Economic Review 104 (6), 1486-1517.

Silva, D. H., 2016. The risk channel of unconventional monetary policy.

Simsek, A., 2013a. Belief disagreements and collateral constraints. Econometrica 81 (1), 1-53.

Simsek, A., 2013b. Speculation and risk sharing with new financial assets. The Quarterly journal of economics 128 (3), 1365-1396.

Tobin, J., 1975. Keynesian models of recession and depression. The American Economic Review 65 (2), 195-202.

Varian, H. R., 1989. Differences of opinion in financial markets. In: financial Risk: Theory, Evidence and implications. Springer, pp. 3-37.

Werning, I., 2012. Managing a liquidity trap: Monetary and fiscal policy. NBER working paper no. 17344 .

Xiong, W., Yan, H., 2010. Heterogeneous expectations and bond markets. Review of Financial Studies 23 (4), 1433-1466.

Zapatero, F., 1998. Effects of financial innovations on market volatility when beliefs are heterogeneous. Journal of Economic Dynamics and Control 22 (4), 597-626. 


\title{
Online Appendix for: A RISK-CENTRIC MODEL OF DEMAND RECESSIONS AND SPECULATION
}

\author{
Ricardo J. Caballero \\ Alp Simsek \\ MIT and NBER. caball@mit.eduＭIT, NBER, and CEPR. asimsek@mit.edu
}

This online appendix contains supplementary material for A Risk-centric Model of Demand Recessions and Speculation. Sections A E contain the omitted derivations and proofs as well as the extensions related to our theoretical analysis in Sections II. VI. Section F has information about our data sources and details for our empirical analysis in Section VII.

\section{A. Omitted derivations for the two period model}

This section presents the derivations and proofs omitted from the main text for the two period model that we analyze in Section II. We start by presenting the details of the baseline case analyzed in the main text. We then analyze an extension in which the elasticity of substitution (EIS) is different than one and show that our conclusions remain qualitatively unchanged. Finally, we analyze the extension with belief disagreements discussed in the main text. Throughout, recall that the market portfolio is the claim to all output at date 1. Combining Eqs. (1) and (2), the return on the market portfolio is also log normally distributed, that is,

$$
r^{m}\left(z_{1}\right)=\log \left(\frac{Q_{1}}{z_{1}}\right) \sim N\left(g-\log Q-\frac{\sigma^{2}}{2}, \sigma^{2}\right) .
$$

\section{A.1. Baseline two period model}

For this case, most of the analysis is provided in the main text. Here, we formally state the investor's problem and derive the optimality conditions. The investor takes the returns as given and solves the following problem,

$$
\begin{array}{ll} 
& \max _{c_{0}, a_{0}, \omega^{m}} \log c_{0}+e^{-\rho} \log U_{1} \\
& \text { where } U_{1}=\left(E\left[c_{1}\left(z_{1}\right)^{1-\gamma}\right]\right)^{1 /(1-\gamma)} \\
\text { s.t. } & c_{0}+a_{0}=y_{0}+Q \\
\text { and } & c_{1}\left(z_{1}\right)=a_{0}\left(\omega^{m} \exp \left(r^{m}\left(z_{1}\right)\right)+\left(1-\omega^{m}\right) \exp \left(r^{f}\right)\right) .
\end{array}
$$

Here, $c_{1}\left(z_{1}\right)$ denotes total financial wealth, which equals consumption (since the economy ends at date 1). Note that the investor has Epstein-Zin preferences with EIS coefficient equal to one and the RRA coefficient equal to $\gamma>0$. The case with $\gamma=1$ is equivalent to time-separable log utility as in the dynamic model. 
In view of the Epstein-Zin functional form, the investor's problem naturally splits into two steps. Conditional on savings, $a_{0}$, she solves a portfolio optimization problem, that is, $U_{1}=R^{C E} a_{0}$, where

$$
\begin{aligned}
R^{C E} & =\max _{\omega^{m}}\left(E\left[\left(R^{p}\left(z_{1}\right)\right)^{1-\gamma}\right]\right)^{1 /(1-\gamma)} \\
\text { and } R^{p}\left(z_{1}\right) & =\left(\omega^{m} \exp \left(r^{m}\left(z_{1}\right)\right)+\left(1-\omega^{m}\right) \exp \left(r^{f}\right)\right) .
\end{aligned}
$$

Here, we used the observation that the portfolio problem is linearly homogeneous. The variable, $R^{p}\left(z_{1}\right)$, denotes the realized portfolio return per dollar, and $R^{C E}$ denotes the optimal certaintyequivalent portfolio return. In turn, the investor chooses asset holdings, $a_{0}$, that solve the intertemporal problem,

$$
\max _{a_{0}} \log \left(y_{0}+Q-a_{0}\right)+e^{-\rho} \log \left(R^{C E} a_{0}\right) .
$$

The first order condition for this problem implies Eq. (4) in the main text. That is, regardless of her certainty-equivalent portfolio return, the investor consumes and saves a constant fraction of her lifetime wealth.

It remains to characterize the optimal portfolio weight, $\omega^{m}$, as well as the certainty-equivalent return, $R^{C E}$. Even though the return on the market portfolio is log-normally distributed (see Eq. A.1), the portfolio return, $R^{p}\left(z_{1}\right)$, is in general not log-normally distributed (since it is the sum of a log-normal variable and a constant). Following Campbell and Viceira (2002), we assume the investor solves an approximate version of the portfolio problem $(A .2)$ in which the $\log$ portfolio return is also normally distributed. To state the problem, let $\pi^{p} \equiv \log E\left[R^{p}\right]-r^{f}$ and $\left(\sigma^{p}\right)^{2} \equiv \operatorname{var}\left(\log R^{p}\right)$ to denote respectively the risk premium and the variance of the market portfolio (measured in log returns). Then, the approximate portfolio return satisfies,

$$
\begin{aligned}
\pi^{p} & =\omega^{m} \pi^{k} \\
\text { where } \pi^{k} & \equiv \log \left(E\left[\exp \left(r^{m}\left(z_{1}\right)\right)\right]\right)-r^{f}=E\left[r^{m}\left(z_{1}\right)\right]-r^{f}+\frac{\sigma^{2}}{2} .
\end{aligned}
$$

Hence, the risk premium on the portfolio return depends linearly on the risk premium on the market portfolio (measured in log returns). We also have,

$$
\sigma^{p}=\omega^{m} \sigma .
$$

Thus, the volatility of the portfolio also depends linearly on the volatility of the market portfolio (measured in log returns). These identities hold exactly in continuous time. In the two period model, they hold approximately when the period time-length is small. Moreover, they become exact for the level the risk premium that ensures equilibrium, $\omega^{m}=1$, since in this case the portfolio return is actually log-normally distributed.

Taking the log of the objective function in problem $(A .2)$, and using the log-normality assumption, the problem can be equivalently rewritten as,

$$
\log R^{C E}-r^{f}=\max _{\omega^{m}} \pi^{p}-\frac{1}{2} \gamma\left(\sigma^{p}\right)^{2},
$$

where $\pi^{p}$ and $\sigma^{p}$ are defined in Eqs. A.4 and A.5. It follows that, up to an approximation (that becomes exact in equilibrium), the investor's problem turns into standard mean-variance optimization. Taking the first order condition, we obtain Eq. (6) in the main text. Substituting 
$\omega^{m}=1$ and $E\left[r^{m}\left(z_{1}\right)\right]=g-\log Q-\frac{\sigma^{2}}{2}[$ cf. Eq. A.1)] into this expression, we further obtain Eq. (7) in the main text.

For future reference, we also obtain a closed-form solution for the certainty-equivalent return, $R^{C E}$. Substituting Eqs. A.4 and $A .5$ together with $\omega^{m}=1$ into $A .6$, and using $E\left[r^{m}\left(z_{1}\right)\right]=$ $g-\log Q-\frac{\sigma^{2}}{2}$, we obtain:

$$
\log R^{C E}=g-\log Q-\frac{1}{2} \gamma \sigma^{2}
$$

As expected, $R^{C E}$ increases with expected growth, $g$, and decreases with the volatility, $\sigma$, and the risk aversion, $\gamma$.

\section{A.2. More general EIS}

Now consider the same model with the difference that we allow the EIS, denoted by $\varepsilon$, to be different than one. We first characterize the equilibrium. We then describe how a risk premium shock affects the equilibrium and show that our conclusions from the main text remain qualitatively unchanged.

Equilibrium with more general EIS. In this case, the representative investor solves the following problem,

$$
\begin{aligned}
\max _{c_{0}, a_{0}, \omega^{m},\left\{c_{1}\left(z_{1}\right)\right\}} & U_{0}=\frac{c_{0}^{1-1 / \varepsilon}-1}{1-1 / \varepsilon}+e^{-\rho} \frac{U_{1}^{1-1 / \varepsilon}-1}{1-1 / \varepsilon} \\
\text { where } & U_{1}=\left(E\left[c_{1}\left(z_{1}\right)^{1-\gamma}\right]\right)^{1 /(1-\gamma)} \\
\text { s.t. } & c_{0}+a_{0}=y_{0}+Q \\
\text { and } & c_{1}\left(z_{1}\right)=a_{0}\left(\omega^{m} \exp \left(r^{m}\left(z_{1}\right)\right)+\left(1-\omega^{m}\right) \exp \left(r^{f}\right)\right) .
\end{aligned}
$$

The case with $\varepsilon=1$ is equivalent to the earlier problem.

Most of the analysis remains unchanged. As before, the investor's problem splits into two parts. The portfolio problem $A .2$ as well as its solution remains unchanged. In particular, Eqs. (6) and (7) from the main text apply. Moreover, the certainty equivalent return, $R^{C E}$, is still given by Eq. A.7.

The main difference concerns the intertemporal problem $A .3$, which is now given by,

$$
\max _{a_{0}}\left(y_{0}+Q-a_{0}\right)^{1-1 / \varepsilon}+e^{-\rho}\left(R^{C E} a_{0}\right)^{1-1 / \varepsilon} .
$$

Taking the first order condition for the intertemporal problem and rearranging terms, we obtain the consumption function,

$$
c_{0}=\frac{1}{1+e^{-\rho \varepsilon}\left(R^{C E}\right)^{(\varepsilon-1)}}\left(y_{0}+Q\right) .
$$

Combining this expression with the aggregate resource constraint, $y_{0}=c_{0}$, we obtain the following analogue of the output-asset price relation [cf. Eq. (5)],

$$
y_{0}=e^{\rho \varepsilon}\left(R^{C E}\right)^{1-\varepsilon} Q .
$$

The expression shows that consumption is not only influenced by a wealth effect, as in the baseline 
analysis, but also by substitution and income effects. When $\varepsilon>1$, the substitution effect dominates the income effect. All else equal, a decline in the attractiveness of investment opportunities captured by a reduction in $R^{C E}$ tends to reduce savings and increase consumption, which in turn increases output. Conversely, when $\varepsilon<1$, the income effect dominates the substitution effect. In this case, a decline in $R^{C E}$ tends to increase savings and reduce consumption and output.

The equilibrium is found by jointly solving Eqs. (A.8) and (A.7) together with Eq. (7) and the constrained policy interest rate. Collecting the equations together, the equilibrium tuple, $\left(y_{0}, Q, R^{C E}, r^{f}\right)$, is the solution to the following system,

$$
\begin{aligned}
\log y_{0} & =\rho \varepsilon+(1-\varepsilon) \log R^{C E}+\log Q \\
\log R^{C E} & =g-\log Q-\frac{1}{2} \gamma \sigma^{2} \\
\sigma & =\frac{1}{\gamma} \frac{g-\log Q-r^{f}}{\sigma} \\
r^{f} & =\max \left(r^{f *}, 0\right) \text { where } r^{f *} \text { ensures } y_{0}=z_{0} .
\end{aligned}
$$

To characterize the solution further, consider the case in which the equilibrium is supply determined, $y_{0}=z_{0}=1$. Substituting this into the first two equations, we solve for the first-best price level of the market portfolio as,

$$
\log Q^{*}=-\rho+\frac{(\varepsilon-1)}{\varepsilon}\left(g-\frac{1}{2} \gamma \sigma^{2}\right) .
$$

Substituting this into the last equation, we further obtain an expression for "rstar",

$$
\begin{aligned}
r^{f *} & =\rho+g-\gamma \sigma^{2}-\frac{(\varepsilon-1)}{\varepsilon}\left(g-\frac{1}{2} \gamma \sigma^{2}\right) \\
& =\rho+\frac{g}{\varepsilon}-\frac{1}{2} \gamma\left(1+\frac{1}{\varepsilon}\right) \sigma^{2} .
\end{aligned}
$$

Note that setting $\varepsilon=1$ recovers Eq. (8) in the main text.

Now consider the case in which the interest rate is at its lower bound, $r^{f}=0$. Substituting this into the equation system $(A .9)$, we obtain,

$$
\begin{aligned}
\log Q & =g-\gamma \sigma^{2} \\
\text { and } \log y_{0} & =\varepsilon\left(\rho+\log Q-\frac{(\varepsilon-1)}{\varepsilon}\left(g-\frac{1}{2} \gamma \sigma^{2}\right)\right) \\
& =\varepsilon\left(\rho+\frac{g}{\varepsilon}-\frac{1}{2} \gamma\left(1+\frac{1}{\varepsilon}\right) \sigma^{2}\right) .
\end{aligned}
$$

Note that setting $\varepsilon=1$ recovers Eq. (9) in the main text.

Risk premium shocks with more general EIS. Now consider how a risk premium shock that increases $\sigma$ or $\gamma$ (or lowers $g$ ) affects the equilibrium. Eq. A.7) illustrates that this reduces $R^{C E}$ for a given asset price level: as expected, an increase in the risk premium reduces the attractiveness of investment opportunities. Combining this with the output-asset price relation in $(A .8)$, we see that the shock affects consumption and aggregate demand through two channels. As before, it exerts a downward influence on asset prices, which reduces consumption through a wealth effect. 
Unlike before, the induced decline in $R^{C E}$ also affects consumption depending on the balance of income and substitution effects. When $\varepsilon>1$, the second channel works against the wealth effect because investors substitute toward consumption. When $\varepsilon<1$, the second channel reinforces the wealth effect.

Eqs. A.11 and $A .12$ show that the net effect on aggregate demand is qualitatively the same as in the baseline model regardless of the level of EIS. In particular, Eq. A.11) illustrates that the risk premium shock reduces $r^{f *} \cdot{ }^{26}$ Eq. $A .12$ illustrates that, when the interest rate is constrained, $r^{f}=0$, the shock reduces the equilibrium level of output $y_{0}$, as well as the asset price, $Q$. When $\varepsilon>1$, the substitution effect mitigates the magnitude of these declines but it does not overturn them-that is, the wealth effect ultimately dominates. Since the purpose of our model is to obtain qualitative insights, in the main text we assume $\varepsilon=1$ and isolate the wealth effect.

Finally, consider also how the shock affects $Q^{*}$ : the equilibrium asset price that obtains once the interest rate declines sufficiently to ensure output is equal to its supply determined level. In our baseline model, $Q^{*}$ is constant. In general, Eq. A.10 illustrates that $Q^{*}$ can decrease or increase in response to the risk premium shock. When $\varepsilon>1, Q^{*}$ declines, which means that $r^{f *}$ does not need to fully accommodate the price impact of the risk premium shock. The reason is that the substitution effect supports current consumption and reduces the burden on wealth to support aggregate demand. The opposite happens when $\varepsilon<1$, where the substitution effect is dominated by the income effect. In this case $Q^{*}$ needs to rise to support aggregate demand, which is achieved by a larger decline in $r^{f *}$ following the risk premium shock.

\section{A.3. Belief disagreements and speculation}

We next go back to the baseline setup with $\varepsilon=1$ complete the analysis of the case with belief disagreements discussed in the main text. Recall that there are two types of investors, optimists and pessimists, denoted by superscript $i \in\{o, p\}$. With a slight abuse of notation, we also let $\alpha^{o} \equiv \alpha$ and $\alpha^{p} \equiv 1-\alpha$ denote respectively optimists' and pessimists' wealth shares. Investors are identical except possibly their beliefs about aggregate growth. Optimists perceive greater growth, $g^{o}>g^{p}$.

In this case, type $i$ investors solve the following problem,

$$
\begin{aligned}
\max _{c_{0}, a_{0}, \omega^{m},\left\{c_{1}\left(z_{1}\right)\right\}} & \log c_{0}+e^{-\rho} \log U_{1} \\
\text { where } & U_{1}=\left(E^{i}\left[c_{1}\left(z_{1}\right)^{1-\gamma}\right]\right)^{1 /(1-\gamma)} \\
\text { s.t. } & c_{0}+a_{0}=\alpha^{i}\left(y_{0}+Q\right) \\
\text { and } & c_{1}\left(z_{1}\right)=a_{0}\left(\omega^{m} \exp \left(r^{m}\left(z_{1}\right)\right)+\left(1-\omega^{m}\right) \exp \left(r^{f}\right)\right) .
\end{aligned}
$$

Note that we set the EIS equal to one as in the baseline setting. Note also that the asset market clearing condition requires,

$$
\omega^{m, o} a_{0}^{o}+\omega^{m, p} a_{0}^{p}=Q
$$

\footnotetext{
${ }^{26}$ The effect of this risk premium shock on $Q^{*}$ is more subtle (see Eq. $A .10$ ). When $\varepsilon>1, Q^{*}$ declines, which means that $r^{f *}$ does not need to fully accommodate the risk premium shock. The reason is that the substitution effect supports current consumption and reduces the burden on wealth to support aggregate demand. The opposite happens when $\varepsilon<1$, where the substitution effect is dominated by the income effect. In this case $Q^{*}$ needs to rise to support aggregate demand, which is achieved by a larger decline in $r^{f *}$ following the risk premium shock.
} 
that is, the total amount of wealth invested in the market portfolio equals the value of the market portfolio. The rest of the model is the same as in the baseline setting.

To characterize the equilibrium, note that the investor's portfolio problem $A .2$ remains unchanged. Applying the log-normal approximation that we described previously, we obtain Eq. (6) as in the main text, that is,

$$
\omega^{m, i} \sigma \simeq \frac{1}{\gamma} \frac{E^{i}\left[r^{m}\left(z_{1}\right)\right]+\frac{\sigma^{2}}{2}-r^{f}}{\sigma}
$$

Substituting $E^{i}\left[r^{m}\left(z_{1}\right)\right]=g^{i}-\log Q-\frac{\sigma^{2}}{2}$ [cf. Eq. (A.1)] into this expression, we further obtain,

$$
\omega^{m, i} \sigma \simeq \frac{1}{\gamma} \frac{g^{i}-\log Q-r^{f}}{\sigma}
$$

As before, investors choose their share of the market portfolio so that their optimal portfolio risk is proportional to the Sharpe ratio. The difference is that the Sharpe ratio is calculated according to investors' own beliefs (and it is greater for optimists since $g^{o}>g^{p}$ ).

The intertemporal problem A.3 also remains unchanged. Taking the first order condition, we obtain,

$$
c_{0}^{i}=\frac{1}{1+e^{-\rho}} \alpha^{i}\left(y_{0}+Q\right)
$$

Aggregating this equation across investors, and using the aggregate resource constraint (3), shows that the output-asset price relation (5) continues to apply in this setting. Belief heterogeneity does not affect this equation since investors share the same discount rate, $\rho$.

Next note that combining $A .14, A .16$ ) and (5), the asset market clearing condition can be rewritten as,

$$
\alpha \omega^{m, o}+(1-\alpha) \omega^{m, p}=1
$$

Investors' wealth-weighted average portfolio weight on the market portfolio is equal to one. Combining this with Eq. A.15, we obtain the following analogue of Eq. (7),

$$
\sigma \simeq \frac{1}{\gamma} \frac{\alpha^{o} g^{o}+\alpha^{p} g^{p}-\log Q-r^{f}}{\sigma}
$$

Hence, the risk balance condition continues to apply with the difference that the expected growth rate is determined according to a weighted average belief. Another difference is that the condition is typically not exact because investors' shares of the market portfolio typically deviate from one (and thus, their return is typically not log-normal). Specifically, the equilibrium portfolio shares satisfy, $\omega^{o}>1>\omega^{p}$ : optimists' make a leveraged investment in the market portfolio by issuing some risk-free debt, whereas pessimists invest only a fraction of their wealth in the market portfolio (and invest the rest of their wealth in the risk-free asset issued by optimists).

Next consider the supply-determined equilibrium in which output is equal to its potential, $y_{0}=z_{0}=1$. By Eq. (5), this requires the asset price to be at a particular level, $Q^{*}=e^{-\rho}$. Combining this with Eq. A.18 we obtain Eq. (10) in the main text that characterizes "rstar." The level of "rstar" is increasing in optimists' wealth share, $\alpha$. This is because increasing optimists' wealth share tends to increase asset prices, aggregate demand, and output. In a supply-determined equilibrium, the monetary policy increases the interest rate to neutralize the impact of optimists on aggregate demand and output. 
Finally, consider the case in which the interest rate is at its lower bound, $r^{f}=0$. Substituting this into the risk balance condition (A.18), and using the output-asset price relation (5), we obtain Eq. (11) in the main text that characterizes the equilibrium level of output in a demand recession. In this case, increasing optimists' wealth share translates into an actual increase in asset prices, aggregate demand, and output, because the monetary policy cannot neutralize these effects due to the constraint on the interest rate. 


\section{B. Omitted derivations for the dynamic model}

This section presents the details of the dynamic model that we present and analyze in Sections III. V. Sections B.1 B.3 describe derivations and proofs omitted from the main text for the dynamic model. Section B.4 describes how we parameterize the model. The subsequent section C presents the details of the welfare analysis for the same model.

\section{B.1. Omitted derivations in Section III}

\section{B.1.1 Portfolio problem and its recursive formulation}

A type $i$ investor's portfolio problem (at some time $t$ and state $s$ ) can be written as,

$$
\begin{aligned}
& V_{t, s}^{i}\left(a_{t, s}^{i}\right)=\max _{\left[\tilde{c}_{\tilde{t}, \tilde{s}}, \tilde{\omega}_{\tilde{t}, \tilde{s}}^{m}, \tilde{\omega}_{\tilde{\tilde{t}}, \tilde{s}}^{\tilde{s}^{\prime}}\right]_{\tilde{t} \geq t, \tilde{s}}} E_{t, s}^{i}\left[\int_{t}^{\infty} e^{-\rho \tilde{t}} \log \tilde{c}_{\tilde{t}, \tilde{s}}^{i} d \tilde{t}\right] \\
& \text { s.t. }\left\{\begin{array}{c}
d a_{t, s}^{i}=\left(a_{t, s}^{i}\left(r_{t, s}^{f}+\tilde{\omega}_{t, s}^{m}\left(r_{t, s}^{m}-r_{t, s}^{f}\right)-\tilde{\omega}_{\tilde{t}, \tilde{s}}^{\tilde{s}^{\prime}}\right)-\tilde{c}_{t, s}\right) d t+\tilde{\omega}_{t, s}^{m} a_{t, s}^{i} \sigma_{t, s}^{m} d Z_{t} \quad \text { absent transition, } \\
a_{t, s^{\prime}}^{i}=a_{t, s}^{i}\left(1+\tilde{\omega}_{t, s}^{m} \frac{Q_{t, s^{\prime}}-Q_{t, s}}{Q_{t, s}}+\tilde{\omega}_{t, s}^{s^{\prime}} \frac{1}{p_{t, s}^{s^{\prime}}}\right) \quad \text { if there is a transition to state } s^{\prime} \neq s .
\end{array}\right.
\end{aligned}
$$

Here, $E_{t, s}^{i}[\cdot]$ denotes the expectations operator that corresponds to the investor's beliefs for state transition probabilities.

The HJB equation corresponding to this problem is given by,

$$
\begin{aligned}
\rho V_{t, s}^{i}\left(a_{t, s}^{i}\right) & =\max _{\tilde{\omega}^{m}, \tilde{\omega}^{s^{\prime}}, \tilde{c}} \log \tilde{c}+\frac{\partial V_{t, s}^{i}}{\partial a}\left(a_{t, s}^{i}\left(r_{t, s}^{f}+\tilde{\omega}^{m}\left(r_{t, s}^{m}-r_{t, s}^{f}\right)-\tilde{\omega}^{s^{\prime}}\right)-\tilde{c}\right) \\
& +\frac{1}{2} \frac{\partial^{2} V_{t, s}^{i}}{\partial a^{2}}\left(\tilde{\omega}^{m} a_{t, s}^{i} \sigma_{t, s}^{m}\right)^{2}+\frac{\partial V_{t, s}^{i}\left(a_{t, s}^{i}\right)}{\partial t} \\
& +\lambda_{s}^{i}\left(V_{t, s^{\prime}}^{i}\left(a_{t, s}^{i}\left(1+\tilde{\omega}^{m} \frac{Q_{t, s^{\prime}}-Q_{t, s}}{Q_{t, s}}+\frac{\tilde{\omega}^{s^{\prime}}}{p_{t, s}^{s^{\prime}}}\right)\right)-V_{t, s}^{i}\left(a_{t, s}^{i}\right)\right) .
\end{aligned}
$$

In view of the log utility, the solution has the functional form in 48, which we reproduce here,

$$
V_{t, s}^{i}\left(a_{t, s}^{i}\right)=\frac{\log \left(a_{t, s}^{i} / Q_{t, s}\right)}{\rho}+v_{t, s}^{i}
$$

This functional form also implies,

$$
\frac{\partial V_{t, s}^{i}}{\partial a}=\frac{1}{\rho a_{t, s}^{i}} \text { and } \frac{\partial^{2} V_{t, s}^{i}}{\partial a^{2}}=\frac{-1}{\rho\left(a_{t, s}^{i}\right)^{2}} .
$$

The first order condition for $\tilde{c}$ then implies Eq. (23) in the main text. The first order condition for $\tilde{\omega}^{m}$ implies,

$$
\frac{\partial V_{t, s}^{i}}{\partial a} a_{t, s}^{i}\left(r_{t, s}^{m}-r_{t, s}^{f}\right)+\lambda_{s}^{i} \frac{\partial V_{t, s^{\prime}}^{i}\left(a_{t, s^{\prime}}^{i}\right)}{\partial a} a_{t, s}^{i} \frac{Q_{t, s^{\prime}}-Q_{t, s}}{Q_{t, s}}=-\frac{\partial^{2} V_{t, s}^{i}}{\partial a^{2}} \omega_{t, s}^{m}\left(a_{t, s}^{i} \sigma_{t, s}^{m}\right)^{2} .
$$


After substituting for $\frac{\partial V_{t, s}^{i}}{\partial a}, \frac{\partial V_{t, s^{\prime}}^{i}}{\partial a}, \frac{\partial^{2} V_{t, s}^{i}}{\partial a^{2}}$ and rearranging terms, this also implies Eq. (31) in the main text. Finally, the first order condition for $\tilde{\omega}^{s^{\prime}}$ implies,

$$
\frac{p_{t, s}^{s^{\prime}}}{\lambda_{s}^{i}}=\frac{\frac{\partial V_{t, s^{\prime}}^{i}\left(a_{t, s^{\prime}}^{i}\right)}{\partial a}}{\frac{\partial V_{t, s}^{i}\left(a_{t, s}^{i}\right)}{\partial a}}=\frac{1 / a_{t, s^{\prime}}^{i}}{1 / a_{t, s}^{i}},
$$

which is Eq. (32) in the main text. This completes the characterization of the optimality conditions.

\section{B.1.2 Partial characterization of equilibrium}

Proof of Lemma 1. Provided in the main text.

Proof of Lemmas 2 and 3. We prove the two lemmas together since they follow from similar steps. To characterize positions on the market portfolio, note that Eqs. (32) and (31) imply,

$$
\omega_{t, s}^{m, i} \sigma_{t, s}^{m}=\frac{1}{\sigma_{t, s}^{m}}\left(r_{t, s}^{m}-r_{t, s}^{f}+p_{t, s}^{s^{\prime}} \frac{Q_{t, s^{\prime}}-Q_{t, s}}{Q_{t, s}}\right)
$$

This implies $\omega_{t, s}^{m, i}=\omega_{t, s}^{m}$. Combining this observation with Eq. (16), we obtain $\omega_{t, s}^{m, i}=1$. This proves Eq. (28).

To characterize the positions on the contingent security, first consider how type $i$ investors' wealth share changes after a state transition. By definition, we have

$$
a_{t, s}^{i}=\alpha_{t, s}^{i} Q_{t, s} k_{t, s}
$$

After plugging this into Eq. (32), and using $k_{t, s}=k_{t, s^{\prime}}$ (since capital does not jump), we obtain Eq. (33):

$$
\alpha_{t, s^{\prime}}^{i}=\alpha_{t, s}^{i} \lambda_{s}^{i} \frac{1}{\kappa_{t, s}} \text { where } \kappa_{t, s}=p_{t, s}^{s^{\prime}} \frac{Q_{t, s^{\prime}}}{Q_{t, s}} .
$$

Aggregating this expression across all investors, and using $\sum_{i} \alpha_{t, s^{\prime}}^{i}=1$, we obtain $\kappa_{t, s}=\bar{\lambda}_{t, s}$, where $\bar{\lambda}_{t, s}$ denotes the wealth-weighted average belief defined in (27). Substituting this back into Eq. (33), we obtain

$$
\alpha_{t, s^{\prime}}^{i}=\frac{\alpha_{t, s}^{i} \lambda_{s}^{i}}{\bar{\lambda}_{t, s}}
$$

This proves the second line of Eq. (30).

Combining $\kappa_{t, s}=\bar{\lambda}_{t, s}$ with the definition of $\kappa_{t, s}$ in Eq. (33), we obtain an expression for the price of the contingent security,

$$
p_{t, s}^{s^{\prime}}=\bar{\lambda}_{t, s} \frac{1 / Q_{t, s^{\prime}}}{1 / Q_{t, s}}
$$

This proves Eq. (35). Combining this with Eq. $B .3$, and substituting $\omega_{t, s}^{m, i}=1$, we obtain the risk balance condition (34). This completes the proof of Lemma 3.

Next consider the positions type $i$ investors take in the contingent security to achieve the change in their wealth share after transition. The evolution of investors' wealth in Eq. (B.1) together with $\omega_{t, s}^{m . i}=1$ implies

$$
\frac{\alpha_{t, s^{\prime}}^{i}}{\alpha_{t, s}^{i}}=1+\omega_{t, s}^{s^{\prime}} \frac{Q_{t, s}}{Q_{t, s^{\prime}}} \frac{1}{p_{t, s}^{s^{\prime}}} .
$$


Combining this with Eq. (35), we obtain $\frac{\alpha_{t, s}^{i}}{\alpha_{t, s}^{i}}=1+\frac{\omega_{t, s}^{s^{\prime}, i}}{\bar{\lambda}_{t, s}}$. Combining this with the second line of Eq. (30), we solve for type $i$ investors' equilibrium position in the contingent security

$$
\omega_{t, s}^{s^{\prime}, i}=\lambda_{s}^{i}-\bar{\lambda}_{t, s}
$$

This proves Eq. (29).

Next consider how type $i$ investors' wealth share changes absent a state transition. The evolution of investors' wealth in Eq. B.1 together with $\omega_{t, s}^{m . i}=1$ implies

$$
\frac{d a_{t, s}^{i}}{a_{t, s}^{i}}=\left(r_{t, s}^{m}-\omega_{t, s}^{s^{\prime}, i}-\frac{c_{t, s}^{i}}{a_{t, s}^{i}}\right) d t+\sigma_{t, s}^{m} d Z_{t} .
$$

Substituting for $c_{t, s}$ from Eq. 23) and $r_{t, s}^{m}, \sigma_{t, s}^{m}$ from Eqs. 222, we further obtain

$$
\frac{d a_{t, s}^{i}}{a_{t, s}^{i}}=\left(g+\mu_{t, s}^{Q}+\sigma_{s} \sigma_{t, s}^{Q}-\omega_{t, s}^{s^{\prime}, i}\right) d t+\left(\sigma_{s}+\sigma_{t, s}^{Q}\right) d Z_{t} .
$$

Note also we also have [cf. (14)]

$$
\frac{d\left(Q_{t, s} k_{t, s}\right)}{Q_{t, s} k_{t, s}}=\left(g+\mu_{t, s}^{Q}+\sigma_{s} \sigma_{t, s}^{Q}\right) d t+\left(\sigma_{s}+\sigma_{t, s}^{Q}\right) d Z_{t}
$$

Recall that $\alpha_{t, s}^{i}=a_{t, s}^{i} /\left(Q_{t, s} k_{t, s}\right)$. Thus, using the last two displayed equations together with Ito's formula for ratio, we further obtain,

$$
\frac{d \alpha_{t, s}^{i}}{\alpha_{t, s}^{i}}=-\omega_{t, s}^{s^{\prime}, i} d t=-\left(\lambda_{s}^{i}-\bar{\lambda}_{t, s}\right) d t
$$

Here, the last equality substitutes (29). This establishes the first line of Eq. (30).

It remains to prove the last part of Lemma 3. To this end, consider the same economy with the only difference that there is a single investor type (the representative investor) whose beliefs about transition probabilities are allowed to be possibly time-varying and stochastic. Consider a history in which the investor's beliefs agree with the wealth-weighted average belief, $\bar{\lambda}_{t, s}$. Then, the representative investor's portfolio optimality conditions imply that Eqs. (32) and (31) hold after replacing $\lambda_{s}^{i}$ with $\bar{\lambda}_{t, s}$. The market clearing conditions (16) imply $\omega_{t, s}^{m, i}=1$ and $a_{t, s}^{i}=Q_{t, s}$. Substituting these expressions into the portfolio optimality conditions, we obtain Eqs. (34-35). This shows that asset prices are determined as if there is a representative investor with the wealthweighted average belief and completes the proof of the lemmas.

\section{B.1.3 New Keynesian microfoundation for nominal rigidities}

The supply side of our model features nominal rigidities similar to the standard New Keynesian setting. There is a continuum of measure one of monopolistically competitive production firms denoted by $\nu$. These firms own the capital stock (in equal proportion) and produce differentiated goods, $y_{t, s}(\nu)$, subject to the technology,

$$
y_{t, s}(\nu)=A \eta_{t, s}(\nu) k_{t, s}
$$


Here, $\eta_{t, s}(\nu) \in[0,1]$ denotes the firm's choice of capital utilization. We assume utilization is free up to $\eta_{t, s}(\nu)=1$ and infinitely costly afterwards. The production firms sell their output to a competitive sector that produces the final output according to the CES technology,

$$
y_{t, s}=\left(\int_{0}^{1} y_{t, s}(\nu)^{\frac{\varepsilon-1}{\varepsilon}} d \nu\right)^{\varepsilon /(\varepsilon-1)},
$$

for some $\varepsilon>1$. Thus, the demand for the firms' goods implies,

$$
y_{t, s}(\nu) \leq p_{t, s}(\nu)^{-\varepsilon} y_{t, s}, \text { where } p_{t, s}(\nu)=P_{t, s}(\nu) / P .
$$

Here, $p_{t, s}(\nu)$ denotes the firm's relative price, which depends on its nominal price, $P_{t, s}(\nu)$, as well as the ideal nominal price index, $P_{t, s}=\left(\int P_{t, s}(\nu)^{1-\varepsilon} d \nu\right)^{1 /(1-\varepsilon)}$. We write the demand constraint as an inequality because an individual firm can in principle refuse to meet the demand for its goods.

Without price rigidities, the firm chooses $\eta_{t, s}(\nu) \in[0,1], y_{t, s}(\nu), p_{t, s}(\nu)$ to maximize its earnings, $p_{t, s}(\nu) y_{t, s}(\nu)$, subject to the supply constraint in $B .4$ and the demand constraint, (B.6). In this case, the demand constraint holds as equality (because otherwise the firm can always raise its price to keep its production unchanged and raise its earnings). By combining the constraints, the firm's problem can be written as,

$$
\max _{p_{t, s}(\nu), \eta_{t, s}(\nu)} p_{t, s}(\nu)^{1-\varepsilon} y_{t, s} \text { s.t. } 0 \leq \eta_{t, s}(\nu)=\frac{p_{t, s}(\nu)^{-\varepsilon} y_{t, s}}{A k_{t, s}} \leq 1
$$

Inspecting this problem reveals that the solution features full factor utilization, $\eta_{t, s}(\nu)=1$. This is because, when $\eta_{t, s}(\nu)<1$, the marginal cost of production is zero. Thus, the firm can always lower its price and increase its demand and production, which in turn increases its earnings. Hence, at the optimum, the firms set $\eta_{t, s}(\nu)=1$ and $y_{t, s}(\nu)=A k_{t, s}$. To produce at this level, they set the relative price level, $p_{t, s}(\nu)=\left(\frac{y_{t, s}}{A k_{t, s}}\right)^{-1 / \varepsilon}$. Since all firms are identical, we also have $p_{t, s}(\nu)=1$ and $y_{t, s}=y_{t, s}(\nu)=A k_{t, s}$. In particular, output is determined by aggregate supply at full factor utilization.

Now consider the alternative setting in which firms have a preset nominal price that is equal for all firms, $P_{t, s}(\nu)=P$. This also implies the relative price of a firm is fixed and equal to one, $p_{t, s}(\nu)=1$. The firm chooses the remaining variables, $\eta_{t, s}(\nu) \in[0,1], y_{t, s}(\nu)$, to maximize its earnings, $y_{t, s}(\nu)$, subject to the supply constraint in (B.4) and the demand constraint, (B.6). Combining the constraints and using $p_{t, s}(\nu)=1$, the firm's problem can be written as,

$$
\max _{\eta_{t, s}(\nu)} A \eta_{t, s}(\nu) k_{t, s} \text { s.t. } 0 \leq \eta_{t, s}(\nu) \leq 1 \text { and } A \eta_{t, s}(\nu) k_{t, s} \leq y_{t, s}
$$

The solution is given by, $\eta_{t, s}(\nu)=\min \left(1, \frac{y_{t, s}}{A k_{t, s}}\right)$. Intuitively, when $\eta_{t, s}(\nu)<1$ and $A \eta_{t, s}(\nu) k_{t, s}<$ $y_{t, s}$, the marginal cost of production is zero and there is some unmet demand for firms' goods. The firm optimally increases its production until the supply or the demand constraints bind. Combining this observation with the production technology for the final output, we also obtain, $y_{t, s} \leq A k_{t, s}$. This implies that the demand constraint holds as equality also in this case. In particular, we have $\eta_{t, s}(\nu)=\frac{y_{t, s}}{A k_{t, s}} \leq 1$.

In sum, when the firms' nominal prices are fixed, aggregate output is determined by aggregate demand subject to the capacity constraint, which verifies Eq. (18) in the dynamic model (and Eq. (3) in the two period model). 
Note also that, in equilibrium, firms' equilibrium earnings are equal to aggregate output, $y_{t, s}$. Since firms own the capital (and there is no rental market for capital), the division of these earnings between return to capital and monopoly profits is indeterminate. This division does not play an important role in our baseline model but it matters when we introduce investment. In Online Appendix Section $\mathrm{D}$ with endogenous investment (that we present subsequently), we use slightly different microfoundations that ensure earnings accrue to firms in the form of return to capital, i.e., there are no monopoly profits, which helps to simplify the exposition.

\section{B.2. Omitted derivations in Section IV}

Proof of Proposition 1. Provided in the main text. The predictions regarding the effect of risk premium shocks on consumption and output follow from combining the characterization with Eqs. (24) and (21).

\section{B.3. Omitted derivations in Section V}

Proof of Proposition 2, Eq. (44) follows from Lemma 2. To establish the remaining results, we use Lemma 3 that establishes the risk balance condition.

First consider the equilibrium for the high-risk-premium state, $s=2$. Applying Eq. (34) for $s=2$ and substituting $r_{t, 2}^{f}=0$ and $\sigma_{t, 2}^{Q}=0$, we obtain Eq. 477 that describes the risk balance condition for the high-risk-premium state. Combining this expression with Eq. (44), we obtain the differential equation system,

$$
\begin{aligned}
\dot{q}_{t, 2} & =-\left(\rho+g+\bar{\lambda}_{2}\left(\alpha_{t, 2}\right)\left(1-\frac{\exp \left(q_{2}\right)}{Q^{*}}\right)-\sigma_{2}^{2}\right), \\
\dot{\alpha}_{t, 2} & =-\left(\lambda_{2}^{o}-\lambda_{2}^{p}\right) \alpha_{t, 2}\left(1-\alpha_{t, 2}\right) .
\end{aligned}
$$

This system describes the joint dynamics of the price and optimists' wealth share, $\left(q_{t, 2}, \alpha_{t, 2}\right)$, conditional on there not being a transition. We next analyze the solution to this system using the phase diagram over the range $\alpha \in[0,1]$ and $q_{2} \in\left[q_{2}^{p}, q_{2}^{o}\right]$. Here, recall that $q_{2}^{i}$ corresponds to the equilibrium log price with common beliefs characterized in Section IV corresponding to type $i$ investors' belief.

First note that the system has two steady states given by, $\left(\alpha_{t, 2}=0, q_{t, 2}=q_{2}^{p}\right)$, and $\left(\alpha_{t, 2}=1, q_{t, 2}=q_{2}^{o}\right)$. Next note that the system satisfies the Lipschitz condition over the relevant range. Thus, the vector flows that describe the law of motion do not cross. Next consider the locus, $\dot{q}_{2}=0$. By comparing Eqs. (47) and (38), this locus is exactly the same as the price that would obtain if investors shared the same wealth-weighted average belief, denoted by $q_{2}=q_{2}^{h}(\alpha)$. Using our analysis in Section IV, we also find that $q_{2}^{h}(\alpha)$ is strictly increasing in $\alpha$. Moreover, $q_{2}<q_{2}^{h}(\alpha)$ implies $\dot{q}_{t, 2}<0$ whereas $q_{2}>q_{2}^{h}(\alpha)$ implies $\dot{q}_{t, 2}>0$. Finally, note that $\dot{\alpha}_{t, 2}<0$ for each $\alpha \in(0,1)$.

Combining these observations, the phase diagram has the shape in Figure B.1. This in turn implies that the system is saddle path stable. Given any $\alpha_{t, 2} \in[0,1)$, there exists a unique solution, $q_{t, 2}$, which ensures that $\lim _{t \rightarrow \infty} q_{t, 2}=q_{2}^{p}$. We define the price function (the saddle path) as $q_{2}(\alpha)$. Note that the price function satisfies $q_{2}(\alpha)<q_{2}^{h}(\alpha)$ for each $\alpha \in(0,1)$, since the saddle path cannot cross the locus, $\dot{q}_{t, 2}=0$. Note also that $q_{2}(1)=q_{2}^{o}$, since the saddle path crosses the other steady-state, $\left(\alpha_{t, 2}=1, q_{t, 2}=q_{2}^{o}\right)$. Finally, recall that $q_{2}<q_{2}^{h}(\alpha)$ implies $\dot{q}_{t, 2}<0$. Combining this with $\dot{\alpha}_{t, 2}<0$, we further obtain $\frac{d q_{2}(\alpha)}{d \alpha}>0$ for each $\alpha \in(0,1)$.

Next note that, after substituting $\dot{q}_{t, 2}=q_{2}^{\prime}(\alpha) \dot{\alpha}_{t, 2}$, Eq. (B.7) implies the differential equation 45) in $\alpha$-domain. Thus, the above analysis shows there exists a solution to the differential equation 


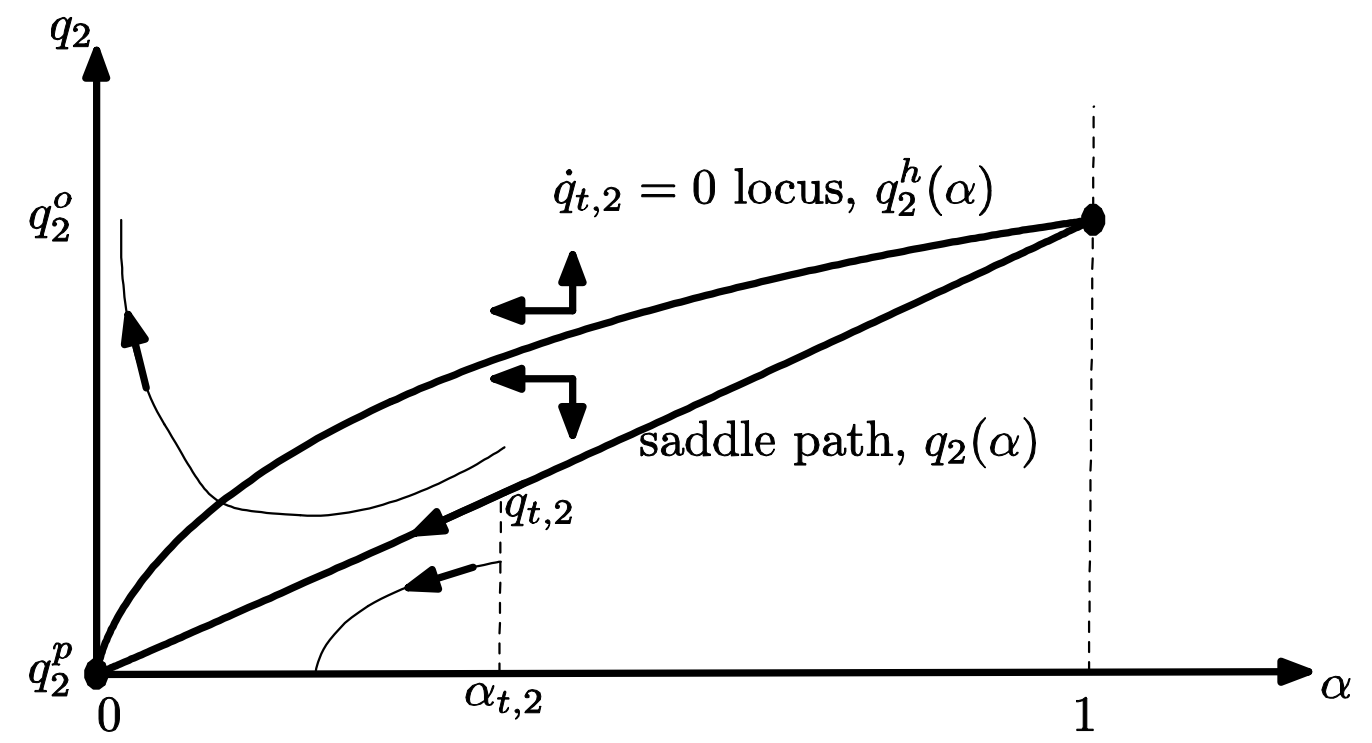

Figure B.1: The phase diagram for the equilibrium with heterogeneous beliefs.

with $q_{2}(0)=q_{2}^{p}$ and $q_{2}(1)=q_{2}^{o}$. Moreover, the solution is strictly increasing in $\alpha$, and it satisfies $q_{2}(\alpha)<q_{2}^{h}(\alpha)$ for each $\alpha \in(0,1)$. Note also that this solution is unique since the saddle path is unique. This completes the characterization of the equilibrium for the high-risk-premium state $s=2$. The claims for $c_{t, 2} / k_{t, 2}$ and $y_{t, 2} / k_{t, 2}$ follow from Eqs. (24) and (21).

Finally consider the equilibrium in the low-risk-premium state, $s=1$. In the conjectured equilibrium, we have $Q_{t, 1}=Q^{*}$, which also implies $\mu_{t, 1}^{Q}=\sigma_{t, 1}^{Q}=0$. Substituting these expressions into Eq. (34) for $s=1$, we obtain the risk balance condition for the low-risk-premium state,

$$
\sigma_{1}=\frac{1}{\sigma_{1}}\left(g+\rho-r_{t, 1}^{f}+\bar{\lambda}_{t, 1}\left(1-\frac{Q^{*}}{Q_{t, 2}}\right)\right)
$$

Writing the equilibrium variables as a function of optimists' wealth share, we obtain $r_{t, 1}^{f}=r_{1}^{f}(\alpha)$ and $\bar{\lambda}_{t, 1}=\bar{\lambda}_{1}(\alpha)$ and $Q_{t, 2}=\exp \left(q_{2}\left(\alpha^{\prime}\right)\right)$, where $\alpha^{\prime}=\alpha \lambda_{1}^{o} / \bar{\lambda}_{1}(\alpha)$ denotes optimists' wealth share after a transition [cf. Eq. 44 ]. Substituting these expressions into the risk balance condition and rearranging terms, we obtain Eq. (46) in the main text that, which we replicate here,

$$
r_{1}^{f}(\alpha)=\rho+g-\bar{\lambda}_{1}(\alpha)\left(\frac{Q^{*}}{\exp \left(q_{2}\left(\alpha^{\prime}\right)\right)}-1\right)-\sigma_{1}^{2} .
$$

Note also that $\frac{d r_{1}^{f}(\alpha)}{d \alpha}>0$ because $\bar{\lambda}_{1}(\alpha)$ is decreasing in $\alpha$ (in view of Assumption 4), and $q_{2}\left(\alpha^{\prime}\right)$ is strictly increasing in $\alpha$. The latter observation follows since $\alpha^{\prime}=\frac{\alpha \lambda_{1}^{o}}{\alpha \lambda_{1}^{o}+(1-\alpha) \lambda_{1}^{p}}$ is increasing in $\alpha$ (in view of Assumption 4$)$ and $q_{2}(\cdot)$ is a strictly increasing function. Note also that $r_{1}^{f}(\alpha)>r_{1}^{f}(0)>0$, where the latter inequality follows since Assumptions 1-3 holds for the pessimistic belief. Thus, the interest rate in state 1 is always positive, which verifies our conjecture and completes the proof of the second part of the proposition. 


\section{B.4. Details of the parameterization}

This section describes the details of the parameterization of the dynamic model that we use to numerically illustrate our findings. This parameterization is only meant to be reasonable, as its purpose is to give a sense of potential magnitudes. Throughout, we measure time in years so that the continuous-time rates we choose correspond to (approximate) yearly rates.

Since we do not explicitly model steady-state inflation (for simplicity), we interpret the growth rate in our model as $g=\tilde{g}+\pi$ where $\tilde{g}$ can be thought of as the real growth rate and $\pi \geq 0$ can be thought of as the steady-state inflation. With this adjustment, we can interpret the returns in our model as capturing the corresponding nominal returns in the data. In particular, the zero lower bound constraint in the model $(19)$ becomes a restriction on the nominal risk-free rate (as in the data). We set $\pi=2 \%$ based on the Fed's inflation target in recent decades; and $\tilde{g}=3 \%$ based on pre-recession estimates for the U.S. trend output growth, which leads to:

$$
g=5 \% .
$$

For the discount rate, we set,

$$
\rho=4 \%,
$$

based on the yearly discount rates typically assumed in the literature. This implies a first-best (nominal) return to capital given by $r^{m, *}=\rho+g=9 \%$, which is consistent with the historical estimates for the weighted-average return on stocks and housing in Jordà et al. (2019).

We set the variance in the low-risk-premium state to target the first-best nominal risk-free interest rate in the boom given by, $r_{1}^{f, *}=7 \%$ (equivalently, a real risk-free rate given by $5 \%$ ). We target a relatively high $r_{1}^{f, *}$ because this is the highest level of interest rate that can be observed in our environment - the actual interest rate in the boom will be lower. Using (36), this leads to:

$$
\sigma_{1}^{2}=2 \%
$$

We set the variance in the high-risk-premium state to target a first-best interest rate is only slightly negative, $r_{2}^{f, *}=-1 \%$, which leads to:

$$
\sigma_{2}^{2}=10 \%
$$

These choices (together with the choices of $\rho$ and $g$ ) ensure that Assumption 1 holds. For the productivity level, we set $A=1$. This does not play a role as it scales all variables.

It remains to set investors' beliefs for transition probabilities, $\left(\lambda_{s}^{i}\right)_{s \in\{1,2\}, i \in\{o, p\}}$. We set:

$$
\begin{aligned}
& \lambda_{1}^{o}=1 / 25 \text { and } \lambda_{2}^{o}=1 / 5 \\
& \lambda_{1}^{p}=1 / 5 \text { and } \lambda_{2}^{p}=1 / 25
\end{aligned}
$$

Hence, optimists think a low-risk-premium episode lasts on average 25 years whereas pessimists think it lasts for only 5 years (and vice versa for the high-risk-premium episode). 


\section{Omitted derivations for the welfare analysis}

This section presents the omitted derivations and proofs for the welfare analysis of the dynamic model that we present in Section VI. Section C.1 establishes the properties of the equilibrium value functions that are used in the main text. Section C.2 describes the details of the equilibrium with macroprudential policy, presents the analyses omitted from the main text (e.g., macroprudential policy in the high-risk-premium state), and presents omitted proofs. Throughout, we focus on the equilibrium characterized in Proposition 2. In particular, the price per unit of capital follows deterministic dynamics absent state transitions, $\sigma_{t, s}^{Q}=0$.

\section{C.1. Value functions in equilibrium}

We first derive the HJB equation that describes the normalized value function in equilibrium and derive Eqs. (49) and (51). We then derive the differential equations in $\alpha$-domain that characterize the value function and its components. In particular, we derive Eq. (52). We then prove Lemmas 4 and 5 that are used in the analysis.

Characterizing the normalized value function in equilibrium. Recall that the value function has the functional form in Eq. (48). Our goal is to characterize the value function per unit of capital, $v_{t, s}^{i}$ (corresponding to $a_{t, s}^{i}=Q_{t, s}$ ). To facilitate the analysis, we define,

$$
\xi_{t, s}^{i}=v_{t, s}^{i}-\frac{\log Q_{t, s}}{\rho} .
$$

Note that $\xi_{t, s}^{i}$ is the value function per unit wealth (corresponding to $a_{t, s}^{i}=1$ ), and that the value function also satisfies $V_{t, s}^{i}\left(a_{t, s}^{i}\right)=\frac{\log \left(a_{t, s}^{i}\right)}{\rho}+\xi_{t, s}^{i}$. We first characterize $\xi_{t, s}^{i}$. We then combine this with Eq. (C.1) to characterize our main object of interest, $v_{t, s}^{i}$.

Consider the recursive version of the portfolio problem in B.2. We substitute the optimal consumption rule from Eq. (23), the contingent allocation rule from Eq. (32), and $a_{t, s}^{i}=1$ (to characterize the value per unit wealth) to obtain,

$$
\begin{aligned}
\rho \xi_{t, s}^{i} & =\log \rho+\frac{1}{\rho}\left(r_{t, s}^{f}+\omega_{t, s}^{m, i}\left(r_{t, s}^{m}-r_{t, s}^{f}\right)-\frac{1}{2}\left(\omega_{t, s}^{m, i}\right)^{2} \sigma_{s}^{2}-\rho-\omega_{t, s}^{s^{\prime}, i}\right) \\
& +\frac{\partial \xi_{t, s}^{i}}{\partial t}+\lambda_{s}^{i}\left(\frac{1}{\rho} \log \left(\frac{\lambda_{s}^{i}}{p_{t, s}^{s^{\prime}}}\right)+\xi_{t, s^{\prime}}^{i}-\xi_{t, s}^{i}\right) .
\end{aligned}
$$

From Lemma 2, the optimal investment in the market portfolio and contingent securities satisfies, $\omega_{t, s}^{m, i}=1$ and $\omega_{t, s}^{s^{\prime}, i}=\lambda_{s}^{i}-\bar{\lambda}_{t, s}$, and the price of the contingent security is given by, $p_{t, s}^{s^{\prime}}=\bar{\lambda}_{t, s} \frac{1 / Q_{t, s^{\prime}}}{1 / Q_{t, s}}$. Here, $\bar{\lambda}_{t, s}$ denotes the weighted average belief defined in 43 . Using these conditions, the HJB equation becomes,

$$
\begin{aligned}
\rho \xi_{t, s}^{i} & =\log \rho+\frac{1}{\rho}\left(\begin{array}{c}
r_{t, s}^{m}-\rho-\frac{1}{2} \sigma_{s}^{2} \\
-\left(\lambda_{s}^{i}-\bar{\lambda}_{t, s}\right)+\lambda_{s}^{i} \log \left(\frac{\lambda_{s}^{i}}{\bar{\lambda}_{t, s}}\right)
\end{array}\right) \\
& +\frac{\partial \xi_{t, s}^{i}}{\partial t}+\lambda_{s}^{i}\left(\frac{1}{\rho} \log \left(\frac{Q_{t, s^{\prime}}}{Q_{t, s}}\right)+\xi_{t, s^{\prime}}^{i}-\xi_{t, s}^{i}\right)
\end{aligned}
$$


After substituting the return to the market portfolio from $(22)$, and using $\sigma_{t, s}^{Q}=0$, the HJB equation can be further simplified as,

$$
\rho \xi_{t, s}^{i}=\begin{gathered}
\log \rho+\frac{1}{\rho}\left(\begin{array}{c}
g+\mu_{t, s}^{Q}-\frac{1}{2} \sigma_{s}^{2} \\
-\left(\lambda_{s}^{i}-\bar{\lambda}_{t, s}\right)+\lambda_{s}^{i} \log \left(\frac{\lambda_{s}^{i}}{\bar{\lambda}_{t, s}}\right)
\end{array}\right) \\
+\frac{\partial \xi_{t, s}^{i}}{\partial t}+\lambda_{s}^{i}\left(\frac{1}{\rho} \log \left(\frac{Q_{t, s^{\prime}}}{Q_{t, s}}\right)+\xi_{t, s^{\prime}}^{i}-\xi_{t, s}^{i}\right)
\end{gathered} .
$$

Here, the term inside the summation on the second line, $-\left(\lambda_{s}^{i}-\bar{\lambda}_{t, s}\right)+\lambda_{s}^{i} \log \left(\frac{\lambda_{s}^{i}}{\bar{\lambda}_{t, s}}\right)$, is zero when there are no disagreements, and it is strictly positive when there are disagreements. This illustrates that speculation increases the expected value for optimists as well as pessimists.

We finally substitute $v_{t, s}^{i}=\xi_{t, s}^{i}+\frac{\log Q_{t, s}}{\rho}$ (cf. C.1) into the HJB equation to obtain the differential equation,

$$
\rho v_{t, s}^{i}=\begin{gathered}
\log \rho+\log \left(Q_{t, s}\right)+\frac{1}{\rho}\left(\begin{array}{c}
g-\frac{1}{2} \sigma_{s}^{2} \\
-\left(\lambda_{s}^{i}-\bar{\lambda}_{t, s}\right)+\lambda_{s}^{i} \log \left(\frac{\lambda_{s}^{i}}{\bar{\lambda}_{t, s}}\right)
\end{array}\right) . \\
+\frac{\partial v_{t, s}^{i}}{\partial t}+\lambda_{s}^{i}\left(v_{t, s^{\prime}}-v_{t, s}\right)
\end{gathered}
$$

Here, we have canceled terms by using the observation that

$$
\frac{\partial \xi_{t, s}^{i}}{\partial t}=\frac{\partial v_{t, s}^{i}}{\partial t}-\frac{1}{\rho} \frac{\partial \log Q_{t, s}}{\partial t}=\frac{\partial v_{t, s}^{i}}{\partial t}-\frac{1}{\rho} \mu_{t, s}^{Q}
$$

The last step also uses $\sigma_{t, s}^{Q}=0$.

We have thus obtained Eq. 49 in the main text. Note also that $v_{t, s}^{i, *}$ solves the same differential equation after substituting $Q_{t, s}=Q^{*}$. Taking the difference of these differential equations, and using $w_{t, s}=v_{t, s}^{i}-v_{t, s}^{i, *}$, we obtain Eq. (51).

Differential equations for the value functions in $\alpha$-domain. We next write the value function and its components, $\left\{v_{t, s}^{i}, v_{t, s}^{i, *}, w_{t, s}\right\}_{s, i}$, as functions of optimists' wealth share, $\left\{v_{s}^{i}(\alpha), v_{s}^{i, *}(\alpha), w_{s}(\alpha)\right\}_{s, i}$. We will characterize these functions as solutions to appropriate differential equations in the $\alpha$-domain.

Recall that the price level in each state can be written as a function of optimists' wealth shares, $q_{t, s}=q_{s}(\alpha)$ (where we also have, $q_{1}(\alpha)=q^{*}$ ). Plugging in these price functions, and using the dynamics of $\alpha_{t, s}$ from Eq. 44), the HJB equation (49) can be written as,

$$
\rho v_{s}^{i}(\alpha)=\begin{gathered}
\log \rho+q_{s}(\alpha)+\frac{1}{\rho}\left(\begin{array}{c}
g-\frac{1}{2} \sigma_{s}^{2} \\
\left.-\left(\lambda_{s}^{i}-\bar{\lambda}_{s}(\alpha)\right)+\lambda_{s}^{i} \log \left(\frac{\lambda_{s}^{i}}{\bar{\lambda}_{s}(\alpha)}\right)\right)
\end{array}\right) . \\
-\frac{\partial v_{s}^{i}}{\partial \alpha}\left(\lambda_{s}^{o}-\lambda_{s}^{p}\right) \alpha(1-\alpha)+\lambda_{s}^{i}\left(v_{s^{\prime}}^{i}\left(\alpha \frac{\lambda_{s}^{o}}{\bar{\lambda}_{s}(\alpha)}\right)-v_{s}^{i}(\alpha)\right)
\end{gathered}
$$

For each $i \in\{o, p\}$, the value functions, $\left(v_{s}^{i}(\alpha)\right)_{s \in\{1,2\}}$, are found by solving this system of ODEs. For $i=o$, the boundary conditions are that the values, $\left\{v_{s}^{o}(1)\right\}_{s}$, are the same as the values in the common belief benchmark characterized in Section [V] when all investors have the optimistic beliefs. For $i=p$, the boundary conditions are that the values, $\left\{v_{s}^{p}(0)\right\}_{s}$, are the same as the values 
in the common belief benchmark when all investors have the pessimistic beliefs.

Likewise, the first-best value functions, $\left(v_{s}^{i, *}(\alpha)\right)_{s \in\{1,2\}}$, are found by solving the analogous system after replacing $q_{s}(\alpha)$ with $q^{*}$ (and changing the boundary conditions appropriately). Finally, substituting the price functions into Eq. (51), the gap-value functions, $\left(w_{s}^{i}(\alpha)\right)_{s, i}$, are found by solving the system in 52 .

For the proofs in this section (as well as in some subsequent sections), we find it useful to work with the transformed state variable,

$$
b_{t, s} \equiv \log \left(\frac{\alpha_{t, s}}{1-\alpha_{t, s}}\right), \text { which implies } \alpha_{t, s}=\frac{1}{1+\exp \left(-b_{t, s}\right)} .
$$

The variable, $b_{t, s}$, varies between $(-\infty, \infty)$ and provides a different measure of optimism, which we refer to as "bullishness." Note that there is a one-to-one relation between optimists' wealth share, $\alpha_{t, s} \in(0,1)$, and the bullishness, $b_{t, s} \in \mathbb{R}=(-\infty,+\infty)$. Optimists' wealth dynamics in (44) become particularly simple when expressed in terms of bullishness,

$$
\left\{\begin{array}{cc}
\dot{b}_{t, s}=-\left(\lambda_{s}^{o}-\lambda_{s}^{p}\right), & \text { if there is no state change, } \\
b_{t, s^{\prime}}=b_{t, s}+\log \lambda_{s}^{o}-\log \lambda_{s}^{p}, & \text { if there is a state change. }
\end{array}\right.
$$

With a slight abuse of notation, we also let $q_{2}(b), w_{s}^{i}(b)$, and so on, denote the equilibrium functions in terms of bullishness. Note also that, since $\frac{d b}{d \alpha}=\frac{1}{\alpha(1-\alpha)}$, we have the identities,

$$
\frac{\partial q_{2}(b)}{\partial b}=\alpha(1-\alpha) \frac{\partial q_{2}(\alpha)}{\partial b} \text { and } \frac{\partial w_{s}^{i}(b)}{\partial b}=\alpha(1-\alpha) \frac{\partial w_{s}^{i}(\alpha)}{\partial \alpha} .
$$

Using this observation, the differential equation for the price function, Eq. (45), can be written in terms of bullishness as,

$$
\frac{\partial q_{2}(b)}{\partial b}\left(\lambda_{2}^{o}-\lambda_{2}^{p}\right)=\rho+g+\bar{\lambda}_{2}(\alpha)\left(1-\frac{Q_{2}}{Q^{*}}\right)-\sigma_{2}^{2}
$$

Likewise, the differential equation for the gap value function, Eq. (52), can be written in terms of bullishness as,

$$
\rho w_{s}^{i}(b)=q_{s}(b)-q^{*}-\left(\lambda_{s}^{o}-\lambda_{s}^{p}\right) \frac{\partial w_{s}^{i}(b)}{\partial b}+\lambda_{s}^{i}\left(w_{s^{\prime}}^{i}\left(b^{\prime}\right)-w_{s}^{i}(b)\right) .
$$

Proof of Lemma 4. To show that the gap value function is increasing, consider its representation in terms of bullishness, $w_{s}^{i}(b)$ [cf. (C.5)], which solves the system in (C.9). We will first describe this function as a fixed point of a contraction mapping. We will then use this contraction mapping to establish the properties of the function.

Recall that, in the time domain, the gap value function solves the HJB equation (51). Integrating this equation forward, we obtain,

$$
w_{s}^{i}\left(b_{0, s}\right)=\int_{0}^{\infty} e^{-\left(\rho+\lambda_{s}^{i}\right) t}\left(q_{s}\left(b_{t, s}\right)-q^{*}+\lambda_{s}^{i} w_{s^{\prime}}^{i}\left(b_{t, s^{\prime}}\right)\right) d t
$$


for each $s \in\{1,2\}$ and $b_{0, s} \in \mathbb{R}$. Here, $b_{t, s}$ denotes bullishness conditional on there not being a transition before time $t$, whereas $b_{t, s^{\prime}}$ denotes the bullishness if there is a transition at time $t$. Solving Eq. (C.6) (given beliefs, $\lambda^{i}$ ) we further obtain,

$$
\begin{aligned}
b_{t, s} & =b_{0, s}-t\left(\lambda_{s}^{o}-\lambda_{s}^{p}\right), \\
b_{t, s^{\prime}} & =b_{0, s}-t\left(\lambda_{s}^{o}-\lambda_{s}^{p}\right)+\log \lambda_{s}^{o}-\log \lambda_{s}^{p} .
\end{aligned}
$$

Hence, Eq. C.10 describes the value function as a solution to an integral equation given the closed form solution for bullishness in (C.11).

Implicitly differentiating the integral equation $C .10$ with respect to $b_{0, s}$, and using Eq. (C.11), we also obtain,

$$
\frac{\partial w_{s}^{i}\left(b_{0, s}\right)}{\partial b}=\int_{0}^{\infty} e^{-\left(\rho+\lambda_{s}^{i}\right) t}\left(\frac{\partial q_{s}\left(b_{t, s}\right)}{\partial b}+\lambda_{s}^{i} \frac{\partial w_{s^{\prime}}^{i}\left(b_{t, s^{\prime}}\right)}{\partial b}\right) d t .
$$

We next let $B\left(\mathbb{R}^{2}\right)$ denote the set of bounded value functions over $\mathbb{R}^{2}$. Given some continuation value function, $\left(\frac{\partial \tilde{w}_{s}^{i}(b)}{\partial b}\right)_{s} \in B\left(\mathbb{R}^{2}\right)$, we define the function, $\left(T \frac{\partial \tilde{w}_{s}^{i}(b)}{\partial b}\right)_{s} \in B\left(\mathbb{R}^{2}\right)$, so that

$$
T \frac{\partial \tilde{w}_{s}^{i}\left(b_{0, s}\right)}{\partial b}=\int_{0}^{\infty} e^{-\left(\rho+\lambda_{s}^{i}\right) t}\left(\frac{\partial q_{s}\left(b_{t, s}\right)}{\partial b}+\lambda_{s}^{i} \frac{\partial \tilde{w}_{s^{\prime}}^{i}\left(b_{t, s^{\prime}}\right)}{\partial b}\right) d t
$$

for each $s$ and $b_{0, s} \in \mathbb{R}$. Note also that the resulting value functions are bounded since the derivative of the price functions, $\left(\frac{\partial q_{s}\left(b_{t, s}\right)}{\partial b}\right)_{s}$, are bounded (see Eq. (C.8)). Thus, Eq. (C.12) describes the derivative functions, $\left(\frac{\partial w_{s}^{i}\left(b_{0, s}\right)}{\partial b}\right)_{s}$, as a fixed point of a corresponding operator $T$ over bounded functions. It can be checked that this operator is a contraction mapping with respect to the sup norm. Thus, it has a unique fixed point that corresponds to the derivative functions. Moreover, since $\frac{\partial q_{s}\left(b_{t, s}\right)}{\partial b}>0$ for each $b$, and $\lambda_{s}^{i}>0$ for each $s$, it can further be seen that the fixed point satisfies, $\frac{\partial w_{s}^{i}\left(b_{0, s}\right)}{\partial b}>0$ for each $b$ and $s \in\{1,2\}$. Using Eq. (C.7), we also obtain $\frac{\partial w_{s}^{i}(\alpha)}{\partial \alpha}>0$ for each $\alpha \in(0,1)$ and $s \in\{1,2\}$, completing the proof.

Proof of Lemma 5. Consider the analysis in Lemma 4 for the special case, $\lambda_{1}^{o}=\lambda_{1}^{p}$. Applying Eq. C.12 for $s=1$, we obtain [since $q_{1}\left(b_{t, s}\right)=q^{*}$ is constant],

$$
\frac{\partial w_{1}^{i}\left(b_{0,1}\right)}{\partial b}=\int_{0}^{\infty} e^{-\left(\rho+\lambda_{1}^{i}\right) t} \lambda_{1}^{i} \frac{\partial w_{2}^{i}\left(b_{t, 2}\right)}{\partial b} d t .
$$

Note also that $\lambda_{1}^{o}=\lambda_{1}^{p}$ and Eq. (C.11) imply $b_{t, 2}=b_{0,1}$ (since there is no speculation). Substituting this into the displayed equation, we obtain $\frac{\partial w_{1}^{i}\left(b_{0,1}\right)}{\partial b}=\frac{\lambda_{1}^{i}}{\rho+\lambda_{1}^{i}} \frac{\partial w_{2}^{i}\left(b_{0,1}\right)}{\partial b}<\frac{\partial w_{2}^{i}\left(b_{0,1}\right)}{\partial b}$. Combining this with Eq. C.7 completes the proof.

\section{C.2. Equilibrium with macroprudential policy}

Recall that macroprudential policy induces optimists to choose allocations as if they have more pessimistic beliefs, $\lambda^{o, p l} \equiv\left(\lambda_{1}^{o, p l}, \lambda_{2}^{o, p l}\right)$, that satisfy, $\lambda_{1}^{o, p l} \geq \lambda_{1}^{o}$ and $\lambda_{2}^{o, p l} \leq \lambda_{2}^{o}$. We next show that this allocation can be implemented with portfolio restrictions on optimists. We then show that the planner's Pareto problem reduces to solving problem (55) in the main text. We also 
derive the equilibrium value functions that result from macroprudential policy. We then analyze macroprudential policy in the recession state, which complements the analysis in the main text (that focuses on the boom state), and present Proposition 4. Finally, we present the proofs of Propositions 3 and 4 .

Implementing the policy with risk limits. Consider the equilibrium that would obtain if optimists had the planner-induced beliefs, $\lambda_{s}^{o, p l}$. Using Lemma 2, optimists' equilibrium portfolios are given by

$$
\omega_{t, s}^{m, o, p l}=1 \text { and } \omega_{t, s}^{s^{\prime}, o, p l}=\left(\lambda_{s}^{o, p l}-\lambda_{s}^{p}\right)\left(1-\alpha_{t, s}\right) .
$$

We first show that the planner can implement the policy by requiring optimists to hold exactly these portfolio weights. We will then relax these portfolio constraints into inequality restrictions (see Eq. (C.15)).

Formally, an optimist solves the HJB problem $B .2$ with the additional constraint $(C .13)$. In view of $\log$ utility, we conjecture that the value function has the same functional form (48) with potentially different normalized values, $\xi_{t, s}^{o}, v_{t, s}^{o}$, that reflect the constraints. Using this functional form, the optimality condition for consumption remains unchanged, $c_{t, s}=\rho a_{t, s}^{o}$ [cf. Eq. (23)]. Plugging this equation and the portfolio holdings in $C .13$ into the objective function in $(B .2)$ verifies that the value function has the conjectured functional form. For later reference, we also obtain that the optimists' unit-wealth value function satisfies [cf. Eq. [C.1]],

$$
\begin{aligned}
\xi_{t, s}^{o}= & \log \rho+\frac{1}{\rho}\left(r_{t, s}^{f}+\omega_{t, s}^{m, o, p l}\left(r_{t, s}^{m}-r_{t, s}^{f}\right)-\rho-\omega_{t, s}^{s^{\prime}, o, p l}\right) \\
& -\frac{1}{2 \rho}\left(\omega_{t, s}^{m, o, p l} \sigma_{s}\right)^{2}+\frac{\partial \xi_{t, s}^{o}}{\partial t}+\lambda_{s}^{o}\left(\frac{1}{\rho} \log \left(\frac{a_{t, s^{\prime}}^{o}}{a_{t, s}^{o}}\right)+\xi_{t, s^{\prime}}^{o}-\xi_{t, s}^{o}\right) .
\end{aligned}
$$

Here, $\frac{a_{t, s^{\prime}}^{o}}{a_{t, s}^{o}}=1+\omega_{t, s}^{m, o, p l} \frac{Q_{t, s^{\prime}}-Q_{t, s}}{Q_{t, s}}+\frac{\omega_{t, s}^{s^{\prime}, o, p l}}{p_{t, s}^{s^{\prime}}}$ in view of the budget constraints $B .1$. Hence, the value function has a similar characterization as before [cf. Eq. (C.2)] with the difference that optimists' portfolio holdings reflect the portfolio constraints.

Since pessimists are unconstrained, their optimality conditions are unchanged. It follows that the equilibrium takes the form in Section $\mathrm{V}$ with the difference that investors' beliefs are replaced by their as-if beliefs, $\lambda_{s}^{i, p l}$. This verifies that the planner can implement the policy using the portfolio restrictions in $C .13$. We next show that these restrictions can be relaxed to the following inequality constraints,

$$
\begin{aligned}
\omega_{t, s}^{m, o, p l} & \leq 1 \text { for each } s \\
\omega_{t, 1}^{2, o, p l} & \geq \underline{\omega}_{t, 1}^{2, o} \equiv \lambda_{1}^{o, p l}-\bar{\lambda}_{t, 1}^{p l} \text { and } \omega_{t, 2}^{1, o, p l} \leq \bar{\omega}_{t, 2}^{1, o} \equiv \lambda_{2}^{o, p l}-\bar{\lambda}_{t, 2}^{p l} .
\end{aligned}
$$

In particular, we will establish that all inequality constraints bind, which implies that optimists optimally choose the portfolio weights in Eq. C.13. Thus, our earlier analysis continues to apply when optimists are subject to the more relaxed restrictions in C.15.

The result follows from the assumption that the planner-induced beliefs are more pessimistic than optimists' actual beliefs, $\lambda_{1}^{o, p l} \geq \lambda_{1}^{o}$ and $\lambda_{2}^{o, p l} \leq \lambda_{2}^{o}$. To see this formally, note that the 
optimality condition for the market portfolio is given by the following generalization of Eq. (31),

$$
\omega_{t, s}^{m, o, p l} \sigma_{t, s}^{m} \leq \frac{1}{\sigma_{t, s}^{m}}\left(r_{t, s}^{m}-r_{t, s}^{f}+\lambda_{s}^{o} \frac{a_{t, s}^{o}}{a_{t, s^{\prime}}^{o}} \frac{Q_{t, s^{\prime}}-Q_{t, s}}{Q_{t, s}}\right) \text { and } \omega_{t, s}^{m, o, p l} \leq 1,
$$

with complementary slackness. We claim that this holds with $\omega_{t, s}^{m, o, p l}=1$.

To see this, first note that,

$$
\lambda_{s}^{o} \frac{a_{t, s}^{o}}{a_{t, s^{\prime}}^{o}} \frac{Q_{t, s^{\prime}}-Q_{t, s}}{Q_{t, s}}=\lambda_{s}^{o} \frac{\bar{\lambda}_{t, s}^{p l}}{\lambda_{s}^{o, p l}} \frac{Q_{t, s^{\prime}}-Q_{t, s}}{Q_{t, s^{\prime}}} \geq \bar{\lambda}_{t, s}^{p l} \frac{Q_{t, s^{\prime}}-Q_{t, s}}{Q_{t, s^{\prime}}} .
$$

Here, the equality follows because optimists' wealth share dynamics are determined by as-if beliefs, that is, $\frac{a_{t, s^{\prime}}^{o}}{a_{t, s}^{o}}=\frac{\lambda_{s}^{o, p l}}{\bar{\lambda}_{t, s}^{p l}} \frac{Q_{t, s^{\prime}}}{Q_{t, s}}[\mathrm{cf}$. Eq. 444] ]. The inequality follows by considering separately the two cases, $s \in\{1,2\}$. For $s=2$, the inequality holds since $Q_{t, s^{\prime}}-Q_{t, s}>0$ and the beliefs satisfy, $\lambda_{s}^{o} \geq \lambda_{s}^{o, p l}$. For $s=1$, the inequality holds since $Q_{t, s^{\prime}}-Q_{t, s}<0$ and the beliefs satisfy, $\lambda_{s}^{o, p l} \geq \lambda_{s}^{o}$. Note also that in equilibrium the return to the market portfolio satisfies the risk balance condition (34) with as-if beliefs,

$$
\sigma_{t, s}^{m}=\frac{1}{\sigma_{t, s}^{m}}\left(r_{t, s}^{m}-r_{t, s}^{f}+\bar{\lambda}_{t, s}^{p l}\left(1-\frac{Q_{t, s}}{Q_{t, s^{\prime}}}\right)\right) \text {. }
$$

Combining these expressions implies, $\sigma_{t, s}^{m} \leq \frac{1}{\sigma_{t, s}^{m}}\left(r_{t, s}^{m}-r_{t, s}^{f}+\lambda_{s}^{o} \frac{a_{t, s}^{o}}{a_{t, s^{\prime}}^{o}} \frac{Q_{t, s^{\prime}}-Q_{t, s}}{Q_{t, s}}\right)$. This in turn implies the optimality condition $C .16$ is satisfied with $\omega_{t, s}^{m, o, p l}=1$, proving the claim.

A similar analysis shows that optimists also choose the corner allocations in contingent securities, $\omega_{t, 1}^{2, o, p l}=\underline{\omega}_{t, 1}^{2, o}$ and $\omega_{t, 2}^{1, o, p l}=\bar{\omega}_{t, 2}^{1, o}$, verifying that the portfolio constraints $C .13$ can be relaxed to the inequality constraints in (C.15).

Simplifying the planner's problem. Recall that, to trace the Pareto frontier, we allow the planner to do a one-time wealth transfer among the investors at time 0. Let $V_{t, s}^{i}\left(a_{t, s}^{i} \mid\left\{\lambda_{t}^{o, p l}\right\}\right)$ denote type $i$ investors' expected value in equilibrium when she starts with wealth $a_{t, s}^{i}$ and the planner commits to implement the policy, $\left\{\lambda_{t}^{o, p l}\right\}$. Then, the planner's Pareto problem can be written as,

$$
\max _{\tilde{\lambda}^{o, p l}, \tilde{\alpha}_{0, s}} \gamma^{o} V_{0, s}^{o}\left(\tilde{\alpha}_{0, s} Q_{0, s} k_{0, s} \mid \tilde{\lambda}^{o, p l}\right)+\gamma^{p} V_{0, s}^{p}\left(\left(1-\tilde{\alpha}_{0, s}\right) Q_{0, s} k_{0, s} \mid \tilde{\lambda}^{o, p l}\right)
$$

Here, $\gamma^{o}, \gamma^{p} \geq 0$ (with at least one strict inequality) denote the Pareto weights, and $Q_{0, s}$ denotes the endogenous equilibrium price that obtains under the planner's policy.

Next recall that the investors' value function with macroprudential policy has the same functional form in (48) (with potentially different $\xi_{t, s}^{o}, v_{t, s}^{o}$ for optimists that reflect the constraints). After substituting $a_{t, s}^{i}=\alpha_{t, s}^{i} k_{t, s} Q_{t, s}$, the functional form implies,

$$
V_{t, s}^{i}=v_{t, s}^{i}+\frac{\log \left(\alpha_{t, s}^{i}\right)+\log \left(k_{t, s}\right)}{\rho} .
$$


Using this expression, the planner's problem C.17 can be rewritten as,

$$
\max _{\tilde{\lambda}^{o, p l}, \tilde{\alpha}_{0, s}}\left(\gamma^{o} v_{0, s}^{o}+\gamma^{p} v_{0, s}^{p}\right)+\frac{\gamma^{o} \log \left(\tilde{\alpha}_{0, s}^{o}\right)+\gamma^{p} \log \left(1-\tilde{\alpha}_{0, s}^{o}\right)}{\rho}+\frac{\left(\gamma^{o}+\gamma^{p}\right) \log \left(k_{0, s}\right)}{\rho} .
$$

Here, the last term (that features capital) is a constant that doesn't affect optimization. The second term links the planner's choice of wealth redistribution, $\alpha_{0, s}^{o}, \alpha_{0, s}^{p}$, to her Pareto weights, $\gamma^{o}, \gamma^{p}$. Specifically, the first order condition with respect to optimists' wealth share implies $\frac{\gamma^{o}}{\gamma^{p}}=\frac{\alpha_{0, s}}{1-\alpha_{0, s}}$. Thus, the planner effectively maximizes the first term after substituting $\gamma^{o}$ and $\gamma^{p}$ respectively with the optimal choice of $\alpha_{0, s}$ and $1-\alpha_{0, s}$. This leads to the simplified problem (55) in the main text.

Characterizing the value functions with macroprudential policy. We first show that the normalized value functions, $v_{t, s}^{i}$, are characterized as the solution to the following differential equation system,

$$
\rho v_{t, s}^{i}-\frac{\partial v_{t, s}^{i}}{\partial t}=\log \rho+q_{t, s}+\frac{1}{\rho}\left(\begin{array}{c}
g-\frac{1}{2} \sigma_{s}^{2} \\
-\left(\lambda_{s}^{i, p l}-\bar{\lambda}_{t, s}^{p l}\right)+\lambda_{s}^{i} \log \left(\frac{\lambda_{s}^{i, p l}}{\bar{\lambda}_{t, s}^{p l}}\right)
\end{array}\right)+\lambda_{s}^{i}\left(v_{t, s^{\prime}}^{i}-v_{t, s}^{i}\right) .
$$

This is a generalization of Eq. (49) in which investors' positions are calculated according to their as-if beliefs, $\lambda_{s}^{i, p l}$, but the transition probabilities are calculated according to their actual beliefs, $\lambda_{s}^{i}$.

First consider the pessimists. Since they are unconstrained, their value function is characterized by solving the earlier equation system (C.14). In this case, equation $(C .18$ also holds since it is the same as the earlier equation.

Next consider the optimists. In this case, optimists' wealth share dynamics are determined by as-if beliefs. In particular, we have [cf. Eq. 440]

$$
\frac{a_{t, s^{\prime}}^{o}}{a_{t, s}^{o}}=\frac{\lambda_{s}^{o, p l}}{\bar{\lambda}_{t, s}^{p l}} \frac{Q_{t, s^{\prime}}}{Q_{t, s}}
$$

Plugging this expression as well as Eq. C.13 into Eq. C.14 , optimists' unit-wealth value function satisfies,

$$
\begin{aligned}
\xi_{t, s}^{o}= & \log \rho+\frac{1}{\rho}\left(\begin{array}{c}
r_{t, s}^{m}-\rho-\frac{1}{2} \sigma_{s}^{2} \\
-\left(\lambda_{s}^{o, p l}-\bar{\lambda}_{t, s}^{p l}\right)+\lambda_{s}^{o} \log \left(\frac{\lambda_{t, s}^{o, p l}}{\bar{\lambda}_{t, s}^{p l}}\right)
\end{array}\right) \\
& +\frac{\partial \xi_{t, s}^{o}}{\partial t}+\lambda_{s}^{o}\left(\frac{1}{\rho} \log \left(\frac{Q_{t, s^{\prime}}}{Q_{t, s}}\right)+\xi_{t, s^{\prime}}^{o}-\xi_{t, s}^{o}\right),
\end{aligned}
$$

This is the same as Eq. C.14 with the difference that the as-if beliefs, $\lambda_{s}^{o, p l}$, are used to calculate their positions on (and the payoffs from) the contingent securities, whereas the actual beliefs, $\lambda_{s}^{o}$, are used to calculate the transition probabilities. Using the same steps after Eq. (C.14), we also obtain (C.18) with $i=o$.

We next characterize the first-best and the gap value functions, $v_{t, s}^{i, *}$ and $w_{t, s}^{i}$, that we use in the main text. By definition, the first-best value function solves the same differential equation (C.18) 
after substituting $q_{t, s}=q^{*}$. It follows that the gap value function $w_{t, s}^{i}=v_{t, s}^{i}-v_{t, s}^{i, *}$, solves,

$$
\rho w_{t, s}^{i}-\frac{\partial w_{t, s}^{i}}{\partial t}=q_{t, s}-q^{*}+\lambda_{s}^{i}\left(w_{t, s^{\prime}}^{i}-w_{t, s}^{i}\right)
$$

which is the same as the differential equation (51) without macroprudential policy. The latter affects the path of prices, $q_{t, s}$, but it does not affect how these prices translate into gap values.

Note also that, as before, the value functions can be written as functions of optimists' wealth share, $\left\{v_{s}^{i}(\alpha), v_{s}^{i, *}(\alpha), w_{s}(\alpha)\right\}_{s, i}$. For completeness, we also characterize the differential equations that these functions satisfy in equilibrium with macroprudential policy. Combining Eq. C.18 with the dynamics of optimists' wealth share conditional on no transition, $\dot{\alpha}_{t, s}=-\left(\lambda_{s}^{o, p l}-\lambda_{s}^{p}\right) \alpha_{t, s}\left(1-\alpha_{t, s}\right)$, the value functions, $\left(v_{s}^{i}(\alpha)\right)_{s, i}$, are found by solving,

$$
\rho v_{s}^{i}(\alpha)=\left[\begin{array}{c}
\log \rho+q_{s}^{p l}(\alpha)+\frac{1}{\rho}\left(\begin{array}{c}
g-\frac{1}{2} \sigma_{s}^{2} \\
-\left(\lambda_{s}^{i, p l}-\bar{\lambda}_{t, s}^{p l}\right)+\lambda_{s}^{i} \log \left(\frac{\lambda_{s}^{i, p l}}{\bar{\lambda}_{t, s}^{p l}}\right)
\end{array}\right) \\
-\frac{\partial v_{s}^{i}}{\partial \alpha}\left(\lambda_{s}^{o, p l}-\lambda_{s}^{p}\right) \alpha(1-\alpha)+\lambda_{s}^{i}\left(v_{s^{\prime}}^{i}\left(\alpha \frac{\lambda_{s}^{o, p l}}{\bar{\lambda}_{t, s}^{p l}}\right)-v_{s}^{i}(\alpha)\right)
\end{array}\right]
$$

with appropriate boundary conditions. As in the main text, we denote the price functions with $q_{s}^{p l}(\alpha)$ to emphasize that they are determined by as-if beliefs. Likewise, the first-best value functions, $\left(v_{s}^{i, *}(\alpha)\right)_{s \in\{1,2\}}$, are found by solving the analogous system after replacing $q_{s}(\alpha)$ with $q^{*}$. Finally, combining Eq. (51) with the dynamics of optimists' wealth share, the gap-value functions, $\left(w_{s}^{i}(\alpha)\right)_{s, i}$, are found by solving Eq. (54) in the main text

Macroprudential policy in the recession state. The analysis in the main text concerns macroprudential policy in the boom state and maintains the assumption that $\lambda_{2}^{o, p l}=\lambda_{2}^{o}$. We next consider the polar opposite case in which the economy is currently in the recession state $s=2$, and the planner can apply macroprudential policy in this state, $\lambda_{2}^{o, p l} \leq \lambda_{2}^{o}$ (she can induce optimists to act as if the recovery is less likely), but not in the other state, $\lambda_{1}^{o, p l}=\lambda_{1}^{o}$. We obtain a sharp result for the special case in which optimists' wealth share is sufficiently large.

Proposition 4. Consider the equilibrium with two belief types characterized in Proposition 2. Consider the macroprudential policy in the recession state, $\lambda_{2}^{o, p l} \leq \lambda_{2}^{o}$ (and suppose $\lambda_{1}^{o, p l}=\lambda_{1}^{o}$ ). There exists a threshold, $\bar{\alpha}<1$, such that if $\alpha \in(\bar{\alpha}, 1]$, then the policy reduces the gap value according to each belief, that is,

$$
\left.\frac{\partial w_{2}^{i}(\alpha)}{\partial\left(-\lambda_{2}^{o, p l}\right)}\right|_{\lambda_{2}^{o, p l}=\lambda_{2}^{o}}<0 \text { for each } i \in\{o, p\}
$$

Thus, for $\alpha \in(\bar{\alpha}, 1]$, the policy also reduces the planner's value, $\left.\frac{\partial v_{s}^{p l}(\alpha)}{\partial\left(-\lambda_{2}^{o, p l}\right)}\right|_{\lambda_{2}^{o}}=\left.\frac{\partial w_{s}^{p l}(\alpha)}{\partial\left(-\lambda_{2}^{o, p l}\right)}\right|_{\lambda_{2}^{o}}<0$.

Thus, in contrast to Proposition 3, macroprudential policy in the recession state can actually reduce the gap value (and therefore also the social welfare). The intuition can be understood by considering two counteracting forces. First, as before, macroprudential policy in the recession state 

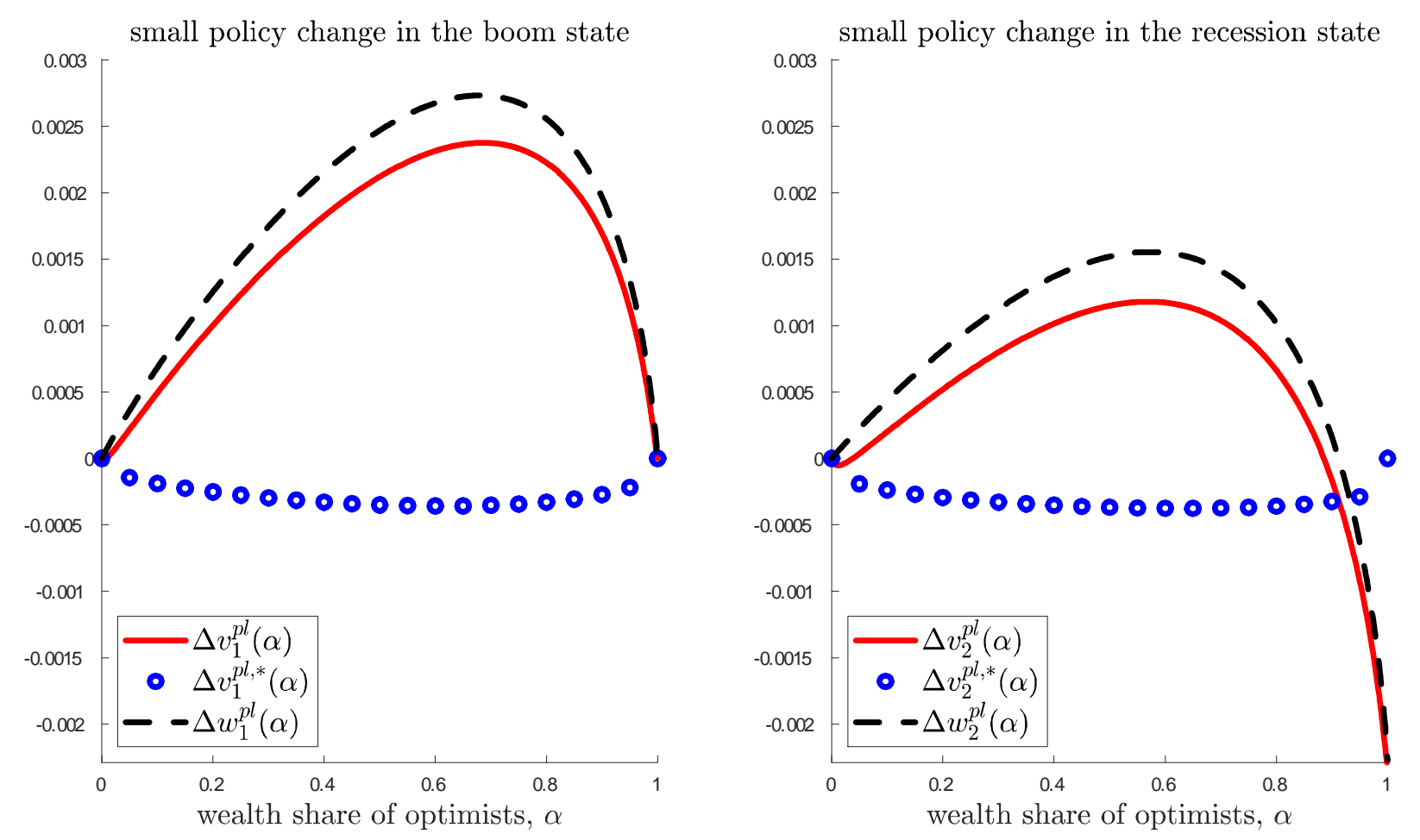

Figure C.1: Welfare effect of macroprudential policy in either the boom or the recession state. The left (resp. the right) panel illustrates the change in the planner's total value function and its components in response to a small change in macroprudential policy in the boom (resp. the recession) state.

is potentially valuable by reallocating optimists' wealth from the boom state $s=1$ to the recession state $s=2$. Intuitively, optimists purchase too many upside contingent securities that pay if there is a transition to the boom state but that impoverish them in case the recession persists. They do not internalize that, if they keep their wealth, they will improve asset prices if the recession lasts longer.

However, there is a second force that does not have a counterpart in the boom state: Macroprudential policy in the recession state also affects the current asset price level, with potential implications for gap value. It can be seen that making optimists less optimistic in the recession state shifts the price function downward, $\frac{\partial q_{2}^{p l}(\alpha)}{\partial\left(-\lambda_{2}^{o, p l}\right)}<0$ (as in the common-belief benchmark we analyzed in Section IV]. Hence, the price impact of macroprudential policy reduces the gap value. Moreover, as optimists dominate the economy, $\alpha \rightarrow 1$, the price impact of the policy is still first order, whereas the beneficial effect from reshuffling optimists' wealth is second order. Thus, when optimists' wealth share is sufficiently large, the net effect of macroprudential policy on the gap value is negative.

This analysis also suggests that, even when the policy in the recession state exerts a net positive effect, it would typically increase the gap value by a smaller amount than a comparable policy in the boom state. Figure C.1 confirms this intuition. The left panel plots the change in the planner's gap value function in the boom state resulting from a small macroprudential policy change. Note that the policy slightly reduces the planner's first-best value function but increases the gap value function. The right panel illustrates the effect of the macroprudential policy in the recession state that would generate a similar distortion in the first-best equilibrium as the policy in the boom 
state ${ }^{27}$ Note that a small macroprudential policy in the recession state has a smaller positive impact on the gap value when optimists' wealth share is small, and it has a negative impact when optimists' wealth share is sufficiently large, illustrating Proposition 4.

Proof of Proposition 3. We will prove the stronger result that

$$
\left.\frac{\partial w_{s}^{i}(\alpha)}{\partial \lambda_{1}^{o, p l}}\right|_{\lambda^{o, p l}=\lambda^{o}}>0 \text { for each } i, s \text { and } \alpha \in(0,1) .
$$

That is, a marginal amount of macroprudential policy in the low-risk-premium state increases the gap value in either state. Combining this with the definition of the planner's gap value function in (56) implies $\left.\frac{\partial w_{s}^{p l}(\alpha)}{\partial \lambda_{1}^{o, p l}}\right|_{\lambda^{o, p l}=\lambda^{o}}>0$. Combining this with $\left.\frac{\partial v_{0, s}^{p l, *}}{\partial \lambda^{o, p l}}\right|_{\lambda^{o, p l}=\lambda^{o}}=0$ (which follows from the First Welfare Theorem) and $v_{0, s}^{p l}=v_{0, s}^{p l, *}+w_{0, s}^{p l}$ implies $\left.\frac{\partial w_{s}^{p l}(\alpha)}{\partial \lambda_{1}^{o, p l}}\right|_{\lambda^{o, p l}=\lambda^{o}}=\left.\frac{\partial v_{s}^{p l}(\alpha)}{\partial \lambda_{1}^{o, p l}}\right|_{\lambda^{o, p l}=\lambda^{o}}$ for each $s$ and $\alpha \in(0,1)$. Applying this result for state $s=1$ proves the proposition.

It remains to prove the claim in (C.19). To this end, fix a belief type $i$ and consider the representation of the gap value function in terms of bullishness, $w_{s}^{i}(b)$ [cf. (C.5)]. Following similar steps as in Lemma 4, we describe this as solution to the integral function,

$$
w_{s}^{i}\left(b_{0, s}\right)=\int_{0}^{\infty} e^{-\left(\rho+\lambda_{s}^{i}\right) t}\left(q_{s}^{p l}\left(b_{t, s}\right)-q^{*}+\lambda_{s}^{i} w_{s^{\prime}}^{i}\left(b_{t, s^{\prime}}\right)\right) d t
$$

for each $s \in\{1,2\}$ and $b_{0, s} \in \mathbb{R}$, where the bullishness has the closed form solution,

$$
\begin{aligned}
b_{t, s} & =b_{0, s}-t\left(\lambda_{s}^{o, p l}-\lambda_{s}^{p}\right) \\
b_{t, s^{\prime}} & =b_{0, s}-t\left(\lambda_{s}^{o, p l}-\lambda_{s}^{p}\right)+\log \lambda_{s}^{o, p l}-\log \lambda_{s}^{p} .
\end{aligned}
$$

The main difference from the analysis in Lemma 4 is that the dynamics of bullishness is influenced by policy, as illustrated by the as-if beliefs in (C.11). In addition, we denote the price functions with $q_{s}^{p l}(b)$ to emphasize they are in principle determined by as-if beliefs.

Next note that in this case the price functions $q_{s}^{p l}(b)$ are actually not affected by the as-if belief, $\lambda_{1}^{o, p l}$. The price function in the low-risk-premium state is not affected because $q_{1}^{p l}(b)=q^{*}$ (because the beliefs continue to satisfy Assumption 3 for small changes). The price function in the high-risk-premium state is also not affected because $\lambda_{1}^{o, p l}$ does not enter the differential equation that characterizes $q_{2}^{p l}(b)$ [see. Eq. (45) or Eq. (C.8)].

Using this observation, we implicitly differentiate the integral equation $C .20$ with respect to $\lambda_{1}^{o, p l}$, and use Eq. C.21, to obtain,

$$
\begin{aligned}
\frac{\partial w_{1}^{i}\left(b_{0,1}\right)}{\partial \lambda_{1}^{o, p l}} & =\int_{0}^{\infty} e^{-\left(\rho+\lambda_{1}^{i}\right) t} \lambda_{1}^{i}\left(\frac{\partial w_{2}^{i}\left(b_{t, 2}\right)}{\partial \lambda_{1}^{o, p l}}+\frac{\partial w_{2}^{i}\left(b_{t, 2}\right)}{\partial b} \frac{d b_{t, 2}}{d \lambda_{1}^{o, p l}}\right) d t \\
\frac{\partial w_{2}^{i}\left(b_{0,2}\right)}{\partial \lambda_{1}^{o, p l}} & =\int_{0}^{\infty} e^{-\left(\rho+\lambda_{1}^{i}\right) t} \lambda_{2}^{i} \frac{\partial w_{1}^{i}\left(b_{t, 1}\right)}{\partial \lambda_{1}^{o, p l}} d t .
\end{aligned}
$$

\footnotetext{
${ }^{27}$ Specifically, we calibrate the policy-induced belief change in the recession state so that the maximum decline in the planner's first-best value function is the same in both cases plotted in Figure $\mid$ C.1 $\max _{\alpha}\left|\Delta v_{2}^{p l, *}(\alpha)\right|=$ $\max _{\alpha}\left|\Delta v_{1}^{p l, *}(\alpha)\right|$.
} 
Note also that, using Eq. C.21 implies, $\frac{d b_{t, 2}}{d \lambda_{1}^{o, p l}}=-t+\frac{1}{\lambda_{1}^{o, p l}}$. Plugging this into the previous system, and evaluating the partial derivatives at $\lambda_{1}^{o, p l}=\lambda_{1}^{o}$, we obtain,

$$
\begin{aligned}
\frac{\partial w_{1}^{i}\left(b_{0,1}\right)}{\partial \lambda_{1}^{o, p l}} & =h\left(b_{0,1}\right)+\int_{0}^{\infty} e^{-\left(\rho+\lambda_{1}^{i}\right) t} \lambda_{1}^{i} \frac{\partial w_{2}^{i}\left(b_{t, 2}\right)}{\partial \lambda_{1}^{o, p l}} d t, \\
\frac{\partial w_{2}^{i}\left(b_{0,2}\right)}{\partial \lambda_{1}^{o, p l}} & =\int_{0}^{\infty} e^{-\left(\rho+\lambda_{1}^{i}\right) t} \lambda_{2}^{i} \frac{\partial w_{1}^{i}\left(b_{t, 1}\right)}{\partial \lambda_{1}^{o, p l}} d t, \\
\text { where } h\left(b_{0,1}\right) & =\int_{0}^{\infty} e^{-\left(\rho+\lambda_{1}^{i}\right) t} \lambda_{1}^{i} \frac{\partial w_{2}^{i}\left(b_{t, 2}\right)}{\partial b}\left(-t+\frac{1}{\lambda_{1}^{o}}\right) d t .
\end{aligned}
$$

Note that the function, $h(b)$, is bounded since the derivative function, $\frac{\partial w_{2}^{i}(b)}{\partial b}$, is bounded (see (C.12)). Hence, Eq. $C .22$ describes the partial derivative functions, $\left(\left.\frac{\partial w_{s}^{i}(b)}{\partial \lambda_{1}^{o, p l}}\right|_{\lambda_{1}^{o, p l}=\lambda_{1}^{o}}\right)_{s}$, as a fixed point of a corresponding operator $T$ over bounded functions. Since $h(b)$ is bounded, it can be checked that the operator $T$ is also a contraction mapping with respect to the sup norm. In particular, it has a fixed point, which corresponds to the partial derivative functions.

The analysis so far applies generally. We next consider the special case, $\lambda_{1}^{o}=\lambda_{1}^{p}$, and show that it implies the partial derivatives are strictly positive. In this case, $\lambda_{1}^{i} \equiv \lambda_{1}$ for each $i \in\{o, p\}$. In addition, Eq. C.11 implies $b_{t, 2}=b_{0,2}$. Using these observations, for each $b_{0,1}$, we have,

$$
\begin{aligned}
h\left(b_{0,1}\right) & =\frac{\partial w_{2}^{i}\left(b_{0,2}\right)}{\partial b} \int_{0}^{\infty} e^{-\left(\rho+\lambda_{1}\right) t} \lambda_{1}\left(-t+\frac{1}{\lambda_{1}}\right) d t \\
& =\frac{\partial w_{2}^{i}\left(b_{0,2}\right)}{\partial b}\left(-\frac{\lambda_{1}}{\rho+\lambda_{1}} \frac{1}{\rho+\lambda_{1}}+\frac{1}{\rho+\lambda_{1}}\right)>0 .
\end{aligned}
$$

Here, the inequality follows since $\frac{\partial w_{2}^{i}\left(b_{0,2}\right)}{\partial b}>0$ [cf. Lemma 4]. Since $h(b)>0$ for each $b$, and $\lambda_{s}^{i}>0$, it can further be seen that the fixed point that solves $C .22$ satisfies $\frac{\partial w_{s}^{i}(b)}{\partial \lambda_{s}^{o, p l}}>0$ for each $b$ and $s \in\{1,2\}$. Using Eq. (C.7), we also obtain $\frac{\partial w_{s}^{i}(\alpha)}{\partial \lambda_{1}^{o, p l}}>0$ for each $s \in\{1,2\}$ and $\alpha \in(0,1)$. Since the analysis applies for any fixed belief type $i$, this establishes the claim in (C.19) and completes the proof.

Proof of Proposition 4. A similar analysis as in the proof of Proposition 3 implies that the partial derivative function, $\frac{\partial w_{s}^{i}(b)}{\partial\left(-\lambda_{2}^{o, p l}\right)}$, is characterized as the fixed point of a contraction mapping over bounded functions (the analogue of Eq. C.22 for state 2). In particular, the partial derivative exists and it is bounded. Moreover, since the corresponding contraction mapping takes continuous functions into continuous functions, the partial derivative is also continuous over $b \in \mathbb{R}$. Using Eq. C.7), we further obtain that the partial derivative, $\frac{\partial w_{s}^{i}(\alpha)}{\partial\left(-\lambda_{2}^{o, p l}\right)}$, is continuous over $\alpha \in(0,1)$.

Next note that $w_{s}^{i}(1) \equiv \lim _{\alpha \rightarrow 1} w_{s}^{i}(\alpha)$ exists and is equal to the value function according to type $i$ beliefs when all investors are optimistic. In particular, the asset prices are given by $q_{1}^{p l}=q^{*}$ and $q_{2}^{p l}=q^{o}$, and the transition probabilities are evaluated according to type $i$ beliefs. Then, following 
the same steps as in our analysis of value functions in Online Appendix Section C.1, we obtain,

$$
\begin{aligned}
\rho w_{s}^{i}(1) & =\beta_{s}^{i} q_{s}^{o}+\left(1-\beta_{s}^{i}\right) q_{s^{\prime}}^{o}-q^{*}, \\
\text { where } \beta_{s}^{i} & =\frac{\rho+\lambda_{s^{\prime}}^{i}}{\rho+\lambda_{s^{\prime}}^{i}+\lambda_{s}^{i}} .
\end{aligned}
$$

Here, $\beta_{s}^{i}$ can be thought of as the expected discount time the investor spends in state $s$ according to type $i$ beliefs. We consider this equation for $s=2$ and take the derivative with respect to $\left(-\lambda_{2}^{o, p l}\right)$ to obtain,

$$
\frac{\partial w_{2}^{i}(1)}{\partial\left(-\lambda_{2}^{o, p l}\right)}=\beta_{2}^{i} \frac{d q_{2}^{o}}{d\left(-\lambda_{2}^{o, p l}\right)}<0
$$

Here, the inequality follows since reducing optimists' optimism reduces the price level in the common belief benchmark (see Section IV).

Note that the inequality, $\frac{\partial w_{2}^{2}(1)}{\partial\left(-\lambda_{2}^{o, p l}\right)}<0$, holds for each belief type $i$. Using the continuity of the partial derivative function, $\frac{\partial w_{2}^{i}(\alpha)}{\partial\left(-\lambda_{2}^{o, p l}\right)}$, we conclude that there exists $\bar{\alpha}$ such that $\left.\frac{\partial w_{2}^{i}(\alpha)}{\partial\left(-\lambda_{2}^{o, p l}\right)}\right|_{\lambda_{2}^{o, p l}=\lambda_{2}^{o}}<0$ for each $i, s$ and $\alpha \in(\bar{\alpha}, 1)$, completing the proof. 


\section{Extension with investment and endogenous growth}

Our baseline setup in the main text assumes there is no investment and the expected growth rate of capital is exogenous. In this section, we analyze a more general environment that relaxes these assumptions. We first present the environment, define the equilibrium, and provide a partial characterization. We then characterize this equilibrium when investors have common beliefs and generalize Proposition 1 to this setting.

\section{D.1. Environment and equilibrium with investment}

We focus on the components that are different than the baseline setting described in Section III.

Potential output and endogenous growth. We modify the equation that describes the dynamics of capital $(12)$ as follows,

$$
\frac{d k_{t, s}}{k_{t, s}}=g_{t, s} d t+\sigma_{s} d Z_{t} \quad \text { where } g_{t, s} \equiv \varphi\left(\iota_{t, s}\right)-\delta
$$

Here, $\iota_{t, s}=\frac{i_{t, s}}{k_{t, s}}$ denotes the investment rate, $\varphi\left(\iota_{t, s}\right)$ denotes a neoclassical production function for capital (we will work with a special case that will be described below), and $\delta$ denotes the depreciation rate. Hence, the growth of capital is no longer exogenous: it depends on the endogenous level of investment as well as depreciation.

Investment firms. To endogenize investment, we introduce a new set of firms, which we refer to as investment firms, that own and manage the aggregate capital stock. These firms rent capital to production firms to earn the instantaneous rental rate, $R_{t, s}$. They also make investment decisions to maximize the value of capital. Letting $\tilde{Q}_{t, s}$ denote the price of capital, the firm's investment problem can generally be written as,

$$
\max _{\iota t, s} \tilde{Q}_{t, s} \varphi\left(\iota_{t, s}\right) k_{t, s}-\iota_{t, s} k_{t, s}
$$

As before, we denote the price of the market portfolio per unit of capital with $Q_{t, s}$. In this case, the market portfolio represents a claim on investment firms as well as production firms. Hence, we have the inequality $\tilde{Q}_{t, s} \leq Q_{t, s}$, where the residual price, $Q_{t, s}-\tilde{Q}_{t, s}$, corresponds to the value of production firms per unit of capital. We make assumptions (that we describe below) so that output accrues to the investment firms in the form of return to capital, $y_{t, s}=R_{t, s} k_{t, s}$, and there are no monopoly profits. This in turn implies that the value of the market portfolio is equal to the value of capital (and the value of production firms is zero), that is,

$$
Q_{t, s}=\tilde{Q}_{t, s}
$$

This simplifies the analysis by ensuring that we have only one price to characterize. Considering a different division of output between return to capital and profits will have a quantitative effect on investment, as illustrated by problem $(\overline{D .2})$, but we conjecture that it would leave our qualitative results on investment unchanged. We leave a systematic exploration of this issue for further research. 
Return of the market portfolio. The price of the market portfolio per unit of capital follows the same equation (13) as in the main text. The volatility of the market portfolio (absent state transitions) is also unchanged and given by $\sigma_{t, s}^{m}=\sigma_{s}+\sigma_{t, s}^{Q}$. However, the return on the market portfolio conditional on no transition is slightly modified and given by,

$$
r_{t, s}^{m}=\frac{y_{t, s}-\iota_{t, s} k_{t, s}}{Q_{t, s} k_{t, s}}+g_{t, s}+\mu_{t, s}^{Q}+\sigma_{s} \sigma_{t, s}^{Q}
$$

Hence, the dividend yield is now net of the investment expenditures the (investment) firms undertake. In addition, the expected growth of the price of the market portfolio is now endogenous and given by $g_{t, s}$.

Nominal rigidities and equilibrium in goods markets. As before, the supply side of our model features nominal rigidities similar to the standard New Keynesian model that ensure output is determined by aggregate demand. In this case, demand comes from investment as well as consumption so we modify Eq. (18) as,

$$
y_{t, s}=\eta_{t, s} A k_{t, s}=\sum_{i} c_{t, s}^{i}+k_{t, s} \iota t, s, \text { where } \eta_{t, s} \in[0,1]
$$

We also modify the microfoundations that we provide in Section B.1.3 so that all output accrues to investment firms as return to capital and there are no monopoly profits, that is,

$$
R_{t, s}=A \eta_{t, s} \text { and thus } y_{t, s}=R_{t, s} k_{t, s}
$$

We relegate a detailed description of these microfoundations to the end of this section. The rest of the model is the same as in Section III. We formally define the equilibrium as follows.

Definition 2. The equilibrium with investment and endogenous growth is a collection of processes for allocations, prices, and returns such that capital evolves according to (12), the price of market portfolio per capital evolves according to (13), its instantaneous return (conditional on no transition) is given by D.4, investment firms maximize (cf. Eqs. (D.7), investors maximize (cf. Online Appendix Section B.1.1), asset markets clear (cf. Eqs. (16) and (17)), production firms maximize (cf. Online Appendix Section D.3), goods markets clear (cf. Eq. (18)), all output accrues to agents in the form of return to capital (D.6), the price of the market portfolio per unit of capital is the same as the price of capital (cf. Eq. (D.3)), and the interest rate policy follows the rule in 20 .

We next provide a partial characterization of the equilibrium with investment. Investors' optimality conditions remain unchanged. Therefore, most of the analysis remains unchanged. The main differences concern the goods market equilibrium analyzed in Section III.A, because aggregate demand is now affected by investment as well as consumption. We next derive the optimal level investment and characterize the goods market equilibrium. We then briefly consider the asset market equilibrium and present the risk balance condition. We conclude the section by deriving the first-best equilibrium without interest rate rigidities.

Investment firms' optimality conditions. Under standard regularity conditions for the capital production function, $\varphi(\iota)$, the solution to problem $D .2$ is determined by the optimality condition,

$$
\varphi^{\prime}\left(\iota_{t, s}\right)=1 / Q_{t, s}
$$


We will work with the special and convenient case proposed by Brunnermeier and Sannikov (2016b): $\varphi(\iota)=\psi \log \left(\frac{\iota}{\psi}+1\right)$. In this case, we obtain the closed form solution,

$$
\iota\left(Q_{t, s}\right)=\psi\left(Q_{t, s}-1\right) .
$$

The parameter, $\psi$, captures the sensitivity of investment to asset prices.

Growth-asset price relation. Note also that the amount of capital produced is given by,

$$
\varphi\left(\iota\left(Q_{t, s}\right)\right)=\psi q_{t, s}, \text { where } q_{t, s} \equiv \log \left(Q_{t, s}\right) .
$$

The log price level, $q_{t, s}$, will simplify some of the expressions. Combining Eq. (D.8) with Eq. (12), we obtain Eq. (42) in the main text, which we replicate here for ease of exposition,

$$
g_{t, s}=\psi q_{t, s}-\delta \text {. }
$$

Hence, the expected growth rate of capital (and potential output) is now endogenous and depends on asset prices. Lower asset prices reduce investment, which translates into lower growth and lower potential output in future periods. As we will describe, this mechanism provides a new source of amplification.

Goods market equilibrium. As in the main text, there is a tight relationship between output and asset prices. Specifically, we have the following analogue of Lemma 1.

Lemma 6 (Output-asset price relation). The equilibrium level of output (per capital) satisfies Eq. (41) in the main text:

$$
y_{t, s} / k_{t, s}=A \eta_{t, s}=(\rho+\psi) Q_{t, s}-\psi .
$$

The equilibrium return and the volatility of the market portfolio (absent state transition) is given by

$$
r_{t, s}^{m}=\rho+\psi q_{t, s}-\delta+\mu_{t, s}^{Q}+\sigma_{s} \sigma_{t, s}^{Q} \text { and } \sigma_{t, s}^{m}=\sigma_{s}+\sigma_{t, s}^{Q} .
$$

To prove this lemma, note that Eq. (24) in the main text continues to apply and implies that aggregate consumption is a constant fraction of aggregate wealth. Plugging this into Eq. (18) and using the investment equation D.7), we obtain $y_{t, s}=\rho Q_{t, s} k_{t, s}+\psi\left(Q_{t, s}-1\right) k_{t, s}$. After rearranging terms, we obtain Eq. 41). Combining this relation with Eq. $D .7$, we obtain $\frac{y_{t, s}-\iota_{t, s} k_{t, s}}{Q_{t, s} k_{t, s}}=\rho$. Substituting this into Eq. (D.5) and using Eq. (42), we obtain Eq. (D.9).

Eq. (41) illustrates that a version of the output-asset price relation in the main text continues to apply [cf. Eq. [21]]. In this case, output and factor utilization depend on the price of capital not only because consumption depends on asset prices through a wealth effect but also because investment depends on asset prices through a standard marginal-Q channel. Full factor utilization, $\eta_{t, s}=1$, obtains only if the price of capital is at a particular level

$$
Q^{*} \equiv \frac{A+\psi}{\rho+\psi}
$$

This is the efficient price level that ensures that the implied consumption and investment clear the goods market. Likewise, the economy features a demand recession, $\eta_{t, s}<1$, if and only if the price of capital is strictly below $Q^{*}$. 
Eq. [D.9 is also similar to its counterpart from the baseline model [cf. Eq. 222]]. As before, the equilibrium dividend yield on the market portfolio is equal to the consumption rate $\rho$. Unlike before, the growth rate of dividends is endogenous and is determined by the growth-asset price relation.

Combining the output-asset price relation with the interest rate policy in (20), we also summarize the goods market side of the economy with (25) as in the main text. In particular, the equilibrium at any time and state takes one of two forms. If the natural interest rate is nonnegative, then the interest rate policy ensures that the price per unit of capital is at the efficient level, $Q_{t, s}=Q^{*}$, capital is fully utilized, $\eta_{t, s}=1$, and output is equal to its potential, $y_{t, s}=A k_{t, s}$. Otherwise, the interest rate is constrained, $r_{t, s}^{f}=0$, the price is at a lower level, $Q_{t, s}<Q^{*}$, and output is determined by aggregate demand according to Eq. (21).

Asset market equilibrium. Since investors' optimality conditions remain unchanged, the analysis in Section III.B remains unchanged. In particular, Lemma 2 that describes investors' portfolios and wealth dynamics still apply. Lemma 3 also applies after appropriately adjusting the return on the market portfolio absent transition. Specifically, the risk balance condition is given by

$$
\begin{aligned}
\sigma_{t, s}^{m} & =\frac{1}{\sigma_{t, s}^{m}}\left(r_{t, s}^{m}-r_{t, s}^{f}+\bar{\lambda}_{t, s} \frac{Q_{t, s^{\prime}}-Q_{t, s}}{Q_{t, s^{\prime}}}\right), \\
\text { where } r_{t, s}^{m} & =\rho+\psi q_{t, s}-\delta+\mu_{t, s}^{Q}+\sigma_{s} \sigma_{t, s}^{Q} \text { and } \sigma_{t, s}^{m}=\sigma_{s}+\sigma_{t, s}^{Q}[\text { cf. Lemma 2 }
\end{aligned}
$$

The condition is essentially the same as in the baseline model [cf. Eq. (34)]. The only difference is that $r_{t, s}^{m}$ reflects the endogenous level of growth, $g_{t, s}=\psi q_{t, s}-\delta$, as opposed to exogenous growth, $g$.

First-best equilibrium. As a benchmark, we characterize the first-best equilibrium without interest rate rigidities. In this case, there is no lower bound constraint on the interest rate, so the price of capital is at its efficient level at all times and states, $Q_{t, s}=Q^{*}$ and $q_{t, s}=q^{*} \equiv \log Q^{*}$. Combining this with Eq. D.10, we solve for "rstar" as,

$$
r_{s}^{f *}=\rho+\psi q^{*}-\delta-\sigma_{s}^{2} \text { for each } s \in\{1,2\} .
$$

As before, in the first-best equilibrium the risk premium shocks are fully absorbed by the interest rate.

\section{D.2. Common beliefs benchmark with investment}

We next characterize the equilibrium with interest rate rigidities for the case in which investors have common beliefs. We generalize Proposition 1 to this setting and illustrate an additional amplification mechanism.

Suppose there is a single investor type with belief denoted by $\lambda_{s} \equiv \lambda_{s}^{i}$. As in the case without investment, we focus on equilibria in which the price per capital and the interest rate will remain constant within states, $Q_{t, s}=Q_{s}$ and $r_{t, s}^{f}=r_{s}^{f}$. In particular, there is no price drift or volatility within a state, $\mu_{t, s}^{Q}=\sigma_{t, s}^{Q}=0$. The risk balance condition D.10 can then be written as

$$
\sigma_{s}=\frac{\rho+\psi q_{s}-\delta+\lambda_{s}\left(1-\frac{Q_{s}}{Q_{s^{\prime}}}\right)-r_{s}^{f}}{\sigma_{s}} \text { for each } s \in\{1,2\} .
$$


To characterize the equilibrium, we make the following analogue of Assumption 1.

Assumption $\mathbf{1}^{\mathrm{I}} \cdot \sigma_{2}^{2}>\rho+\psi q^{*}-\delta>\sigma_{1}^{2}$.

With this assumption, we conjecture that the low-risk-premium state 1 features positive interest rates, efficient asset prices, and full factor utilization, $r_{1}^{f}>0, q_{1}=q^{*}$ and $\eta_{1}=1$, whereas the highrisk-premium state 2 features zero interest rates, lower asset prices, and imperfect factor utilization, $r_{2}^{f}=0, q_{2}<q^{*}$ and $\eta_{2}<1$.

Equilibrium in the high-risk-premium state and amplification from the growth-asset price relation. Under our conjecture, the risk balance condition $(D .12)$ for the high-risk state $s=2$ can be written as,

$$
\sigma_{2}=\frac{\rho+\psi q_{2}-\delta+\lambda_{2}\left(1-\frac{Q_{2}}{Q^{*}}\right)}{\sigma_{2}} .
$$

As before, this equation illustrates an amplification mechanism: Since the recession reduces firms' earnings, a lower price level does not increase the dividend yield (captured by the constant dividend yield, $\rho=\frac{\rho Q_{2}}{Q_{2}}$ ). Unlike before, Eq. $D .13$ illustrates a second amplification mechanism captured by the growth-asset price relation, $g_{2}=\psi q_{2}-\delta$. In particular, a lower price level lowers investment, which reduces the expected growth of potential output and profits, which in turn lowers the return to capital. The strength of this second mechanism depends on the sensitivity of investment to asset prices, captured by the term $\psi q_{2}$. Figure I in the introduction presents a graphical illustration of the two amplification mechanisms.

The stabilizing force from price declines comes from the expected transition into the low-riskpremium state captured by the term, $\lambda_{2}\left(1-\frac{Q_{2}}{Q^{*}}\right)$. As before, to ensure that there exists an equilibrium with positive prices, we need a minimum degree of optimism, which we capture with the following analogue of Assumption 2.

Assumption $2^{\mathrm{I}}$. $\lambda_{2} \geq \lambda_{2}^{\mathrm{min}}$, where $\lambda_{2}^{\mathrm{min}}$ is the unique solution to the following equation over the range $\lambda_{2}^{\min } \geq \psi$ :

$$
\rho+\psi q^{*}-\delta+\lambda_{2}^{\min }-\psi+\psi \log \left(\psi / \lambda_{2}^{\min }\right)=\sigma_{2}^{2} .
$$

This assumption ensures that there exists a unique $Q_{2} \in\left(0, Q^{*}\right)$ that solves Eq. $D .13$ (see the proof at the end of this section).

Equilibrium in the low-risk-premium state. Under our conjecture, the risk balance condition $D .12$ can be written as,

$$
r_{1}^{f}=\rho+\psi q^{*}-\delta-\sigma_{1}^{2}+\lambda_{1}\left(1-\frac{Q^{*}}{Q_{2}}\right)
$$

As before, the interest rate adjusts to ensure that the risk balance condition is satisfied with the efficient price level, $Q_{1}=Q^{*}$. For our conjectured equilibrium, we also assume an upper bound on $\lambda_{1}$ so that the implied interest rate is positive, $r_{1}^{f}>0$, which we capture with the following analogue of Assumption 3.

Assumption $3^{\mathrm{I}}$. $\lambda_{1}<\frac{\rho+\psi q^{*}-\delta-\sigma_{1}^{2}}{Q^{*} / Q_{2}-1}$, where $Q_{2} \in\left(0, Q^{*}\right)$ solves Eq. $D .13$.

As before, Eq. D.14 implies that $r_{1}^{f}$ is decreasing in the transition probability, $\lambda_{1}$, as well as in the asset price drop conditional on transition, $Q^{*} / Q_{2}$. 
The following result summarizes the characterization of equilibrium and generalizes Proposition 1.

Proposition 5. Consider the extended model with investment with two states, $s \in\{1,2\}$, with common beliefs and Assumptions $1^{I}-3^{I}$. There is an equilibrium in which the price per capital and the interest rate are constant within each state, $Q_{t, s}=Q_{s}$ and $r_{t, s}^{f}=r_{s}^{f}$. The low-risk-premium state 1 features a positive interest rate, efficient asset prices and full factor utilization, $r_{1}^{f}>0, Q_{1}=Q^{*}$ and $\eta_{1}=1$. The high-risk state 2 features zero interest rate, lower asset prices, and a demand-driven recession, $r_{2}^{f}=0, Q_{2}<Q^{*}$, and $\eta_{2}<1$, as well as a lower level of consumption, $c_{t, 2} / k_{t, 2}=\rho Q_{2}$, investment, $i_{t, 2} / k_{t, 2}=\psi\left(Q_{2}-1\right)$, output, $y_{t, 2} / k_{t, 2}=(\rho+\psi) Q_{2}-\psi$, and growth, $g_{2}=\psi q_{2}-\delta$. The price of capital in state 2 is characterized as the unique solution to Eq. D.13), and the risk-free rate in state 1 is given by Eq. D.14.

Proof. Most of the proof is provided in the discussion leading to the proposition. The predictions regarding the effect of risk premium shocks on consumption, investment, output, and growth follow from Eqs. (24), (D.7), 41) and 42.

The remaining step is to show that Assumptions $1^{\mathrm{I}}-2^{\mathrm{I}}$ ensure there exists a unique solution, $Q_{2} \in\left(0, Q^{*}\right)$ (equivalently, $\left.q_{2}<q^{*}\right)$ to Eq. D.13.

To this end, we define the function,

$$
f\left(q_{2}, \lambda_{2}\right)=\rho+\psi q_{2}-\delta+\lambda_{2}\left(1-\frac{\exp \left(q_{2}\right)}{Q^{*}}\right)-\sigma_{2}^{2}
$$

The equilibrium price is the solution to, $f\left(q_{2}, \lambda_{2}\right)=0$ (given $\lambda_{2}$ ). Note that $f\left(q_{2}, \lambda_{2}\right)$ is a concave function of $q_{2}$ with $\lim _{q_{2} \rightarrow-\infty} f\left(q_{2}, \lambda_{2}\right)=\lim _{q_{2} \rightarrow \infty} f\left(q_{2}, \lambda_{2}\right)=-\infty$. Its derivative is,

$$
\frac{\partial f\left(q_{2}, \lambda_{2}\right)}{\partial q_{2}}=\psi-\lambda_{2} \exp \left(q_{2}-q^{*}\right) .
$$

Thus, for fixed $\lambda_{2}$, it is maximized at,

$$
q_{2}^{\max }\left(\lambda_{2}\right)=q^{*}+\log \left(\psi / \lambda_{2}\right) .
$$

Moreover, the maximum value is given by

$$
\begin{aligned}
f\left(q_{2}^{\max }\left(\lambda_{2}\right), \lambda_{2}\right) & =\rho-\delta+\psi\left(q^{*}+\log \left(\psi / \lambda_{2}\right)\right)+\lambda_{2}\left(1-\exp \left(\log \left(\psi / \lambda_{2}\right)\right)\right)-\sigma_{2}^{2} \\
& =\rho-\delta+\psi q^{*}+\psi \log \left(\psi / \lambda_{2}\right)+\lambda_{2}-\psi-\sigma_{2}^{2} .
\end{aligned}
$$

Next note that, by Assumption $1^{\mathrm{I}}$, the maximum value is strictly negative when $\lambda_{2}=\psi$, that is, $f\left(q_{2}^{\max }(\psi), \psi\right)<0$. Note also that $\frac{d f\left(q_{2}^{\max }\left(\lambda_{2}\right), \lambda_{2}\right)}{d \lambda_{2}}=1-\frac{\psi}{\lambda_{2}}$, which implies that the maximum value is strictly increasing in the range $\lambda_{2} \geq \psi$. Since $\lim _{\lambda_{2 \rightarrow \infty}} f\left(q_{2}^{\max }\left(\lambda_{2}\right), \lambda_{2}\right)=\infty$, there exists $\lambda_{2}^{\min }>\psi$ that ensures $f\left(q_{2}^{\max }\left(\lambda_{2}^{\min }\right), \lambda_{2}^{\min }\right)=0$. By Assumption $2^{\mathrm{I}}$, the transition probability satisfies $\lambda_{2} \geq \lambda_{2}^{\min }$, which implies that $f\left(q_{2}^{\max }\left(\lambda_{2}\right), \lambda_{2}\right) \geq 0$. By Assumption $1^{\mathrm{I}}$, we also have that $f\left(q^{*}, \lambda_{2}\right)<0$. It follows that, under Assumptions $1^{\mathrm{I}}-2^{\mathrm{I}}$, there exists a unique price level, $q_{2} \in\left[q_{2}^{\max }, q^{*}\right)$, that solves the equation, $f\left(q_{2}, \lambda_{2}\right)=0$. 


\section{D.3. New Keynesian microfoundations for nominal rigidities with invest- ment}

In the rest of this section, we present the microfoundations for nominal rigidities that lead to Eqs. (D.5) and D.6). The production structure is the same as in Online Appendix Section B.1.3. Specifically, there is a continuum of monopolistically competitive production firms that produce intermediate goods according to $(B .4)$, and there is a competitive sector that produces the final good according to $B .5)$. This also implies the demand for production firms is given by $B .6)$. One difference is that production firms do not own the capital but they rent it from investment firms at rate $R_{t, s}$. Hence, they choose how their capital input $k_{t, s}(\nu)$, in addition to their factor utilization rate, $\eta_{t, s}(\nu)$, as well as production and pricing decisions, $y_{t, s}(\nu), p_{t, s}(\nu)$.

These features ensure that the production firm's output will be split between their capital expenditures (that they pay to investment firms) and monopoly profits. To simplify the analysis, we make assumptions so that there are no monopoly profits in equilibrium (and all output accrues to investment firms as return to capital). Specifically, we assume the government taxes the firm's profits lump sum, and redistributes these profits to the firms in the form of a linear subsidy to capital.

Formally, we let $\Pi_{t, s}(\nu)$ denote the equilibrium pre-tax profits of firm $\nu$ (that will be characterized below). We assume each firm is subject to the lump-sum tax determined by the average profits of all firms,

$$
T_{t, s}=\int_{\nu} \Pi_{t, s}(\nu) d \nu
$$

We also let $R_{t, s}-\tau_{t, s}$ denote the after-subsidy cost of renting capital, where $R_{t, s}$ denotes the equilibrium rental rate paid to investment firms, and $\tau_{t, s}$ denotes a linear subsidy paid by the government. We assume the magnitude of the subsidy is determined by the government's breakeven condition,

$$
\tau_{t, s} \int_{\nu} k_{t, s}(\nu) d \nu=T_{t, s}
$$

Without price rigidities, the firm chooses $p_{t, s}(\nu), k_{t, s}(\nu), \eta_{t, s}(\nu) \in[0,1], y_{t, s}(\nu)$, to maximize its (pre-tax) profits,

$$
\Pi_{t, s}(\nu) \equiv p_{t, s}(\nu) y_{t, s}(\nu)-\left(R_{t, s}-\tau_{t, s}\right) k_{t, s}(\nu)
$$

subject to the supply constraint in B.4 and the demand constraint in B.6. As in Online Appendix Section B.1.3, the demand constraint holds as equality. Then, the optimality conditions imply,

$$
\eta_{t, s}(\nu)=1 \text { and } p_{t, s}(\nu)=\frac{\varepsilon}{\varepsilon-1} \frac{R_{t, s}-\tau_{t, s}}{A} .
$$

That is, the firm utilizes its capital at full capacity (as before) and it increases its capital input and production up to the point at which its price is a constant markup over its after-subsidy marginal cost. In a symmetric-price equilibrium, we further have, $p_{t, s}(\nu)=1$. Using Eqs. (B.4) and $(D .16)$, this further implies,

$$
y_{t, s}(\nu)=y_{t, s}=A k_{t, s} \text { and } R_{t, s}=\frac{\varepsilon-1}{\varepsilon} A+\tau_{t, s}=A \text {. }
$$


That is, output is equal to potential output, and capital earns its marginal contribution to potential output (in view of the linear subsidies).

Now consider the alternative setting in which the firms have a preset nominal price that is equal across firms, $P_{t, s}(\nu)=P$. In particular, the relative price of a firm is fixed and equal to one, $p_{t, s}(\nu)=1$. The firm chooses the remaining variables, $k_{t, s}(\nu), \eta_{t, s}(\nu) \in[0,1], y_{t, s}(\nu)$, to maximize its (pre-tax) profits, $\Pi_{t, s}(\nu)$, subject to the supply constraint in (B.4) and the demand constraint, $B .6$. Combining the constraints and using $p_{t, s}(\nu)=1$, the firm's problem can be written as,

$$
\max _{\eta_{t, s}(\nu), k_{t, s}(\nu)} A \eta_{t, s}(\nu) k_{t, s}(\nu)-\left(R_{t, s}-\tau_{t, s}\right) k_{t, s}(\nu) \text { s.t. } 0 \leq \eta_{t, s}(\nu) \leq 1 \text { and } A \eta_{t, s}(\nu) k_{t, s}(\nu) \leq y_{t, s} .
$$

We conjecture an equilibrium in which $R_{t, s}=\tau_{t, s}$ and firms choose symmetric capital inputs, $k_{t, s}(\nu)=k_{t, s}$. Under this equilibrium, the marginal cost of renting capital is zero, $R_{t, s}-\tau_{t, s}=$ 0 . This verifies that it is optimal for firms to choose symmetric inputs, $k_{t, s}(\nu)=k_{t, s}$. After substituting these expressions, the firm's problem becomes equivalent to its counterpart in Online Appendix Section B.1.3. Following the same steps there, the optimal factor utilization is given by $\eta_{t, s}(\nu)=\frac{y_{t, s}}{A k_{t, s}} \leq 1$. Hence, output is determined by aggregate demand, $y_{t, s}$, subject to the capacity constraint, $\eta_{t, s}(\nu) \leq 1$.

In the conjectured equilibrium, the production firms choose the same level of inputs and factor utilization rates and produce the same level of output as each other. Therefore, they also have the same level of pre-tax profits. Using Eqs. $D .17$ together with $R_{t, s}=\tau_{t, s}=0$, we also calculate the pre-tax profit level as $\Pi_{t, s}=y_{t, s}$. Substituting this into Eqs. (D.15) and D.16), we obtain $\tau_{t, s}=y_{t, s} / k_{t, s}=\eta_{t, s} A$. Substituting this into Eq. (D.17), we further obtain $R_{t, s}=y_{t, s} / k_{t, s}=\eta_{t, s} A$. This verifies the conjecture, $R_{t, s}=\tau_{t, s}$.

In sum, when the firms' nominal prices are fixed, aggregate output is determined by aggregate demand subject to the capacity constraint, which verifies Eq. D.5. Moreover, thanks to lumpsum costs to profits and linear subsidies to capital, all output accrues to the investment firms as return to capital, which verifies Eq. D.6. 


\section{E. Extension with more general RRA}

Our baseline dynamic model in the main text focuses on investors that have time-separable log utility. In particular, we assume the relative risk aversion (RRA) as well as the elasticity of substitution (EIS) is equal to one. In this section, we analyze a model in which we allow for a more general RRA but we still set the EIS equal to one. This helps to clarify the role of the assumption on the RRA for our results (see Online Appendix Section A.2 for the role of the assumption on the EIS).

Our analysis proceeds in two steps. First, we generalize the partial characterization of equilibrium in Section III. We observe that a more general RRA introduces dynamic hedging motives. These motives complicate the analysis with belief disagreements, because investors' wealth dynamics are influenced by their relative dynamic hedging motives in addition to belief disagreements. In particular, we illustrate that the separability property from Section III.B no longer applies. Second, we focus on common beliefs (in which case the analysis is tractable) and investigate how investors' dynamic hedging motive affects the severity of recessions driven by risk premium shocks. Our analysis suggests that, in the empirically relevant case of RRA greater than one, dynamic hedging motives are likely to amplify the effect of risk premium shocks on asset prices and output.

\section{E.1. Environment and equilibrium with more general RRA}

Consider the baseline dynamic model described in Section III with the only difference that investors have Epstein-Zin preferences with the discount rate $\rho$, the RRA denoted by $\gamma \neq 1$, and the EIS equal to 1. The limit case, $\gamma \rightarrow 1$, corresponds to the baseline dynamic model. The rest of the model is unchanged. We next define investors' preferences formally and derive the corresponding HJB equation. We then derive the first order conditions and provide a partial characterization of equilibrium. Finally, we fully characterize the equilibrium with common beliefs and investigate its comparative statics.

\section{E.1.1 Recursive preferences and the HJB equation}

Following Duffie and Epstein (1992), we define investor $i$ 's utility recursively as the solution to:

$$
U_{t, s}^{i}=E_{t, s}\left[\int_{t}^{\infty} f\left(c_{u, \tilde{s}}, U_{u, \tilde{s}}^{i}\right) d u\right]
$$

where

$$
f(c, U)=\rho(1-\gamma) U\left(\log (c)-\frac{1}{1-\gamma} \log ((1-\gamma) U)\right)
$$

Here, $f(\cdot)$ is called an aggregator function. As explained by Duffie and Epstein (1992), the aggregator function is not unique since monotone transformations of utility leave preferences unchanged while affecting the aggregator function. The aggregator function in $E .2$ corresponds to the socalled "normalized utility" that simplifies the analysis with diffusion processes.

In particular, the aggregator in $E .2$ (together with homothetic preferences) implies that the utility of an investor with wealth $a_{t, s}^{i}$ can be written as (see Di Tella (2017)):

$$
U_{t, s}^{i}\left(a_{t, s}^{i}\right)=\frac{\left(a_{t, s}^{i} \zeta_{t, s}^{i} / Q_{t, s}\right)^{1-\gamma}}{1-\gamma}
$$


The process, $\zeta_{t, s}^{i}$, captures forward-looking investment opportunities. We refer to it as the wealth multiplier since a doubling of $\zeta_{t, s}^{i}$ has the same effect on the investor's utility as a doubling of her wealth. Note that we also normalize the wealth multiplier so that it provides a measure of utility when the investor has one unit of capital (or wealth $a_{t, s}^{i}=Q_{t, s}$ ).

The formulation in E.1-E.3 is useful since it allows for a dynamic programming approach. Specifically, suppose that as long as there is no transition the investor's wealth $a_{t, s}^{i}$ follows the process

$$
\frac{d a_{t, s}^{i}}{a_{t, s}^{i}}=\mu_{t, s}^{a} d t+\sigma_{t, s}^{a} d Z_{t}
$$

Then, the HJB equation corresponding to the investor's problem is sufficient for optimality (see Duffie and Epstein (1992)):

$$
0=\max _{\tilde{\omega}^{m}, \tilde{\omega}^{s^{\prime}}, \tilde{c}} f\left(\tilde{c}, U_{t, s}^{i}\right)+\frac{\partial U_{t, s}^{i}}{\partial a} a_{t, s}^{i} \mu_{t, s}^{a}+\frac{\partial U_{t, s}^{i}}{\partial t}+\frac{1}{2} \frac{\partial^{2} U_{t, s}^{i}}{\partial a^{2}}\left(a_{t, s}^{i} \sigma_{t, s}^{a}\right)^{2}+\lambda_{s}^{i}\left(U_{t, s^{\prime}}^{i}-U_{t, s}^{i}\right) .
$$

Note also that the evolution of investors' wealth is still given by Eq. B.1. Using this equation and substituting the aggregator function from $E .2$, we obtain the following analogue of the HJB equation for the baseline model [cf. B.2]:

$$
\begin{aligned}
0 & =\max _{\tilde{\omega}^{m}, \tilde{\omega}^{s^{\prime}}, \tilde{c}} \rho(1-\gamma) U_{t, s}^{i}\left(\log (\tilde{c})-\frac{1}{1-\gamma} \log \left((1-\gamma) U_{t, s}^{i}\right)\right) \\
& +\frac{\partial U_{t, s}^{i}}{\partial a}\left(a_{t, s}^{i}\left(r_{t, s}^{f}+\tilde{\omega}^{m}\left(r_{t, s}^{m}-r_{t, s}^{f}\right)-\tilde{\omega}^{s^{\prime}}\right)-\tilde{c}\right)+\frac{\partial U_{t, s}^{i}\left(a_{t, s}^{i}\right)}{\partial t} \\
& +\frac{1}{2} \frac{\partial^{2} U_{t, s}^{i}}{\partial a^{2}}\left(\tilde{\omega}^{m} a_{t, s}^{i} \sigma_{t, s}^{m}\right)^{2} \\
& +\lambda_{s}^{i}\left(U_{t, s^{\prime}}^{i}\left(a_{t, s}^{i}\left(1+\tilde{\omega}^{m} \frac{Q_{t, s^{\prime}}-Q_{t, s}}{Q_{t, s}}+\frac{\tilde{\omega}^{s^{\prime}}}{p_{t, s}^{s^{\prime}}}\right)\right)-U_{t, s}^{i}\left(a_{t, s}^{i}\right)\right) .
\end{aligned}
$$

\section{E.1.2 Optimality conditions}

To derive the optimality conditions, first note that the functional form for $U_{t, s}^{i}$ in $E .3$ implies

$$
\frac{\partial U_{t, s}^{i}}{\partial a}=\left(\frac{\zeta_{t, s}^{i}}{Q_{t, s}}\right)^{1-\gamma}\left(a_{t, s}^{i}\right)^{-\gamma} \text { and } \frac{\partial^{2} U_{t, s}^{i}}{\partial a^{2}}=-\gamma\left(\frac{\zeta_{t, s}^{i}}{Q_{t, s}}\right)^{1-\gamma}\left(a_{t, s}^{i}\right)^{-\gamma-1}
$$

The first order condition for $\tilde{c}$ in problem $E .4$ then implies

$$
c_{t, s}^{i}=\rho \frac{(1-\gamma) U_{t, s}^{i}}{\partial U_{t, s}^{i} / \partial a}=\rho a_{t, s}^{i} .
$$

The optimality condition for consumption is the same as before [cf. [23)]. As in the baseline model, the assumption that EIS is equal to one ensures that investors spend a constant fraction of their wealth. 
The first order condition for $\tilde{\omega}^{m}$ in problem E.4 implies,

$$
\frac{\partial U_{t, s}^{i}}{\partial a} a_{t, s}^{i}\left(r_{t, s}^{m}-r_{t, s}^{f}\right)+\lambda_{s}^{i} \frac{\partial U_{t, s^{\prime}}^{i}\left(a_{t, s^{\prime}}^{i}\right)}{\partial a} a_{t, s}^{i} \frac{Q_{t, s^{\prime}}-Q_{t, s}}{Q_{t, s}}=-\frac{\partial^{2} U_{t, s}^{i}}{\partial a^{2}} \omega_{t, s}^{m, i}\left(a_{t, s}^{i} \sigma_{t, s}^{m}\right)^{2} .
$$

After substituting for $\frac{\partial U_{t, s}^{i}}{\partial a}, \frac{\partial U_{t, s^{\prime}}^{i}}{\partial a}, \frac{\partial^{2} U_{t, s}^{i}}{\partial a^{2}}$ and rearranging terms, we obtain:

$$
\omega_{t, s}^{m, i} \sigma_{t, s}^{m}=\frac{1}{\gamma \sigma_{t, s}^{m}}\left(r_{t, s}^{m}-r_{t, s}^{f}+\lambda_{s}^{i}\left(\frac{\zeta_{t, s^{\prime}}^{i} / Q_{t, s^{\prime}}}{\zeta_{t, s}^{i} / Q_{t, s}}\right)^{1-\gamma}\left(\frac{a_{t, s^{\prime}}^{i}}{a_{t, s}^{i}}\right)^{-\gamma} \frac{Q_{t, s^{\prime}}-Q_{t, s}}{Q_{t, s}}\right) .
$$

Finally, the first order condition for $\tilde{\omega}^{s^{\prime}}$ implies that investors choose $\omega_{t, s}^{s^{\prime}, i}$ that ensures:

$$
\frac{p_{t, s}^{s^{\prime}}}{\lambda_{s}^{i}}=\frac{\frac{\partial U_{t, s^{\prime}}^{i}\left(a_{t, s^{\prime}}^{i}\right)}{\partial a}}{\frac{\partial U_{t, s}^{i}\left(a_{t, s}^{i}\right)}{\partial a}}=\left(\frac{\zeta_{t, s^{\prime}}^{i} / Q_{t, s^{\prime}}}{\zeta_{t, s}^{i} / Q_{t, s}}\right)^{1-\gamma}\left(\frac{a_{t, s^{\prime}}^{i}}{a_{t, s}^{i}}\right)^{-\gamma}
$$

When $\gamma \neq 1$, conditions $(E .6)$ and $E .7$ feature two differences relative to their counterpart in the baseline model [cf. (31) and (32)]. First, the investor's desired risk taking also depends on their relative risk aversion-captured by $\gamma$ in the denominator of (E.6). Second, and more subtly, the investor's (relative) marginal utility per unit of wealth after a jump depends not only on her (relative) wealth but also on the (relative) wealth multipliers - captured by $\zeta_{t, s^{\prime}}^{i} \zeta_{t, s}^{i}$ in $E .7$. These terms introduce a dynamic hedging motive into the portfolio choice. To understand these effects, suppose $\zeta_{t, s^{\prime}}^{i}$ decreases so that the wealth multiplier for the transition state becomes lower while keeping all else equal [cf. E.3] ]. This introduces substitution and income effects. The substitution effect reduces the investor's marginal utility per unit of wealth for this state- because investment opportunities become less attractive. The income effect increases the investor's marginal utility per unit of wealth for this state - because the investor became effectively poorer. When $\gamma>1$, the income (resp. the substitution) effect dominates and the investor's marginal utility increases (resp. decreases).

\section{E.1.3 Partial characterization of equilibrium}

We next present a partial characterization of equilibrium that facilitates the subsequent analysis.

Goods market equilibrium. First consider the goods market equilibrium. The analysis in Section III.A remains unchanged. In particular, since Eq. (23) still holds, Lemma 1 that captures the output-asset price relation still applies. Therefore, we have Eq. (21) (that describes output in terms of $Q_{t, s}$ ) and Eq. 222 (that describes the return on the market portfolio absent transition).

Asset market equilibrium. Next consider the asset markets. As before, the equilibrium in asset markets depend on investors' wealth shares [cf. (26)]

$$
\alpha_{t, s}^{i}=\frac{a_{t, s}^{i}}{k_{t, s} Q_{t, s}}
$$


We next generalize Lemmas 2 and 3 from Section $I I I . B$ to this setting. To state the result, we define type $i$ investors' multiplier-adjusted belief for transition as

$$
\Lambda_{t, s}^{i}=\left(\frac{\zeta_{t, s^{\prime}}^{i}}{\zeta_{t, s}^{i}}\right)^{1-\gamma} \lambda_{s}^{i} .
$$

We also define the wealth-weighted average multiplier-adjusted belief as

$$
\bar{\Lambda}_{t, s} \equiv\left(\sum_{i} \alpha_{t, s}^{i}\left(\Lambda_{t, s}^{i}\right)^{1 / \gamma}\right)^{\gamma} .
$$

Note that $\bar{\Lambda}_{t, s}^{i}$ is a weighted average of multiplier-adjusted beliefs (although not necessarily a linear average).

Lemma 7 (Wealth-share dynamics and the risk balance condition). Investors hold identical positions on the market portfolio

$$
\omega_{t, s}^{m, i}=1 \quad \text { for each } i .
$$

They hold possibly heterogeneous positions on the contingent security given by

$$
\omega_{t, s}^{s^{\prime}, i}=\bar{\Lambda}_{t, s}^{1-1 / \gamma}\left(\left(\Lambda_{t, s}^{i}\right)^{1 / \gamma}-\bar{\Lambda}_{t, s}^{1 / \gamma}\right)
$$

Type $i$ investors' wealth share evolves according to

$$
\begin{gathered}
\dot{\alpha}_{t, s}^{i} / \alpha_{t, s}^{i}=-\omega_{t, s}^{s^{\prime}, i}=\bar{\Lambda}_{t, s}^{1-1 / \gamma}\left(\bar{\Lambda}_{t, s}^{1 / \gamma}-\left(\Lambda_{t, s}^{i}\right)^{1 / \gamma}\right), \quad \text { if there is no state change, } \\
\alpha_{t, s^{\prime}}^{i} / \alpha_{t, s}^{i}=\left(\Lambda_{t, s}^{i} / \bar{\Lambda}_{t, s}\right)^{1 / \gamma}, \quad \text { if there is a state change to } s^{\prime} .
\end{gathered}
$$

The equilibrium price of the market portfolio satisfies

$$
\begin{aligned}
\sigma_{t, s}^{m} & =\frac{1}{\gamma \sigma_{t, s}^{m}}\left(r_{t, s}^{m}-r_{t, s}^{f}+\bar{\Lambda}_{t, s}\left(1-\frac{Q_{t, s}}{Q_{t, s^{\prime}}}\right)\right), \\
\text { where } r_{t, s}^{m} & =\rho+g+\mu_{t, s}^{Q}+\sigma_{s} \sigma_{t, s}^{Q} \text { and } \sigma_{t, s}^{m}=\sigma_{s}+\sigma_{t, s}^{Q} \text { [cf. Lemma 1]. }
\end{aligned}
$$

The equilibrium price of the contingent security satisfies

$$
p_{t, s}^{s^{\prime}}=\bar{\Lambda}_{t, s} \frac{1 / Q_{t, s^{\prime}}}{1 / Q_{t, s}}
$$

The proof follows similar steps as in the main text and is relegated to the end of the section.

Eq. E.10 is the same as its counterpart in the main text [cf. Eq. (28)]. As before, investors express their differences in beliefs through their holdings of the contingent securities. Consequently, they hold identical positions on the market portfolio. As in the main text, this feature allows for equilibria with deterministic wealth share and asset price dynamics absent state transitions. Specifically, we will focus on equilibria in which the price per capital can be written as a function of investors' wealth shares. For these equilibria, Eq. E.10) also implies $\sigma_{t, s}^{Q}=0$ (see Remark 4 ).

Eqs. E.11-E.12) are in general (unless $\gamma=1$ ) different than their counterparts in the main text [cf. Eqs. $29-30]$ ]. In this case, the wealth share dynamics are determined by the multiplier- 
adjusted belief, $\Lambda_{t, s}^{i}=\left(\frac{\zeta_{t, s^{\prime}}^{i}}{\zeta_{t, s}^{i}}\right)^{1-\gamma} \lambda_{s}^{i}$, as opposed to the unadjusted belief, $\lambda_{s}^{i}$. This illustrates that wealth fluctuations depend not only on investors' belief differences but also on investors' relative dynamic hedging motives. The latter depends on how the transition affects an investor's wealth multiplier, $\zeta_{t, s^{\prime}}^{i} / \zeta_{t, s}^{i}$, relative to the other investor's wealth multiplier, $\zeta_{t, s^{\prime}}^{j} / \zeta_{t, s}^{j}$. When $\gamma>1$, a decrease in an investor's relative multiplier increases the investor's wealth share after transition. Intuitively, since the income effect dominates, the investor brings more wealth to this state to hedge the decline in investment opportunities.

Eqs. E.13-E.14 are very similar to their counterparts in the main text [cf. Eqs. (34-35)]. In particular, Eq. (E.13) shows that the risk balance condition generalizes to this setting with two differences. First, investors' desired risk taking also depends on their relative risk aversioncaptured by $\gamma$ in the denominator. Second, the wealth-weighted average transition belief, $\bar{\lambda}_{s}^{i}$, is replaced by the wealth-weighted average multiplier-adjusted belief, $\bar{\Lambda}_{t, s}^{i}$. This reflects the dynamic hedging motives.

Lemma 7 suggests that, unlike before, investors' wealth dynamics cannot be characterized separately from asset prices (cf. Remark 5). This is because the evolution of investors' wealth shares, $\left\{\alpha_{t, s}^{i}\right\}_{i}$, depends on investors' relative wealth multipliers, $\left\{\zeta_{t, s^{\prime}}^{i} / \zeta_{t, s}^{i}\right\}_{i}$; and the latter (typically) depends on asset prices.

To illustrate this and to facilitate the rest of the analysis, we present another lemma that characterizes the wealth multiplier $\zeta_{t, s}^{i}$. To state the result, we normalize the wealth multiplier. Specifically, we define the normalized value, $v_{t, s}^{i}$, so that the following holds at all times and states

$$
\zeta_{t, s}^{i}=\exp \left(\rho v_{t, s}^{i}\right)
$$

This normalization simplifies the analysis and ensures continuity with the baseline analysis. Specifically, for the limit case $\gamma \rightarrow 1$, Eq. $E .3$ implies that the value function has the same form as in the baseline model, $U_{t, s}^{i}\left(a_{t, s}^{i}\right)=\rho\left(\frac{\log \left(a_{t, s}^{i} / Q_{t, s}\right)}{\rho}+\log v_{t, s}^{i}\right)$ [cf. (48)]. Recall that $q_{t, s}=\log Q_{t, s}$ denotes the log asset price.

To simplify the expressions, we state the lemma under the assumption that the wealth multiplier as well as the price per capital follow deterministic dynamics absent state transitions. This will be the case in equilibrium because these variables can be written as a function of investors' wealth shares, and the latter follows deterministic dynamics absent state transitions (see Remark 4 ). Formally, note that $\zeta_{t, s}^{i}$ in general follows an endogenous diffusion process within each state,

$$
\frac{d \zeta_{t, s}}{\zeta_{t, s}}=\mu_{t, s}^{\zeta} d t+\sigma_{t, s}^{\zeta} d Z_{t} \quad \text { for } s \in\{1,2\}
$$

We assume $\sigma_{t, s}^{\zeta}=0$ as well as $\sigma_{t, s}^{Q}=0$ [cf. (13)].

Lemma 8 (Wealth multiplier). Consider an equilibrium with $\sigma_{t, s}^{\zeta}=\sigma_{t, s}^{Q}=0$. Then, the normalized value, $v_{t, s}^{i}$ (where the wealth multiplier is $\zeta_{t, s}^{i}=\exp \left(\rho v_{t, s}^{i}\right)$ ) is the solution to the following 
differential equation

$$
\begin{aligned}
& \rho v_{t, s}^{i}-\frac{\partial v_{t, s}^{i}}{\partial t}=\log \rho+q_{t, s}+\frac{1}{\rho}\left(\begin{array}{c}
g-\frac{1}{2} \gamma \sigma_{s}^{2}+\frac{\dot{\alpha}_{t, s}^{i}}{\alpha_{t, s}^{i}} \\
+\lambda_{s}^{i} V\left\{\frac{\alpha_{t, s^{\prime}}^{i}}{\alpha_{t, s}^{i}} \exp \left(\rho\left(v_{t, s^{\prime}}^{i}-v_{t, s}^{i}\right)\right)\right\}
\end{array}\right), \\
& \text { where } V\{c\}=\frac{c^{1-\gamma}-1}{1-\gamma} \\
& \text { and } \frac{\dot{\alpha}_{t, s}^{i}}{\alpha_{t, s}^{i}}=\bar{\Lambda}_{t, s}^{1-1 / \gamma}\left(\bar{\Lambda}_{t, s}^{1 / \gamma}-\left(\Lambda_{t, s}^{i}\right)^{1 / \gamma}\right), \frac{\alpha_{t, s^{\prime}}^{i}}{\alpha_{t, s}^{i}}=\left(\frac{\Lambda_{t, s}^{i}}{\bar{\Lambda}_{t, s}}\right)^{1 / \gamma} \text { [cf. Lemma [7]. }
\end{aligned}
$$

The proof follows from combining Eq. E.4 with our characterization of equilibrium and is relegated to the end of this section. Note also that, in the limit as $\gamma \rightarrow 1$, we recover Eq. (49) that characterizes $v_{t, s}^{i}$ in the baseline model. Hence, Eq. E.16 provides a more general characterization for the normalized value function that applies for arbitrary $\gamma$.

Eq. E.16 shows that the normalized value (and therefore the wealth share multiplier) depends on asset prices, $q_{t, s}$. Intuitively, asset prices affect investors' welfare (per capital) because they determine output and consumption [cf. Eqs. 24) and (21)]. Importantly, Eq. E.16) also illustrates that these effects depend on investors' belief types (in complex fashion). For example, consider an equilibrium as in the baseline model in which the high-risk-premium state features relatively low asset prices whereas the low-risk-premium state features efficient asset prices, $q_{t, 2}<q_{t, 1}=q^{*}$. Suppose also that the economy is currently in the high-risk-premium state $s=2$. Then, Eq. E.16) suggests that (all else equal) pessimists that perceive a lower probability of transition to the lowrisk-premium state (lower $\lambda_{2}^{i}$ ) will have lower $v_{t, 2}^{i}$ than optimists - and more so when $q_{t, 2}$ is lower.

First-best equilibrium with common beliefs. For future reference, we conclude this section by solving for the first-best equilibrium without interest rate rigidities. In this case, there is no lower bound constraint on the interest rate, so the price of capital is at its efficient level at all times and states, $Q_{t, s}=Q^{*}$ and $q_{t, s}=q^{*} \equiv \log Q^{*}$. Combining this with Eq. E.13, we solve for "rstar" as,

$$
r_{s}^{f *}=\rho+g-\gamma \sigma_{s}^{2} \text { for each } s \in\{1,2\} .
$$

As before, in the first-best equilibrium the risk premium shocks are fully absorbed by the interest rate.

\section{E.2. Common beliefs benchmark with more general RRA}

We next characterize the equilibrium with interest rate rigidities for the case in which investors have common beliefs. We generalize Proposition 1 to this setting and discuss how the dynamic hedging motives affect the severity of demand recessions driven by risk premium shocks.

Suppose there is a single investor type with belief denoted by $\lambda_{s} \equiv \lambda_{s}^{i}$. As before, we conjecture that the price and the interest rate will remain constant within states, $Q_{t, s}=Q_{s}$ and $r_{t, s}^{f}=r_{s}^{f}$. This implies the wealth multiplier is also constant within states, $\zeta_{t, s}=\zeta_{s}$. Then, using Eq. E.13, 
we obtain the following risk balance conditions,

$$
\sigma_{s}=\frac{1}{\gamma \sigma_{s}}\left(\rho+g+\exp \left(\rho(1-\gamma)\left(v_{s^{\prime}}-v_{s}\right)\right) \lambda_{s}\left(1-\frac{Q_{s}}{Q_{s^{\prime}}}\right)-r_{s}^{f}\right) \text { for } s \in\{1,2\}
$$

Here, we substituted the wealth multiplier with normalized value, $\zeta_{s}=\exp \left(\rho v_{s}\right)[\mathrm{cf}$. E.15)]. Using Eq. E.16, we also characterize the normalized value as the solution to

$$
\begin{aligned}
\rho v_{s}= & \log \rho+q_{s}+\frac{1}{\rho}\left(g-\frac{1}{2} \gamma \sigma_{s}^{2}+\lambda_{s} V\left\{\exp \left(\rho\left(v_{s^{\prime}}-v_{s}\right)\right)\right\}\right) \text { for } s \in\{1,2\}, \\
& \text { where } V\{c\}=\frac{c^{1-\gamma}-1}{1-\gamma} .
\end{aligned}
$$

The equilibrium tuple, $\left\{r_{s}^{f}, Q_{s}, v_{s}\right\}_{s \in\{1,2\}}$, is found by solving Eqs. E.18 E.19 together with the goods market equilibrium conditions (25).

To characterize the equilibrium further, we make the following analogue of Assumption 1

Assumption $1^{\mathrm{D}} \cdot \sigma_{2}^{2}>\frac{\rho+g}{\gamma}>\sigma_{1}^{2}$.

This assumption ensures that the first best equilibrium in (E.17) is not feasible. Therefore, we conjecture that the interest rate constraint binds in the high-risk-premium state but not in the low-risk-premium state, $r_{1}^{f}>0, Q_{1}=Q^{*}$ and $r_{2}^{f}=0, Q_{2}<Q^{*}$.

Equilibrium in the high-risk-premium state and dynamic hedging motives. Under our conjecture, the risk balance condition $(E .18)$ for the high-risk-premium state $s=2$ can be written as,

$$
\gamma \sigma_{2}^{2}=\rho+g+\exp (\rho(1-\gamma) \Delta v) \lambda_{2}\left(1-\frac{Q_{2}}{Q^{*}}\right)
$$

where we define $\Delta v=v_{1}-v_{2}$ as the difference in the normalized value between the low and high-risk-premium states. Taking the difference of Eq. E.19 across the two states, we further obtain

$$
\rho^{2} \Delta v=\rho\left(q^{*}-q_{2}\right)+\frac{1}{2} \gamma\left(\sigma_{2}^{2}-\sigma_{1}^{2}\right)+\lambda_{1} V\left\{\exp (-\rho \Delta v)-\lambda_{2} V\{\exp (\rho \Delta v)\}\right\} .
$$

The pair, $\left(q_{2}, \Delta v\right)$, corresponds to the solution to the two equations $E .20$ and $E .21$. As before, we need a lower bound on $\lambda_{2}$ to ensure the existence of an equilibrium with positive asset price. Under an appropriate parametric restriction, there exists a solution that satisfies $q_{2}<q^{*}$.

Given the equilibrium price level, Eq. (E.21) implies $\Delta v>0$. To see this, note that $\rho\left(q^{*}-q_{2}\right)+$ $\frac{1}{2} \gamma\left(\sigma_{2}^{2}-\sigma_{1}^{2}\right)>0$ Note also that the left-hand-side is an increasing function of $\Delta v$ whereas the right-hand-side is a decreasing function. Hence, the equilibrium satisfies $\Delta v>0$. As expected, the normalized value is higher in the low-risk-premium state (that features higher prices and lower uncertainty) than in the high-risk-premium state.

To understand how the dynamic hedging motives affect the equilibrium in the high-risk-premium state, it is instructive to consider a particular comparative statics exercise: specifically, suppose $\sigma_{1}^{2}$ declines. Eq. E.21 illustrates that this increases the equilibrium level of $\Delta v$. As expected, a decline in $\sigma_{1}^{2}$ makes the investment opportunities in state 1 relatively more attractive. Equivalently, it makes the investment opportunities in state 2 relatively less attractive. Eq. E.20 illustrates 
that this change affects the equilibrium asset price only through its impact on $\Delta v$. Moreover, the same equation illustrates that the change would not affect the equilibrium price in the baseline model with $\gamma=1$. Hence, this exercise is useful to understand how a decline in the relative attractiveness of investment opportunities in the high-risk-premium state affects the equilibrium price in this state.

Eq. E.20 implies that the induced increase in $\Delta v$ decreases (resp. increases) $q_{2}$ when $\gamma>1$ (resp. $\gamma<1$ ). Intuitively, a decline in the (relative) attractiveness investment opportunities in the high-risk-premium state generates substitution and income effects that influence the investors' marginal utility and discount factor across states [cf. (E.7)]. The substitution effect increases the investor's (relative) marginal utility in the low-risk-premium state - she would like to bring wealth to the low-risk-premium state to take advantage of the more attractive investment opportunities. The income effect increases the investor's (relative) marginal utility in the high-risk-premium stateshe would like to bring more wealth to the high-risk-premium state to hedge the decline in the attractiveness of investment opportunities. When $\gamma>1$, the income effect (or the hedging motive) dominates and an increase in $\Delta v$ increases the investor's marginal utility and discount factor for the high-risk-premium relative to the low-risk-premium state. Since $q_{2}<q^{*}$, this reweighting of discount factors reduces current asset valuations. Since the interest rate is constrained, this also leads to a decline in the equilibrium price, $q_{2}$ [cf. [E.20]].

Equilibrium in the low-risk-premium state. Under our conjecture, the risk balance condition E.13 can be written as,

$$
r_{1}^{f}=\rho+g-\gamma \sigma_{1}^{2}-\exp (\rho(1-\gamma)(-\Delta v)) \lambda_{1}\left(\frac{Q^{*}}{Q_{2}}-1\right)
$$

As before, the interest rate adjusts to ensure that the risk balance condition is satisfied with the efficient price level, $Q_{1}=Q^{*}$. As before, we need an appropriate parametric restriction (an upper bound on $\lambda_{1}$ ) to ensure that the implied interest rate is positive, $r_{1}^{f}>0$.

Eq. E.22 illustrates that in this state the dynamic hedging motives affect the interest rate, $r_{1}^{f}$, rather than the price level, $Q_{1}=Q^{*}$. In particular, all else equal, an increase in $\Delta v$ decreases (resp. increases) $r_{1}^{f}$ when $\gamma>1$ (resp. $\gamma<1$ ). As before, when $\gamma>1$, the income effect (or the hedging motive) dominates and an increase in $\Delta v$ increases the investor's marginal utility and discount factor for the high-risk-premium relative to the low-risk-premium state. As before, this reweighting of discount factors reduces current asset valuations. In this case, the interest rate declines to offset the price impact of the shock. This ensures that asset prices and output are equal to their efficient levels but the interest rate is lower.

\section{E.3. Omitted proofs}

Proof of Lemma 7. Note that, substituting Eqs. (E.7) into E.6), we find

$$
\omega_{t, s}^{m, i} \sigma_{t, s}^{m}=\frac{1}{\gamma \sigma_{t, s}^{m}}\left(r_{t, s}^{m}-r_{t, s}^{f}+p_{t, s}^{s^{\prime}} \frac{Q_{t, s^{\prime}}-Q_{t, s}}{Q_{t, s}}\right)
$$

This shows that investors allocate identical portfolio weights to the market portfolio, $\omega_{t, s}^{m, i}=\omega_{t, s}^{m}$. Combining this with the market clearing condition (16), we find that these identical portfolio weights are equal to one,

$$
\omega_{t, s}^{m, i}=1
$$


This proves E.10.

To characterize the positions on the contingent security, first consider how type $i$ investors' wealth share changes after a state transition. Using (26) to rewrite Eq. (E.7), we obtain the following analogue of Eq. (33):

$$
\alpha_{t, s^{\prime}}^{i}=\alpha_{t, s}^{i}\left(\Lambda_{t, s}^{i} \frac{1}{\kappa_{t, s}}\right)^{1 / \gamma} \text { where } \kappa_{t, s}=p_{t, s}^{s^{\prime}} \frac{Q_{t, s^{\prime}}}{Q_{t, s}}
$$

Recall that $\Lambda_{t, s}^{i}=\left(\frac{\zeta_{t, s^{\prime}}^{i}}{\zeta_{t, s}^{i}}\right)^{1-\gamma} \lambda_{s}^{i}[$ cf. E.8] $]$. Aggregating this expression across all investors, and using $\sum_{i} \alpha_{t, s^{\prime}}^{i}=1$, we obtain

$$
\kappa_{t, s}=\bar{\Lambda}_{t, s}^{i} \equiv\left(\sum_{i} \alpha_{t, s}^{i} \Lambda_{t, s}^{1 / \gamma}\right)^{\gamma} .
$$

Substituting this back into 33 , we obtain

$$
\frac{\alpha_{t, s^{\prime}}^{i}}{\alpha_{t, s}^{i}}=\left(\frac{\Lambda_{t, s}^{i}}{\bar{\Lambda}_{t, s}}\right)^{1 / \gamma}
$$

This proves the second line of Eq. E.12.

Combining $\kappa_{t, s}=\bar{\Lambda}_{t, s}=1$ with the definition of $\kappa_{t, s}$ in Eq. (33), we obtain an expression for the price of the contingent security,

$$
p_{t, s}^{s^{\prime}}=\bar{\Lambda}_{t, s} \frac{1 / Q_{t, s^{\prime}}}{1 / Q_{t, s}}
$$

This proves Eq. E.14). Combining this with Eq. E.23), and substituting $\omega_{t, s}^{m, i}=1$, we obtain the risk balance condition $E .13$.

Next consider the positions type $i$ investors take in the contingent security to achieve the change in their wealth share after transition. Following the same steps as in the proof of Lemma 2, we obtain $\frac{\alpha_{t, s^{\prime}}^{i}}{\alpha_{t, s}^{i}}=1+\frac{\omega_{t, s}^{s^{\prime}, i}}{\bar{\Lambda}_{t, s}}$. Combining this with the second line of Eq. E.12, we solve for type $i$ investors' equilibrium position in the contingent security

$$
\omega_{t, s}^{s^{\prime}, i}=\left(\bar{\Lambda}_{t, s}\right)\left(\left(\frac{\Lambda_{t, s}^{i}}{\bar{\Lambda}_{t, s}}\right)^{1 / \gamma}-1\right) .
$$

Rearranging this expression proves Eq. E.11.

Finally consider how type $i$ investors' wealth share changes absent a state transition. Following the same steps as in the proof of Lemma 2, we obtain $\frac{d \alpha_{t, s}^{i}}{\alpha_{t, s}^{i}}=-\omega_{t, s}^{s^{\prime}, i} d t$. Substituting Eq. E.11 proves the first line of Eq. E.12 and completes the proof of the lemma.

Proof of Lemma 8, First consider the differential equation that characterizes the wealth multiplier, $\zeta_{t, s}^{i}$. Using Eqs. E.3 and E.4 along with the characterizations in Lemma 1 (which 
applies also in this context) and Lemma 7, as well as $\sigma_{t, s}^{Q}=0$, we obtain

$$
\log \zeta_{t, s}^{i}=\log \rho+q_{t, s}+\frac{1}{\rho}\left(\begin{array}{c}
g-\frac{1}{2} \gamma \sigma_{s}^{2}-\omega_{t, s}^{s^{\prime}, i}+\frac{\partial \zeta_{t, s}^{i} / \partial t}{\zeta_{t, s}^{i}} \\
+\lambda_{s \frac{1}{1-\gamma}}^{i}\left(\left(\frac{\alpha_{t, s^{\prime}}^{i}}{\alpha_{t, s}^{i}} \frac{\zeta_{t, s}^{i}}{\zeta_{t, s}^{i}}\right)^{1-\gamma}-1\right)
\end{array}\right) .
$$

Next, we substitute $\zeta_{t, s}^{i}=\exp \left(\rho v_{t, s}^{i}\right)$ and use $\sigma_{t, s}^{\zeta}=0$ (which implies $v_{t, s}^{i}$ is also deterministic absent state transitions) to obtain

$$
\rho v_{t, s}^{i}-\frac{\partial v_{t, s}^{i}}{\partial t}=\log \rho+q_{t, s}+\frac{1}{\rho}\left(g-\frac{1}{2} \gamma \sigma_{s}^{2}-\omega_{t, s}^{s^{\prime}, i}+\lambda_{s}^{i} \frac{1}{1-\gamma}\left(\left(\frac{\alpha_{t, s^{\prime}}^{i}}{\alpha_{t, s}^{i}} \frac{\zeta_{t, s^{\prime}}^{i}}{\zeta_{t, s}^{i}}\right)^{1-\gamma}-1\right)\right)
$$

Substituting $\omega_{t, s}^{s^{\prime}, i}=-\frac{\dot{\alpha}_{t, s}^{i}}{\alpha_{t, s}^{i}}$ from Lemma 7 proves Eq. E.16. 


\section{F. Data details and omitted empirical results}

This section presents the details of the data sources and variable construction used in Section VII. and presents the empirical results (tables and figures) omitted from the main text.

House price index. We rely on the cross-country quarterly panel dataset described in Mack et al. (2011). The dataset is regularly updated and publicly available at https://www.dallasfed.org/institute/houseprice. We use the inflation-adjusted (real) house price index measure to construct the shock variable in our regression analysis (see (58)). Our country coverage is to a large extent determined by the availability of this measure. In particular, we exclude a few developed countries such as Portugal, Austria, and Greece for which we do not have data on house prices that we can consistently compare with house prices in other countries.

Euro or Exchange Rate Mechanism (Euro/ERM) status. We hand-collect this data from various online sources. A country-quarter is included in the Euro/ERM sample if the country is a member of the Euro or the European Exchange Rate mechanism in most of the corresponding calendar year. Table F.1 describes the Euro/ERM status by year for all countries in our sample.

GDP, consumption, investment. We obtain this data from the OECD's quarterly national accounts dataset (available at https://stats.oecd.org). We use the variables calculated according to the expenditure approach. The corresponding OECD subject codes are as follows:

- GDP: "B1_GE" (Gross domestic product - expenditure approach).

- Consumption: "P31S14_S15" (Private final consumption expenditure)

- Investment: "P51" (Gross fixed capital formation)

For each of these variables, we use the measures that are adjusted for inflation as well as seasonality. The OECD measure code is: "LNBQRSA" (National currency, chained volume estimates, national reference year, quarterly levels, seasonally adjusted).

Relative GDP (with PPP-adjusted prices in a common base year). We obtain an alternative GDP measure from the OECD's annual national accounts dataset (available at https://stats.oecd.org). We use the variable calculated according to the expenditure approach (with subject code "B1_GE"), measured with PPP-adjusted prices in a common base year. The OECD measure code is: "VPVOB" (Current prices, constant PPPs, OECD base year). We use the value of this measure in 1990 to weight all of our regressions (see (58)).

CPI. We obtain this data from the OECD's prices and purchasing power parities dataset (available at https://stats.oecd.org). We use the core CPI measure that excludes food and energy. The OECD subject code is: "CPGRLE" (Consumer prices - all items non-food, non-energy). We use the annual measure, which is less subject to seasonality, and we linearly interpolate this to obtain a quarterly measure.

Unemployment rate. We obtain this data from the OECD's key short-term economic indicators database (available at https://stats.oecd.org). We use the harmonized unemployment rate measure with seasonal adjustment and at quarterly frequency. The OECD subject code is "LRHUTTTT" (Harmonized unemployment rate: all persons, s.a). 
The policy interest rate. Obtaining the policy interest rate is not as trivial as it might sound since different central banks conduct monetary policy in terms of different target rates (and sometimes without specifying a target rate, or by monitoring multiple rates). On the other hand, the selection does not substantially affect the results since short-term risk-free rates within a developed country are often highly correlated. Following Romer and Romer (2018), we use announced policy target rates when available, and otherwise we use collateralized short-term market rates (such as Repo rates or Lombard rates). For Eurozone countries, we use the local collateralized rate until the country joins the Euro, and we switch to the European Central Bank's (ECB) main refinancing operations (MRO) rate after the country joins the Euro.

For most of the countries, we construct our own measure of the policy interest rate according to the above selection criteria by using data from the Global Financial Data's GFDATABASE (GFD). This is a proprietary database that contains a wealth of information on various asset prices (see https://www.globalfinancialdata.com for details).

For a few countries (specified below), we instead rely on the Bank for International Settlements's (BIS) database on central bank policy interest rates (publicly available at https://www.bis.org/statistics/cbpol.htm). We switch to the BIS measure when we cannot construct an appropriate measure using the GFD; or when the BIS measure has greater coverage than ours and the two measures are highly correlated. From either database, we obtain monthly data and convert to quarterly data by averaging over the months within the quarter.

- United States: GFD ticker "IDUSAFFD” (USA Fed Funds Official Target Rate).

- United Kingdom: GFD ticker "IDGBRD” (Bank of England Base Lending Rate).

- Australia: GFD ticker "IDAUSD” (Australia Reserve Bank Overnight Cash Rate).

- South Korea: GFD ticker "IDKORM" (Bank of Korea Discount Rate).

- Germany: GFD ticker "IDDEULD" (Germany Bundesbank Lombard Rate) until the country joins the Euro. Afterwards, we use the ECB MRO rate. The corresponding GFD ticker is: "IDEURMW" (Europe Marginal Rate on Refinancing Operations).

- New Zealand: GFD ticker "IDNZLD” (New Zealand Reserve Bank Official Cash Rate).

- France: GFD ticker "IDFRARD" (Bank of France Repo Rate) until the country joins the Euro.

- Denmark: We use the BIS measure (highly correlated with our measure and greater coverage).

- Finland: GFD ticker "IDFINRM" (Bank of Finland Repo Rate) until the country joins the Euro.

- Sweden: GFD ticker "IDSWERD” (Sweden Riksbank Repo Rate).

- Israel: GFD ticker "IDISRD” (Bank of Israel Discount Rate).

- Italy: GFD ticker "IDITARM" (Bank of Italy Repo Rate) until the country joins the Euro.

- Spain: GFD ticker "IDESPRM" (Bank of Spain Repo Rate) until the country joins the Euro.

- Ireland: GFD ticker "IDIRLRD" (Bank of Ireland Repo Rate) until the country joins the Euro. 
- Belgium: GFD ticker "IDBELRM" (Belgium National Bank Repo Rate) until the country joins the Euro.

- Netherlands: GFD ticker "IDNLDRD" (Netherlands Bank Repo Rate) until the country joins the Euro.

- Norway: GFD ticker "IDNORRD” (Bank of Norway Sight Deposit Rate).

- Japan: GFD ticker "IDJPNCM" (Japan Target Call Rate). GFD data is missing from March 2001 until July 2006. BIS data is also missing for most of this period. We use other sources to hand-fill the interest rate over this period as being equal to $0 \%$ (see for instance, the data from St. Louis Fed at https://fred.stlouisfed.org/series/IRSTCI01JPM156N).

- Switzerland: We use the BIS measure (cannot identify an appropriate rate from the GFD).

- Canada: We use the BIS measure (highly correlated with our measure and greater coverage).

Stock prices. We obtain this data from the GFD. For each country, we try to pick the most popular stock price index (based on Internet searches). We obtain daily data and convert to quarterly data by averaging over all (trading) days within the quarter. We then divide this with our core CPI measure (see above) to obtain a real stock price series.

- United States: GFD ticker “_SPXD” (S\&P500 Index)

- United Kingdom: GFD ticker “_FTSED” (UK FTSE100 Index).

- Australia: GFD ticker “_AXJOD” (Australia S\&P/ASX 200 Index).

- South Korea: GFD ticker “_KS11D” (Korea SE Stock Price Index (KOSPI)).

- Germany: GFD ticker “_GDAXIPD” (Germany DAX Price Index).

- New Zealand: GFD ticker “_NZ15D” (NZSX-15 Index).

- France: GFD ticker “_FCHID” (Paris CAC-40 Index).

- Denmark: GFD ticker “_OMXC20D” (OMX Copenhagen-20 Index).

- Finland: GFD ticker “_OMXH25D” (OMX Helsinki-25 Index).

- Sweden: GFD ticker “_OMXS30D” (OMX Stockholm-30 Index).

- Israel: GFD ticker “_TA125D” (Tel Aviv SE 125 Broad Index).

- Italy: GFD ticker “_BCIJD” (Milan SE MIB-30 Index).

- Spain: GFD ticker “_IBEXD” (Madrid SE IBEX-35 Index).

- Ireland: GFD ticker “_ISEQD” (Ireland ISEQ Overall Price Index).

- Belgium: GFD ticker “_BFXD” (Belgium CBB Bel-20 Index).

- Netherlands: GFD ticker “_AEXD” (Amsterdam AEX Stock Index).

- Norway: GFD ticker “_OSEAXD” (Oslo SE All-Share Index). 
- Japan: GFD ticker “_N225D” (Nikkei 225 Stock Index).

- Switzerland: GFD ticker “_SSMID” (Swiss Market Index).

- Canada: GFD ticker “_GSPTSED” (Canada S\&P/TSX 300 Index).

Earnings. We obtain monthly data on the price-earnings ratio of publicly traded firms from the GFD (typically constructed for a broad sample of stocks chosen by the GFD). We then combine this information with our nominal price index (using the price at the last trading day of the month) to construct a monthly series for earnings. We convert this to a quarterly measure by averaging over the months within the quarter. We then divide this by our core CPI measure to obtain a quarterly real earnings series for publicly traded firms.

GFD ticker for the price earnings ratio typically has the form "SY-three digit country code-PM" (e.g., the ticker for the United States is "SYUSAPM"). One exception is the United Kingdom for which the corresponding GFD code is "_PFTASD" (UK FT-Actuaries PE Ratio).

Credit expansion. Our measure of bank credit is based on Baron and Xiong (2017), who construct a variable, credit expansion, defined as the annualized past three-year change in bank credit to GDP ratio. Mathematically, it is expressed as

$$
\text { credit expansion }=\frac{\Delta\left(\frac{\text { bank credit }}{\mathrm{GDP}}\right)_{t}-\Delta\left(\frac{\text { bank credit }}{\mathrm{GDP}}\right)_{t-12}}{12} \times 4,
$$

where $t$ denotes a quarter. Baron and Xiong (2017) construct this measure by merging data from two sources. Their main source is the "bank credit" measure from the BIS, which covers a large set of countries but is generally available only for postwar years. For this reason, Baron and Xiong (2017) also supplement it with the "bank loans" measure from Schularick and Taylor (2012), which covers fewer countries but more years. Since our panel starts in 1990, we ignore the second source and rely entirely on the BIS measure.

Specifically, we use the quarterly BIS database on credit to the nonfinancial sector (publicly available at https://www.bis.org/statistics/totcredit.htm). We obtain the measure "bank credit to the private nonfinancial sector" expressed in units of percentage of GDP (the corresponding BIS code is "Q:5A:P:B:M:770:A"), which enables us to construct the variable in (F.1). We verify that our variable is highly correlated with the measure constructed by Baron and Xiong (2017) (who generously shared their data with us) - the correlation coefficient for the available country-quarters is 0.975 .

Following Baron and Xiong (2017), we also construct a "credit expansion-std" variable by standardizing the measure in $(F .1)$ by its mean and standard deviation within each country. Since Baron and Xiong (2017) focus on predicting stock prices, they calculate the mean and the standard deviation using only past data so as to avoid any look-ahead bias. Since our focus is different, we ignore this subtlety and calculate the sample statistics using the entire data for the corresponding country (in the BIS database). 
Table F.1: Euro/ERM status by country and year

\begin{tabular}{ccccccccc} 
Country & 1990 & 1991 & 1992 & 1993 & 1994 & 1995 & 1996 & $1997-2017$ \\
\hline \hline Belgium & 1 & 1 & 1 & 1 & 1 & 1 & 1 & 1 \\
Denmark & 1 & 1 & 1 & 1 & 1 & 1 & 1 & 1 \\
Finland & 0 & 0 & 0 & 0 & 0 & 0 & 0 & 1 \\
France & 1 & 1 & 1 & 1 & 1 & 1 & 1 & 1 \\
Germany & 1 & 1 & 1 & 1 & 1 & 1 & 1 & 1 \\
Ireland & 1 & 1 & 1 & 1 & 1 & 1 & 1 & 1 \\
Italy & 1 & 1 & 1 & 0 & 0 & 0 & 0 & 1 \\
Netherlands & 1 & 1 & 1 & 1 & 1 & 1 & 1 & 1 \\
Spain & 1 & 1 & 1 & 1 & 1 & 1 & 1 & 1 \\
Australia & 0 & 0 & 0 & 0 & 0 & 0 & 0 & 0 \\
Canada & 0 & 0 & 0 & 0 & 0 & 0 & 0 & 0 \\
Israel & 0 & 0 & 0 & 0 & 0 & 0 & 0 & 0 \\
Japan & 0 & 0 & 0 & 0 & 0 & 0 & 0 & 0 \\
Korea & 0 & 0 & 0 & 0 & 0 & 0 & 0 & 0 \\
NZL & 0 & 0 & 0 & 0 & 0 & 0 & 0 & 0 \\
Norway & 0 & 0 & 0 & 0 & 0 & 0 & 0 & 0 \\
Sweden & 0 & 1 & 1 & 0 & 0 & 0 & 0 & 0 \\
Switzerland & 0 & 0 & 0 & 0 & 0 & 0 & 0 & 0 \\
UK & 0 & 1 & 1 & 0 & 0 & 0 & 0 & 0 \\
USA & 0 & 0 & 0 & 0 & 0 & 0 & 0 & 0 \\
\hline \hline
\end{tabular}

Euro status. Belgium, Finland, France, Germany, Ireland, Italy, Netherlands, Spain adopted the Euro in 1999. Denmark hasn't adopted the Euro but is a member of the ERM. 
Table F.2: Summary statistics by ERM for the baseline regression sample

\begin{tabular}{lccccccc}
\hline \hline & \multicolumn{2}{c}{ ERM sample } & \multicolumn{2}{c}{ Non-ERM sample } & \multicolumn{2}{c}{ Difference } \\
& Mean & Std.Deviation & Mean & Std.Deviation & Mean & Std.Error \\
\hline$\Delta \log$ house prices (real) & 0.0047 & 0.0181 & 0.0054 & 0.0187 & -0.0007 & $(0.0023)$ \\
$\Delta \log$ GDP (real) & 0.0047 & 0.0124 & 0.0065 & 0.0092 & -0.0018 & $(0.0009)$ \\
policy interest rate (nominal) & 0.0232 & 0.0196 & 0.0349 & 0.0289 & -0.0117 & $(0.0038)$ \\
$\Delta \log$ CPI (core) & 0.0041 & 0.0027 & 0.0046 & 0.0039 & -0.0004 & $(0.0005)$ \\
$\Delta$ unemployment rate & -0.0002 & 0.0038 & -0.0002 & 0.0030 & 0.0000 & $(0.0003)$ \\
$\Delta \log$ investment (real) & 0.0043 & 0.0502 & 0.0070 & 0.0295 & -0.0027 & $(0.0018)$ \\
$\Delta$ log consumption (real) & 0.0038 & 0.0091 & 0.0069 & 0.0095 & -0.0031 & $(0.0008)$ \\
earnings to price ratio & 0.0626 & 0.0245 & 0.0584 & 0.0227 & 0.0042 & $(0.0034)$ \\
$\Delta$ log stock prices (real) & 0.0042 & 0.0911 & 0.0111 & 0.0818 & -0.0069 & $(0.0044)$ \\
credit expansion & 0.0148 & 0.0565 & 0.0136 & 0.0298 & 0.0012 & $(0.0083)$ \\
credit expansion-std & 0.1047 & 1.2628 & -0.0346 & 1.1128 & 0.1393 & $(0.2001)$ \\
\hline Observations & 760 & & 1130 & & 1890 & \\
\hline \hline
\end{tabular}

$\Delta$ represents quarterly change. Standard errors are Newey-West standard errors with a bandwidth of 20 quarters. 
Table F.3: Private housing wealth in 2005 (\% of GDP) by Euro/ERM status

\begin{tabular}{lrlr} 
Country (Euro/ERM) & Housing wealth & Country (Non-Euro/ERM) & Housing wealth \\
\hline \hline Spain & 414.33 & Australia & 301.32 \\
Italy & 271.25 & USA & 199.77 \\
France & 253.74 & Korea & 180.12 \\
Netherlands & 222.03 & Japan & 169.74 \\
Germany & 186.77 & Canada & 146.51 \\
Denmark & 168.45 & Norway & 139.48 \\
& & Sweden & 132.10 \\
\hline \hline Average & 252.40 & Average & 181.29 \\
GDP-weighted average & 255.14 & GDP-weighted average & 191.67
\end{tabular}

Table F.4: Stock market capitalization in 2005 (\% of GDP) by Euro/ERM status

\begin{tabular}{lrlr} 
Country (Euro/ERM) & Market cap & Country (Non-Euro/ERM) & Market cap \\
\hline \hline Finland & 102.48 & Switzerland & 229.68 \\
Netherlands & 87.37 & USA & 129.84 \\
Spain & 82.95 & Canada & 126.75 \\
France & 80.07 & UK & 121.32 \\
Belgium & 74.47 & Australia & 116.08 \\
Denmark & 67.30 & Sweden & 103.83 \\
Ireland & 53.90 & Korea & 96.16 \\
Italy & 43.08 & Israel & 86.04 \\
Germany & 42.01 & Norway & 79.94 \\
& & Japan & 61.89 \\
\hline \hline Average & 69.22 & Average & 115.16 \\
GDP-weighted average & 61.84 & GDP-weighted average & 120.26
\end{tabular}

Data sources. We obtain housing wealth to GDP ratio from the World Inequality Database (WID) which is publicly available at https://wid.world/. We construct the ratio by combining yearly series on "private housing assets" (WID indicator, "mpwhou") and "gross domestic product (WID indicator, "mgdpro").

We obtain stock market capitalization to GDP ratio as yearly series from the GFD. The corresponding ticker has the form "CM.MKT.LCAP.GD.ZS three digit country code" (e.g., the ticker for the United States is "CM.MKT.LCAP.GD.ZS USA").

For both tables, we construct the GDP-weighted averages by using our relative GDP measure (in 2005) described earlier in this section. 

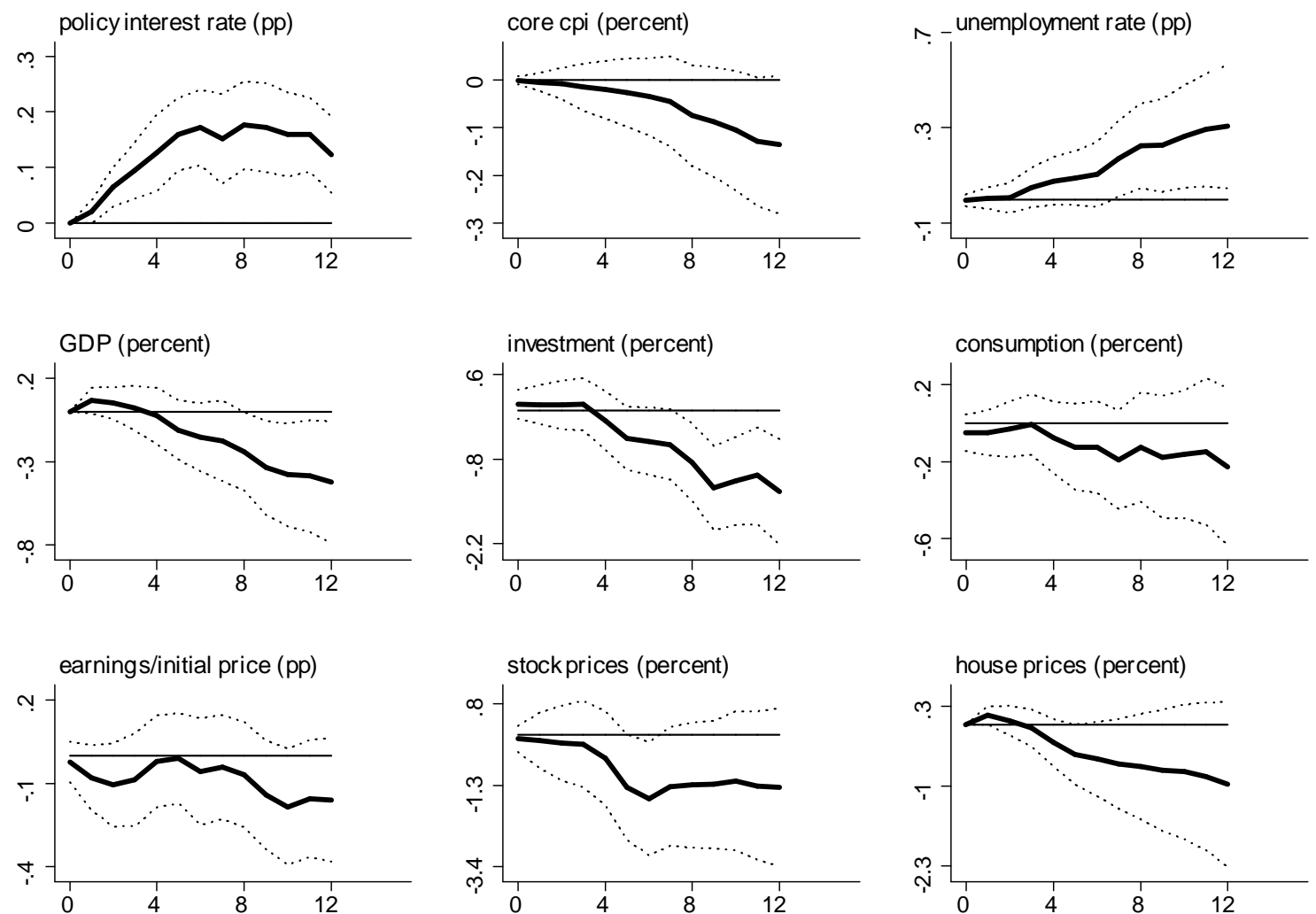

Figure F.1: Impulse responses to one percent decrease in real house prices: Euro/ERM minus non-Euro/ERM. The panels illustrate the differences in coefficients between the ERM and the non-ERM samples corresponding to the baseline regression results in Figure VIII 

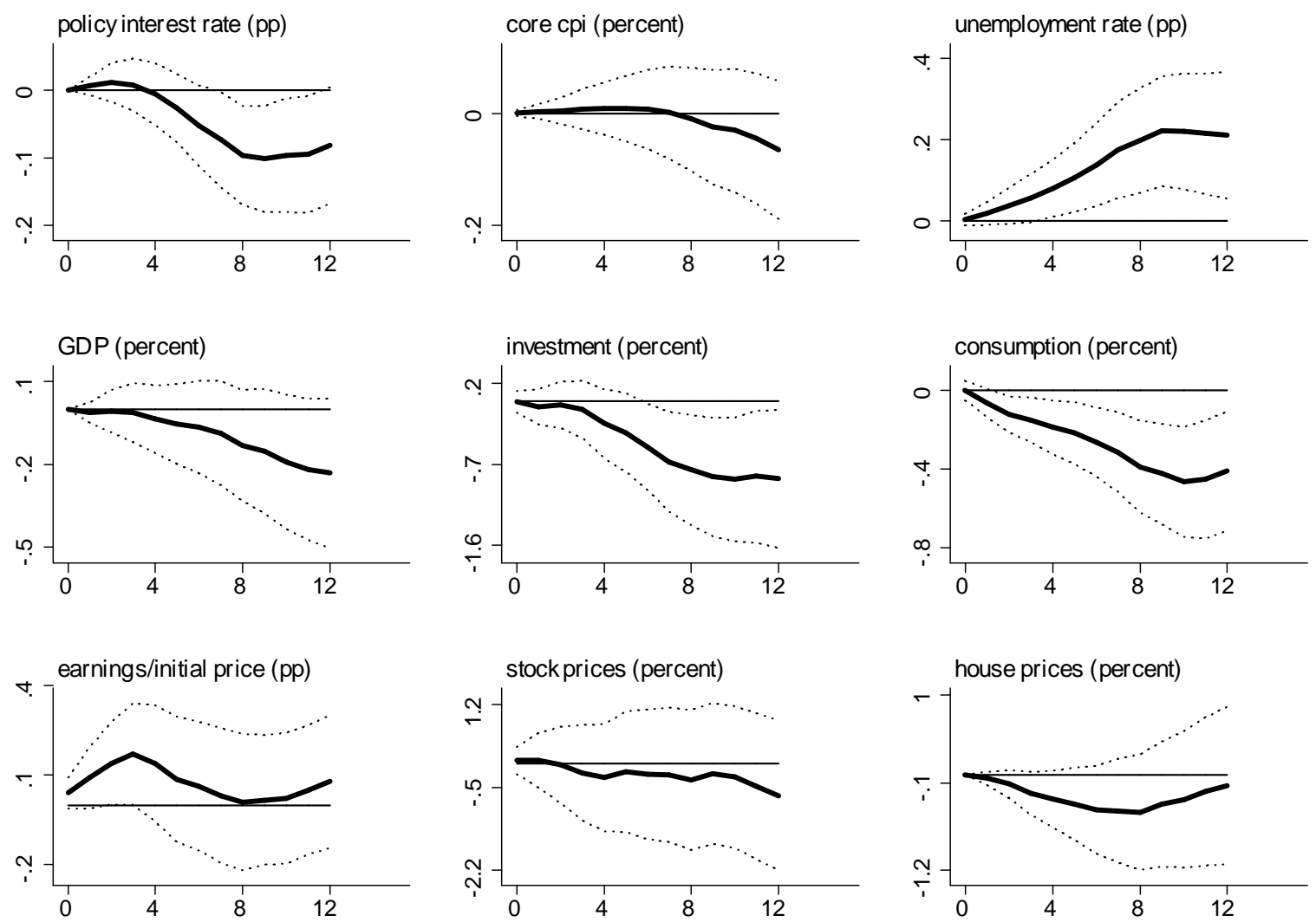

Figure F.2: Additional impulse responses to one percent decrease in real house prices when credit expansion has been one standard deviation above average: Euro/ERM minus nonEuro/ERM. The panels illustrate the differences in coefficients between the ERM and the non-ERM samples corresponding to the regression results with credit interaction in Figure IX 

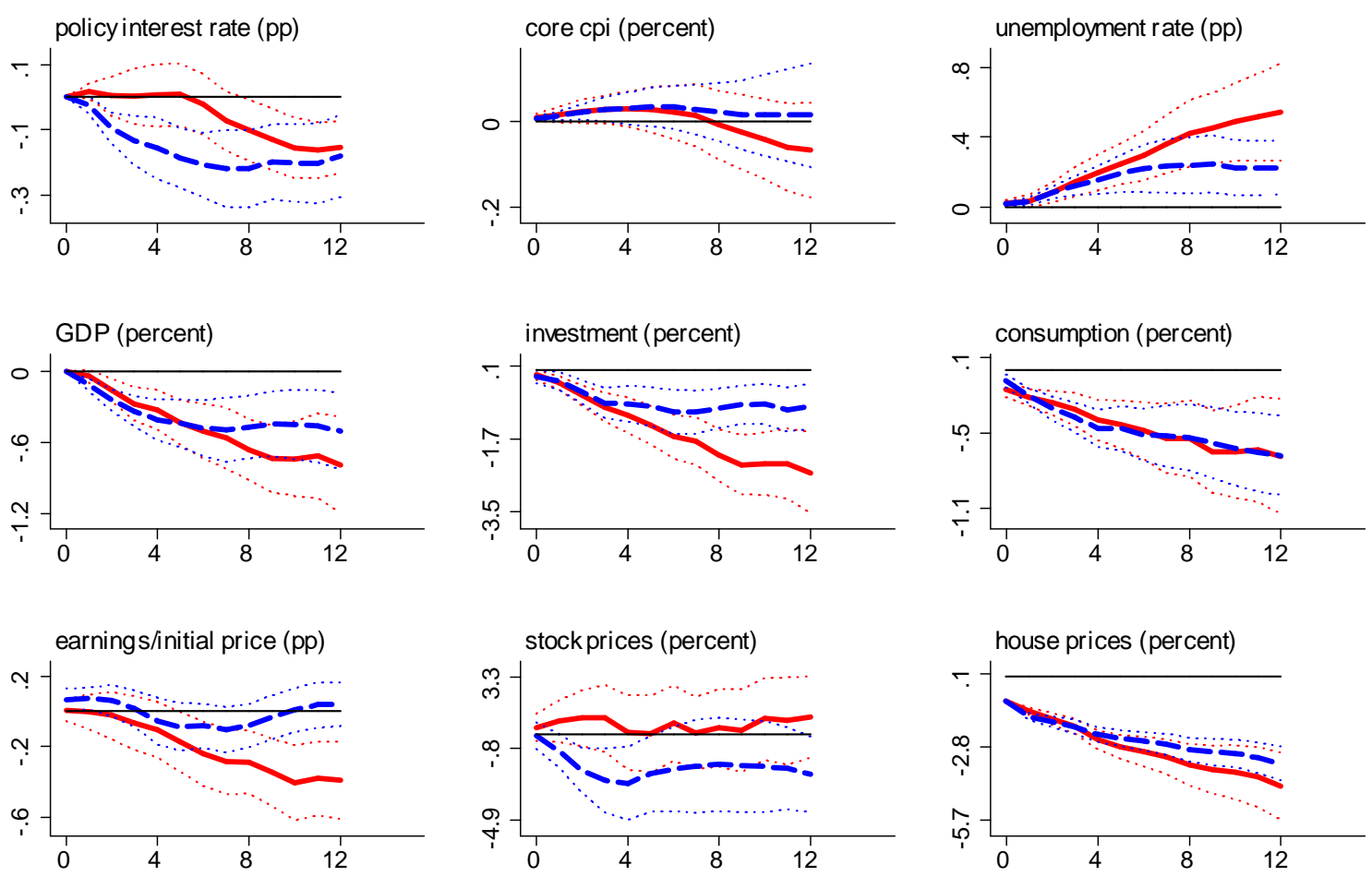

\section{Euro/ERM}

Figure F.3: Impulse responses to one percent decrease in real house prices: No time fixed effects. The panels illustrate the analogues of the baseline regression results in Figure VIII with the difference that time fixed effects are excluded from the regressions. 

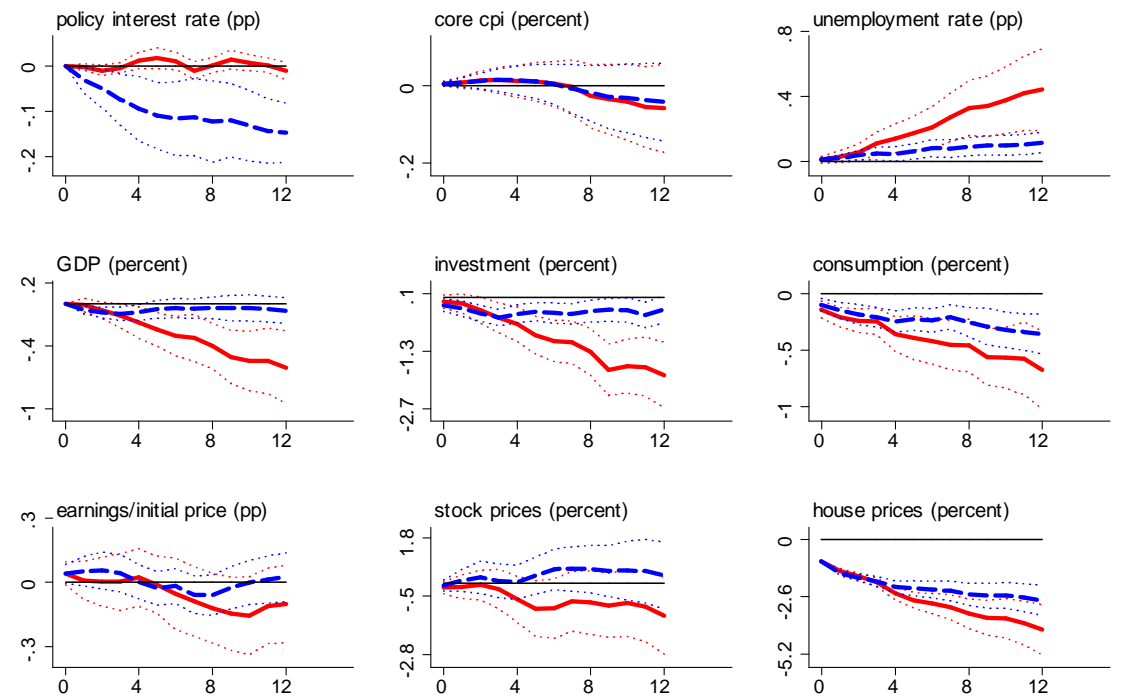

Euro/ERM - - - Non-Euro/ERM

Figure F.4: Impulse responses to one percent decrease in real house prices: 1980-2017. The analogues of the results in Figure VIII with a sample that starts in 1980Q1 (as opposed to 1990Q1).
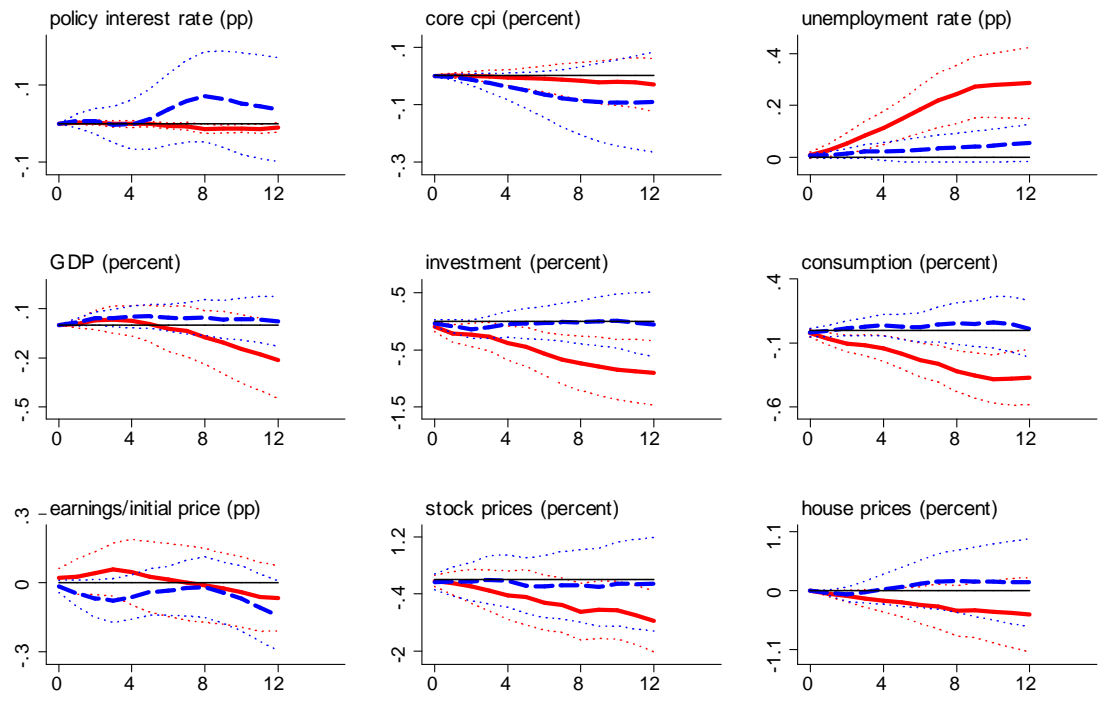

Euro/ERM ——- Non-Euro/ERM

Figure F.5: Additional impulse responses to one percent decrease in real house prices when credit expansion has been one standard deviation above average: 1980-2017. The panels illustrate the analogues of the results in Figure IX with a sample that starts in 1980Q1 (as opposed to 1990Q1). 

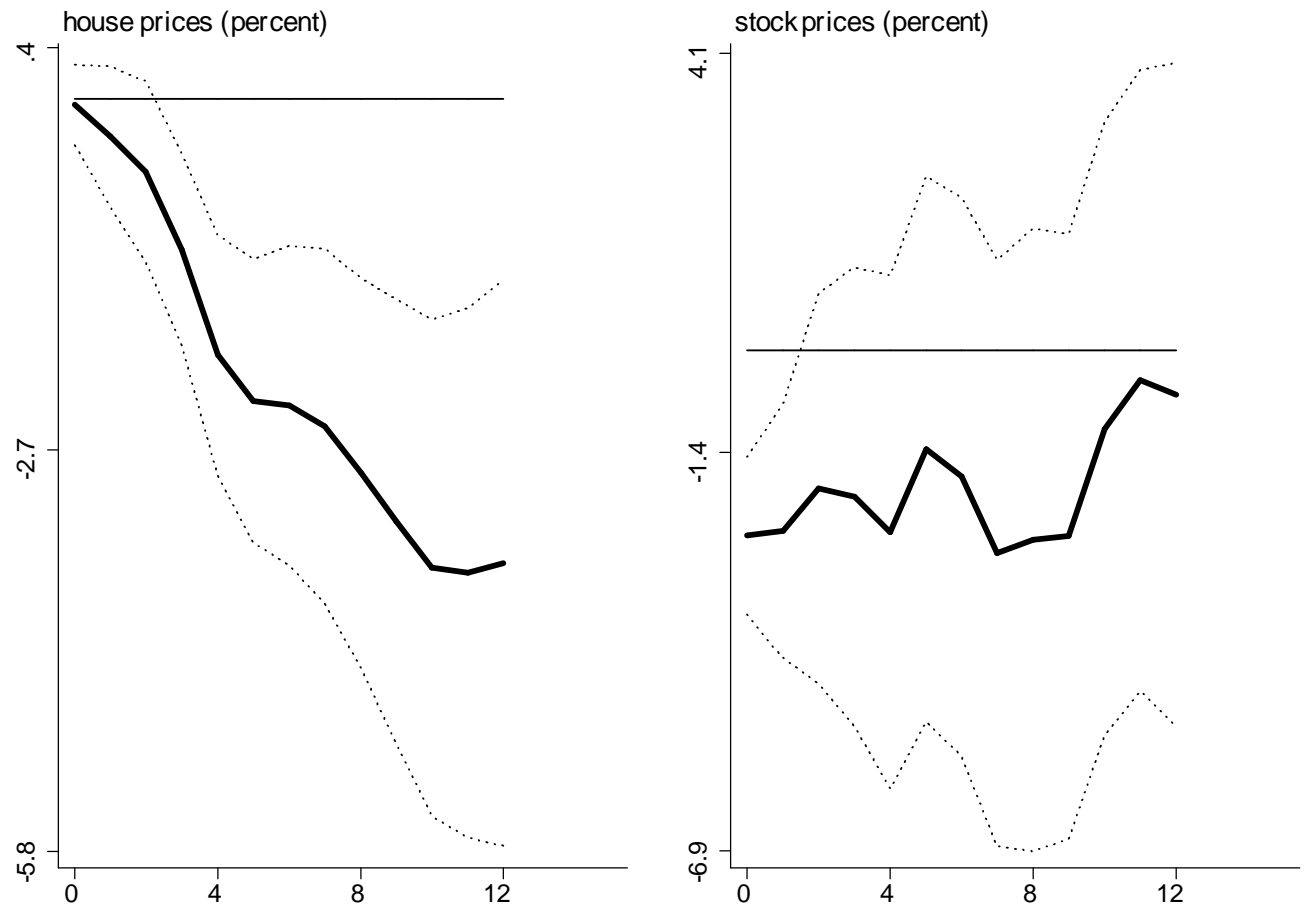

Figure F.6: Impulse responses to one percentage point increase in the policy interest rate (for the full sample). The panels illustrate the analogues of the baseline regression results in Figure VIII] where we consider shocks to the policy interest rate as opposed to house prices. Specifically, we run the analogue of the specification in (58) (on the full sample) where the shock variable is the level of the policy interest rate and the outcome variable is log house prices (left panel) or log stock prices (right panel). The solid lines plot the coefficients corresponding to the the policy interest rate variable. All regressions include time and country fixed effects; 12 lags of the level of the policy interest rate, contemporaneous value and 12 lags of the first difference of log GDP, 12 lags of the first difference of log house prices, and 12 lags of the first difference of log stock prices. The dotted lines show $95 \%$ confidence intervals calculated according to Newey-West standard errors with a bandwidth of 20 quarters. All regressions are weighted by countries' PPP-adjusted GDP in 1990. Data is unbalanced quarterly panel that spans 1990Q1-2017Q4. All variables except for the policy interest rate are adjusted for inflation. The sources and the definitions of variables are described earlier in this appendix. 